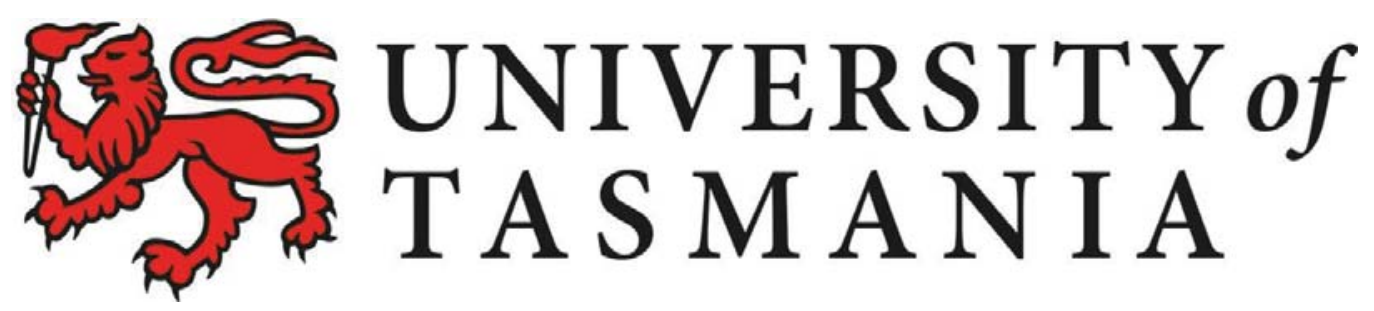

\author{
The Role of E-Portfolios in Higher \\ Education: The Experience of Pre-Service \\ Teachers
}

Maliheh Babaee, B.A., M.A.

A thesis submitted in fulfilment of the requirements for the degree of Doctor of Philosophy

Faculty of Education, University of Tasmania, Australia 


\section{Declaration of Originality}

This thesis contains no material, which has been accepted, for a degree or diploma by a University or any other institution, except by way of background information and duly acknowledged in the thesis. To the best of my knowledge and belief, it contains no material previously published or written by another person except where due acknowledgement is made in the text of the thesis nor does the thesis contain any material that infringes copyright.

Name: Maliheh Babaee

Date: 26 Oct 2016 


\section{Authority of Access}

This thesis may be made available for loan and limited copying in accordance with the Copyright Act 1968.

Name: Maliheh Babaee

Date: 26 Oct 2016 


\section{Statement of Ethical Conduct}

The research associated with this thesis abides by the international and Australian codes on human and animal experimentation, the guidelines by the Australian Government's Office of the Gene Technology Regulator and the rulings of the Safety, Ethics and Institutional Biosafety Committees of the University.

Signature:

Name: Maliheh Babaee

Date: 26 Oct 2016 


\begin{abstract}
The term e-portfolio refers to a portfolio in electronic format that allows users to collect evidence of learning in several media types (e.g., audio, video, text, and graphics) and to organise these using hypertext links (Barrett, 2001). E-portfolios have been introduced into teacher education programs internationally to help preservice teachers (PST) build records of their learning and reflections, and allow them to assemble collections of evidence of their achievements against graduate standards. These e-portfolios may function as digital CVs; and also support lifelong learning after graduation (Oakley, Pegrum, \& Johnston, 2014). Through investigating the experience of e-portfolio use by PSTs, this thesis provides significant evidence about the high quality implementation of e-portfolios in higher education. The thesis explores the reasons behind the participants' success in an e-portfolio-based unit. In particular, the research explores the reasons why a number of the participants were more successful than others when using e-portfolios. This is the first research which has examined PSTs perspectives on e-portfolio-based learning within constructivism, students' approach to learning (SAL), the 3P model (presage, process, and product) of learning, and self-regulated learning (SRL). An e-portfolio-based unit in the Faculty of Education in an Australian University was investigated using a mixed methods research design to analyse the data gathered through conducting pre-unit and post-unit interviews. The qualitative analysis examines the participants' conceptions of e-portfolios, their perceptions of the teaching and learning context, and the effect of these on their approaches to learning and their learning outcomes. A questionnaire was distributed at week 11 to measure how they conceived e-
\end{abstract}


portfolios, how they perceived the quality of the teaching, the clarity of the goals, and the appropriateness of the assessment and workload.

This research showed that there was variation in the academic achievements of the PSTs when using e-portfolios and the results of the analysis confirmed that the learning outcomes at the surface or deep approach to learning were affected by the participants' conceptions of the e-portfolios, their perceived role, and the perceptions of their lecturers' role. In particular, their experience in the course depended on their perception of good teaching, clarity of their goals, and appropriate workload and assessment in the unit. Therefore, these factors seemed to be significantly related to what they did, and the strategies they used when using the e-portfolio. The implications of the results of this thesis are relevant for educators responsible for designing new e-portfolio-based units or courses, and improving the teaching and learning outcomes of existing e-portfolio-based learning. 


\section{Acknowledgement}

I would like to express my most sincere thanks to Professor Michael Prosser and Associate Professor Karen Swabey who have both supervised my $\mathrm{PhD}$ candidature. They have always found the time and energy to discuss the project and my progress. I have obtained so much help from them, and they were always patient, encouraging, and enthusiastic. Both of them are very knowledgeable, kind and sincere in advancing education. I am also very grateful to Dr Thao Le, who provided me with so much encouragement and advice to start my PhD study. I am also very grateful to the University of Tasmania, Faculty of Education, who awarded me the scholarship to pursue my $\mathrm{PhD}$ in Australia. This provided me with the opportunity to experience in person how e-portfolios have been running in different geographical contexts around the world. I have also benefited from communication with Dr Khalil Motallebzadeh, my primary supervisor in my Master's degree in Iran who has been very informative about e-portfolios. I am grateful to Khashayar, my sister Sudeh and my friend Samaneh for their non-stop emotional support. Last but not least, I would like to express my utmost gratitude to my parents. I find it really difficult to express my appreciation completely because it is so boundless, and I would like to dedicate this $\mathrm{PhD}$ thesis to them. It is my greatest wish that the results and insights from this $\mathrm{PhD}$ thesis may help to prepare higher quality e-portfolio-based learning and ultimately enhance high quality learning in different contexts. 


\section{Table of Contents}

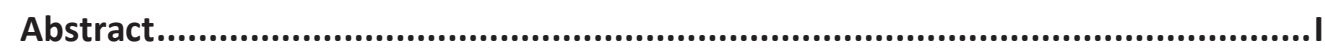

Acknowledgement ...............................................................................................

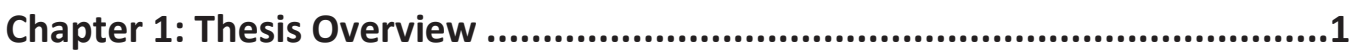

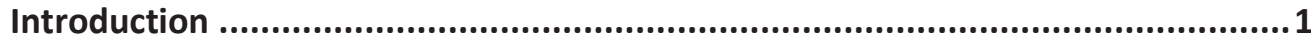

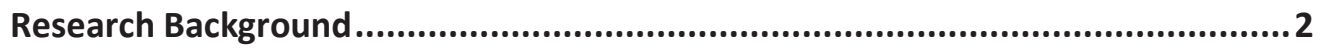

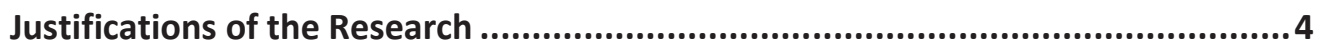

Significance of the Research .............................................................................

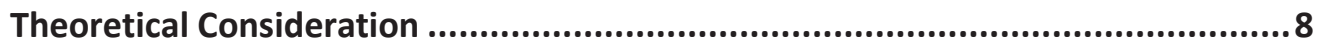

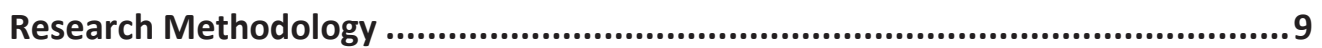

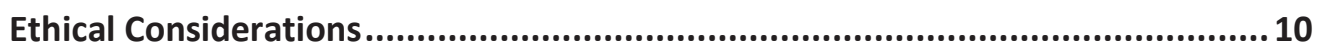

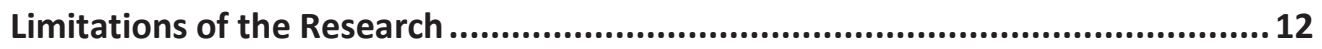

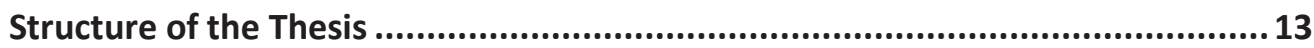

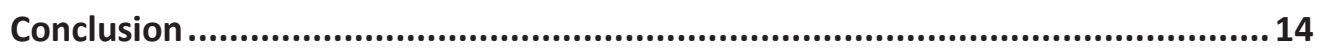

Chapter 2: Literature Review .........................................................16

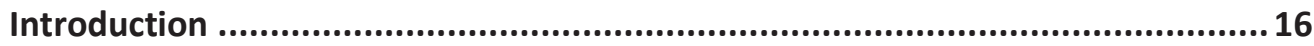

A Shift from Traditional Portfolios to E-portfolios .............................................. 16

Definition of E-portfolios and the Development Process .................................17

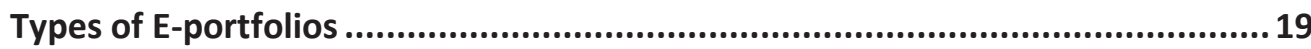

Social Media as a Platform to Design E-portfolios .............................................20

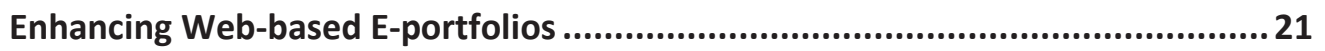

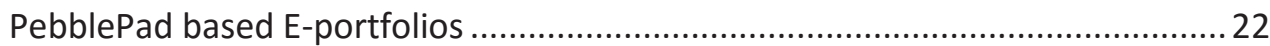

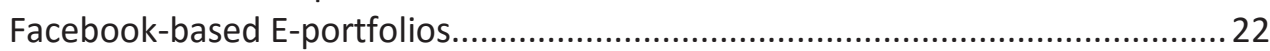

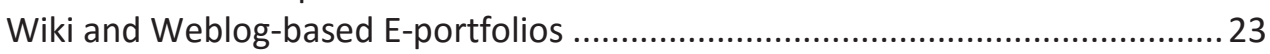

Challenges of Using Social Media in Education..................................................... 24

Enhancement of Conceptual Ideas through E-portfolios .....................................25

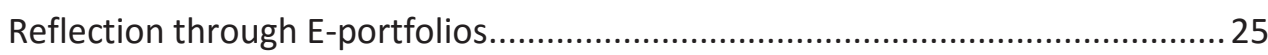


Autonomous Learning through E-portfolios.....

Enhancing Collaboration through E-portfolios................................................... 27

Developing Organisational Skills through the use of E-portfolios Implementation

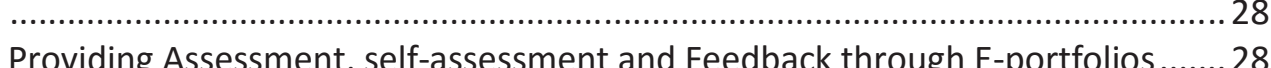

Assessment through the Use of E-portfolios ....................................................... 29

Self-assessment through the Use of E-portfolios.................................................30

Feedback Provision through the Use of E-portfolios ........................................ 30

E-portfolios in the Teacher Education Context ...............................................31

Assessment of PSTs through the Use of E-portfolios .............................................. 32

Developing Teaching Competence through the use of E-portfolios...................... 33

The Impact of Using E-portfolios on PSTs' Identity ...............................................33

Using E-portfolios to Prepare for the Teaching Profession....................................34

E-portfolios and Institute for School Teaching and School Leadership (AITSL) ....35

E-portfolios and the Development of Graduate Attributes ..................................35

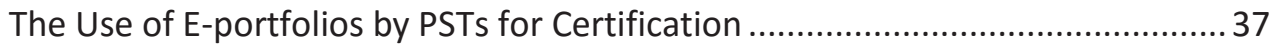

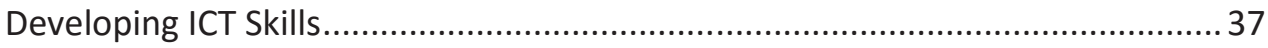

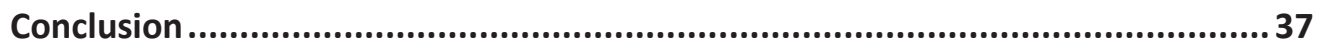

Chapter 3: Research Methodology .............................................................40

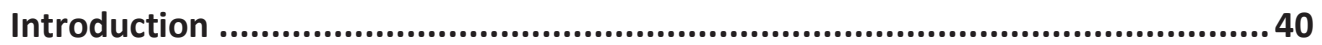

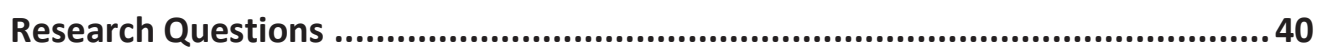

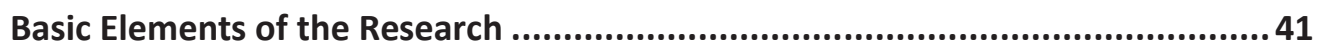

The First Element: Constructivism as the Epistemology .................................. 42

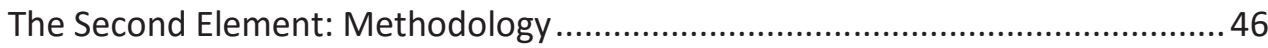

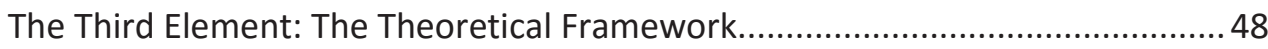

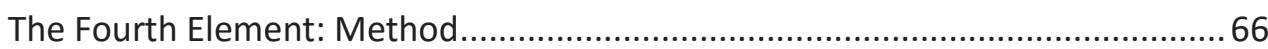

Qualitative Data Analysis: The Grounded Theory .............................................. 75

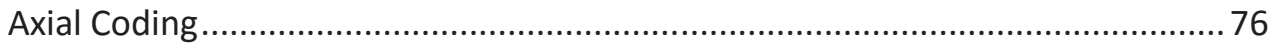

The Main Challenge of Grounded Theory ......................................................... 77

Reliability and Validity for the Qualitative Phase............................................... 78

The Links between the Four Elements of the Research .......................................79

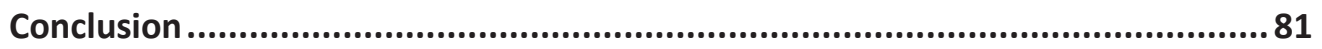

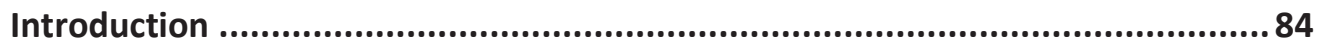

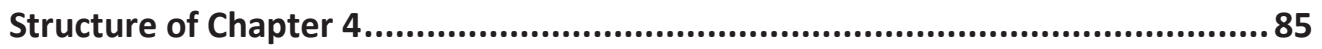

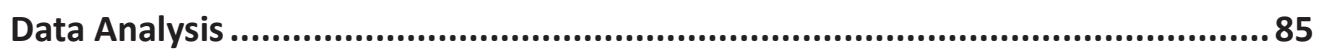

Category 1: Students' Conceptions of the Use of E-Portfolios ..............................86 86

Category 2: Students' Perceptions of the Use of E-portfolios ..............................86 
Category 3: Students' Approaches to Learning.................................................. 90

Category 4: Students' Learning Outcomes............................................................ 94

The Relationship amongst the Categories ......................................................99

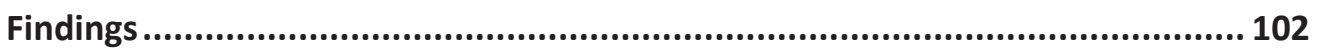

The Case Study of Two Deviant Cases ............................................................. 103

Transition from Surface to Deep Approach: Participant 5 ................................ 104

Transition from Deep to Surface Approach ..................................................... 107

The Reasons behind the Shift in Approach to Learning ..................................... 110

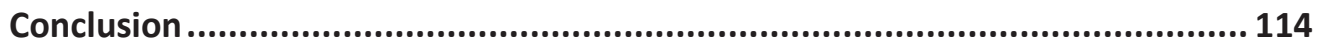

Chapter 5: Quantitative Data Analysis ...............................................116

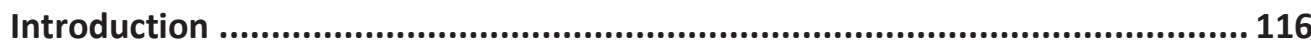

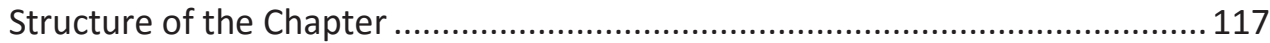

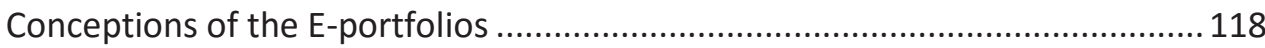

The Perceptions' of the E-portfolio-based Teaching and Learning Context .......119

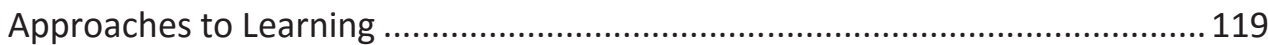

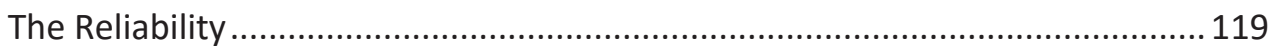

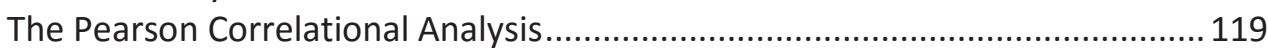

The Second Order Factor Analysis ................................................................ 120

Motivation for Each of the Quantitative Analyses ..........................................120

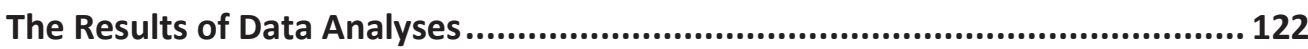

Conceptions of the E-portfolios: Item Factor Analysis....................................... 122

Perceptions of the Unit: Item Factor Analyses............................................... 123

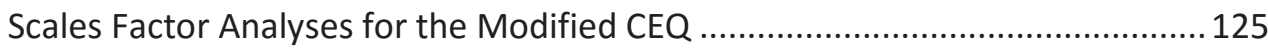

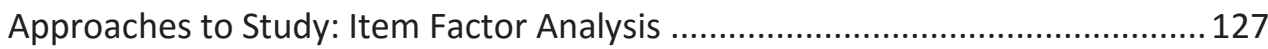

The Reliability of the Scales in the Questionnaire ........................................... 129

Correlation Analysis of Aspects of the Participants' Learning .......................... 132

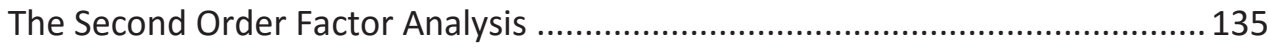

The New Findings in this Research .............................................................. 136

The Results Which Are Consistent with the Previous Research ....................... 136

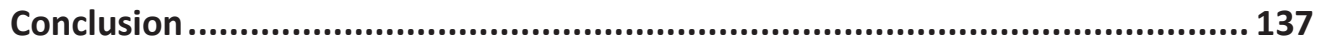

Chapter 6: Discussion and Conclusions..................................................139

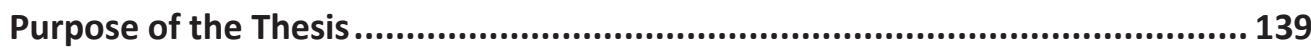

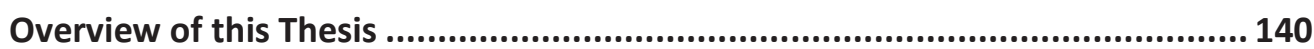

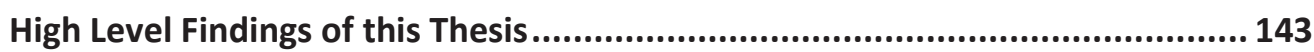


Qualitative Analysis: Chapter 4

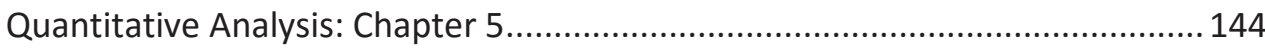

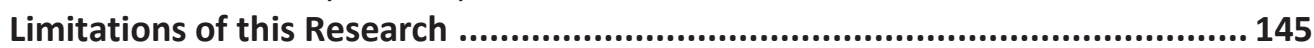

Summary of the Results: Two Research Questions ........................................ 145

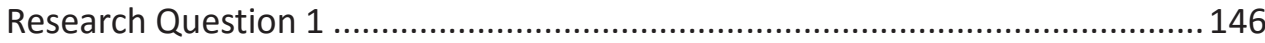

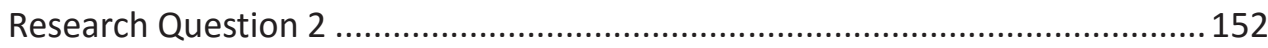

The Implications of the Results to Design E-portfolio-based Units ................... 154

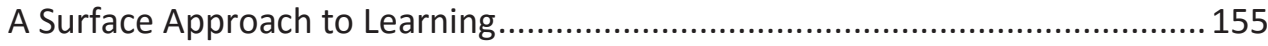

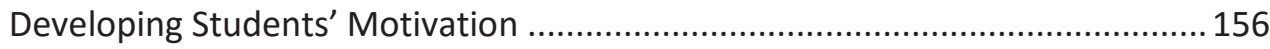

Helping Students Master the Use of Technology............................................ 157

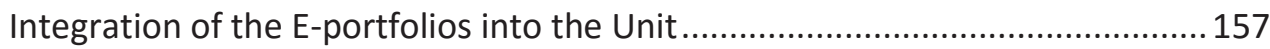

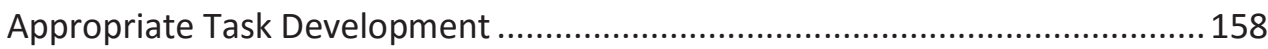

Requirement for Appropriate Level of Reflection............................................ 158

Implementing the Most Appropriate Type of E-portfolios ................................ 160

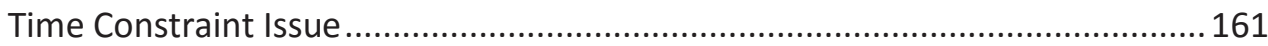

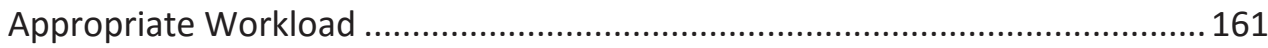

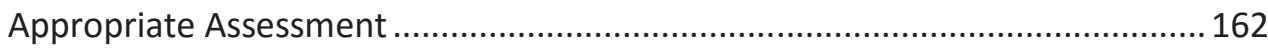

Alterations in the Development of E-portfolios According to the Case Study.... 165

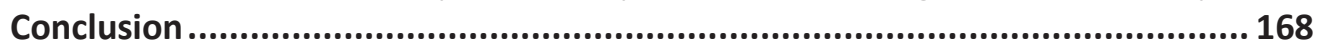

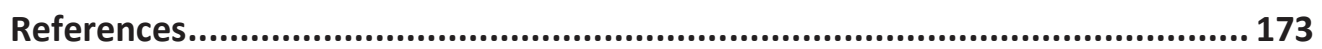

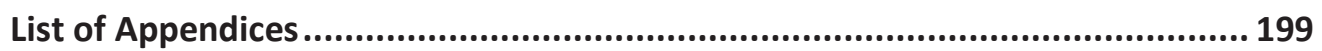

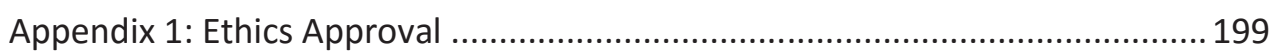

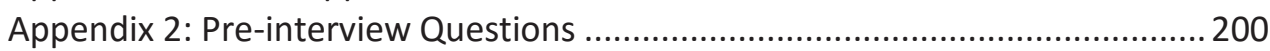

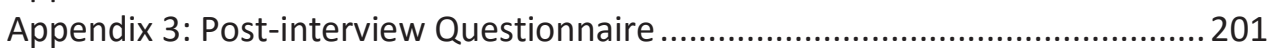

Appendix 4: Questionnaire Questions ...............................................................202 


\section{List of Figures}

Figure 1. Crotty's (1998) four basic elements of the research ..........................41

Figure 2. Constructivist approaches ....................Error! Bookmark not defined.3

Figure 3. Theoretical framework for learning through e-portfolios .........................49

Figure 4. Key Variables in the Research Design .............................................. 81

Figure 5. Aspects of students' perceptions investigated in chapter 5 ...............118

Figure 6 . The role of strategies and motives on adoption of approaches to learning 


\section{List of Tables}

Table 1. E-portfolios-based Learning Activities Aligned with the Theoretical

framework .66

Table 2. Participant of the Semi-structured Interviews .....................................69

Table 3. Design of the Interview Questions........................................................ 70

Table 4. Original Questionnaire Items and Reasons for the Change ..................72

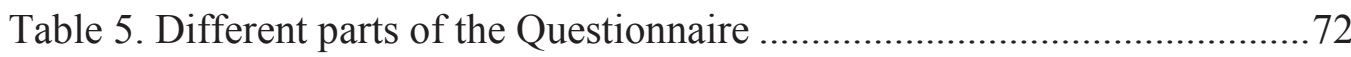

Table 6. Categories and Main Themes in the Pre and Post Interviews...............85

Table 7. Frequency of Responses Related to Perceptions of Learning and Teaching .999

Table 8. The Relationship Between the Categories: Example of a Student who

Adopted a Surface Approach to Learning .99

Table 9. The Relationship Between the Categories: A Student Who Adopted a Deep

Approach to Learning 100

Table 10. Participant 5: Categories, Themes, and Comments Showing Shift from a Surface to Deep Approach to Learning 105

Table 11. Participant 6: Categories, Themes, and Comments Showing a Shift from a

Deeper to Surface Approach to Learning 108

Table 12. Research Questions and Sub-questions and their Link with Questionnaire Items 12220

Table 13. Item Factor Analysis for Students' Conceptions of E-portfolios .12222

Table 14. Factor Analysis of the Modified CEQ Items 12525

Table 15. Exploratory Factor Analysis for the Good Teaching Scale 12626

Table 16. Exploratory Factor Analysis for the Clear Goals...........................1266 
Table 17. Exploratory Factor Analysis for the Appropriate Assessment Scale 1266

Table 18. Exploratory Factor Analysis for the Appropriate Workload ........12727

Table 19. Item Factor Analyses for Students’ Approaches to Learning....... 12828

Table 20. Factor Analysis for the Deep Approach to Learning ....................12929

Table 21. Factor Analysis for the Surface Approach to Learning ..................1299

Table 22. Reliability Estimates of the CEQ Scales.......................................13131

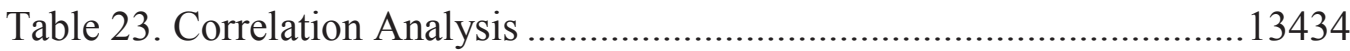

Table 24. The Second Factor analysis of Conceptions of the E-portfolios ..13636 


\section{Chapter 1: Thesis Overview}

\section{Introduction}

Pre-service teachers (PSTs) are increasingly required to reflect on, document and demonstrate their professional competency from the early years of beginning teaching onwards. Supporting PSTs to prepare for the teaching profession through demonstrating their professional competency is a vital role higher education plays to ensure that PSTs can provide evidence of their teaching proficiency. They are future teachers in a world of rapidly developing computer technology. Adopting eportfolios may provide a model for their future classes, and it may help them to collate relevant information to show they are achieving the standards. They can also prepare for the teaching profession by using e-portfolios as a digital resume, showing their knowledge of teaching and learning, and this can be presented to prospective employers. Through the use of e-portfolios, PSTs can showcase the process of their learning, and they have the opportunity to present their persona to broad or specific audiences. However, educational research over the last few decades indicates that there is a significant indirect connection between the way teachers teach and design their courses, and the quality of their students' learning outcomes (Prosser, 2004). This thesis argues that even with the provision of well-designed and implemented eportfolio-based teacher education units, significant variation in the PSTs' experience of the e-portfolio-based context takes place. To investigate PSTs experience of the eportfolio-based unit, this thesis explored PSTs' conceptions of e-portfolios and their perceptions of the e-portfolio-based teaching and learning and investigated the role 
of their perspectives on the adoption of a deep or surface approach to learning when using e-portfolios. The thesis further sought to reveal the reasons for qualitative and quantitative variation in the participants' experience of e-portfolio-based learning. PSTs in their final year of a teacher education programme at an Australian university adopted e-portfolios to assist them in showing how they meet the teaching standards. To conduct the current research, evidence was gathered from each unit of work they undertook as well as from their professional experiences and practicums to explore the effect of e-portfolio implementation on the adoption of their approaches to learning and their learning outcomes.

The purpose of this chapter is to present an overview and an introduction to the research. It describes the aim and research questions, clearly states the specific problems and issues which the study dealt with and explored. It begins by providing a background about the research and contextual information, which forms the basis and rationale for this research. The research questions were developed to investigate this. Theoretical consideration, the research methodology, and ethical consideration are explored, and the limitations of the study are presented. Finally, the structure of the thesis is presented.

\section{Research Background}

This study examined e-portfolio based learning in the context of a theoretical framework which is a combination of constructivism, students' approaches to learning (SAL) and self-regulated learning (SRL) perspectives in order to provide a deeper understanding of how students use e-portfolios to achieve better learning outcomes. SAL and SRL learning theories describe how students learn in the context 
of higher education. Both SAL and SRL are located under the umbrella of constructivism, as it supports the assumptions and principles involved in both of these theories of learning. Therefore, under the tenet of constructivism, SAL and SRL form the theoretical framework for this study. However, the main perspective applied in this research is SAL as most research questions are posed according to SAL, particularly the 3P model of learning. The SRL theory of learning is applied in this research because Printrich (2004) asserted that there is an intertwined relationship between SAL and SRL. Both perspectives focus on constructing knowledge from external and internal environments, as well as setting standards to achieve learning. Although these theories share two general assumptions, they differ regarding their focal points. SAL focuses on student perceptions about context and their approach to learning, while SRL includes motivational, affective, and social contextual factors (Printrich, 2004). SAL and the 3P model of learning form the major theoretical perspective for the research to explore key variables. These key variables in their development include: i) PSTs' conceptions of e-portfolios; ii) their perceptions of teaching and learning context, and iii) their approaches to their learning. From here, it would be possible to explore how the adoption of e-portfolios enhances reconceptualising of teaching standards through reflection on teaching practice in the PSTs' professional experience and practicum as well as their learning as beginning teachers.

A web-based e-portfolio platform called designer to learn in an Australian university was developed for PSTs to present their documents, understanding, and evidence of their teaching philosophy and teaching standards as part of their university experience. The participants selected 
four of the eight focus areas from the AITSL (Australia Institute for Teaching and School Leadership) standards from the graduate level, and in total, they wrote to four focus areas, each in a different standard. Each e-portfolio included information, professional knowledge, professional practice, and professional engagement. There were links to access the artefacts. The e-portfolios lacked social media features such as embedding videos or audios to the platform. Students mainly met four AITSL standards and added some links to artefacts from their placements. Evidence could consist of unit planning, lesson planning, photos of students' work, excerpts from essays PSTs have written, links to literature, ets For each focus area, PSTs were required to write 400 words per criteria (total of 1600 words for the task). The remaining word count was an inkind amount (1900 words) to allow for the time and work put into selecting, linking and/or creating appropriate evidence. Finally, these e-portfolios were used for summative assessment and professional development purposes.

\section{Justifications of the Research}

There are five justifications to conduct research on the role of e-portfolios in higher education. The discussion in Chapter 2 reveals that the majority of research and publications emphasise familiarisation with and facilitation of e-portfolios for PSTs and, therefore, it is significant to conduct a study to investigate the effectiveness of e-portfolios, and the reasons behind students' success when using the tool. This research argues that students' perceptions of the context are a key factor in how they learn (Prosser \& Trigwell, 1999). Different perceptions of those contexts encourage students to adopt different learning approaches (Biggs, 1987; 
Prosser \& Trigwell, 1999). Therefore, it is important to investigate the variation in the quality of approaches to learning that the participants adopt in e-portfolio-based learning. To achieve this goal, the research aims to investigate the efficacy of eportfolios within a theoretical framework by exploring the ways participants learn, and to explore the quality of their learning outcomes in higher education. The research examines how e-portfolios facilitate conceptual change, and how they encourage adoption of a deep approach in developing AITSL standards through selfreflection, self-assessment, ongoing monitoring and lifelong learning.

The second reason is that the quality of teaching and learning in Australian universities has become a central focus in the government agenda (Commonwealth of Australia, 2003). The reason is that over recent years there has been a change in Australian higher education towards outcome-based learning. There have been key benefits of incorporating information and communication technologies (ICT) into outcome based education (Pelliccione \& Dixon, 2008). Therefore, one of the factors which may facilitate higher learning outcomes is the integration of technology into education. PSTs, for example, are future teachers in a challenging world where the development of computer technologies has caused major changes in their profession. Creating an e-portfolio in digital format helps them to improve their technology skills (Lin, 2008), and as a result, there has been a growing interest in the adoption of e-portfolios (Faulkner \& Allan, 2009).

Benefits of e-portfolios in higher education include supporting learners to become critical thinkers, applying theories and concepts to concrete, authentic learning (Hauge, 2006), as well as creating an archive of learning progression over time (Smith \& Tillema, 2003). According to Robinson and Udall (2004) when 
students engage with recording their own progress, self-assessing and reflecting critically upon their progress over time, they become stakeholders in their own progress, and it provides an environment for deep learning to happen. Consequently, now that higher education in Australia focuses on outcome-based learning, it is worthwhile to investigate how the use of e-portfolios may encourage students to adopt a deep approach to learning which is associated with higher learning outcomes.

Thirdly, higher education has been criticised for the lack of a link between theoretical and functional knowledge when the lecturer provides declarative knowledge to students (Biggs \& Tang, 2011). Biggs and Tang (2011) argued that students need to put their theoretical knowledge into practice before graduation. In order to address this issue they recommended the use of e-portfolios as they have the potential to bridge the gap between theoretical and functional knowledge.

Fourthly, another change in higher education has been focused on preparing students for employment. Instead of assessing the acquisition of knowledge, universities have been engaged in re-defining curricula and assessment in order to assess key skills including critical thinking, communication technology, lifelong learning and professional skills. For example, in this research PSTs used e-portfolios for certification, and they could use e-portfolios as a résumé for potential employers.

The final justification to conduct this research is that despite the increasing use of e-portfolios in higher education, the Australian e-portfolio Project 2008 Report confirmed that most Australian institutions are in the early stages of adopting e-portfolio concepts to support University-level learning (Faulkner \& Allan, 2009). As a result, innovative aspects of using e-portfolios are new to many learners and therefore the examination of e-portfolios is a new area of research (Parker, Ndoye, \& 
Ritzhaupt, 2012). Therefore, this research investigated the role of e-portfolios in higher education to shed light on how the use of e-portfolios may facilitate higher learning outcomes for students.

\section{Significance of the Research}

This is the first study which has investigated e-portfolio-based learning in the higher education context from different perspectives including: constructivism, selfregulated learning, students' approaches to learning, and the 3P model including presage, process, and product. Prosser and Trigwell (1999) drew on the presageprocess-product (3P) model, which has contributed to understanding the relational aspects of university students' learning experiences and has informed the theoretical framework in this thesis. In this model, students' conceptions of technology, their perceptions of the learning and teaching context are seen to be an interaction between their previous experiences of learning and teaching (Presage) and the learning and teaching context itself. The students' approach to their learning (Process) is in relation to their perceptions of the context, and those approaches are related to the quality of their final learning outcome (Product). The structure and purpose of the model is examined in depth in Chapter 2.

1. Increasing numbers of Australian universities are employing e-portfolios to support learning. Having used an Australian university as a representative sample for the Australian tertiary education institutions, this study provides an examination of how e-portfolios have changed the learning outcomes in the Australian higher education context; 
2. The participants in this study were PSTs at senior level, and they used eportfolios to prepare for the teaching profession. This study examined the effect of using e-portfolios by PSTs in the process of becoming teachers as e-portfolios may bridge the gap between university knowledge and functional knowledge; and

3. There is little understanding of PSTs' perspective of e-portfolio implementation. This research presents insight into the disadvantages and benefits of developing e-portfolios from the PSTs' perspective.

\section{Theoretical Consideration}

Over the last 40 years, research on university students' learning experiences have shown that there is significant variation in what students report they think they are learning (that is, their conception of what they are learning) and how students approach their learning (SAL: that is how students go about learning and why they do the things they do) (Biggs, 2003; Crawford, Gordon, Nicholas, \& Prosser, 1994; Marton, Hounsell, \& Entwistle, 1997; Ramsden, Prosser, Trigwell, \& Martin, 2007; Säljö, 1979; Trigwell \& Ashwin, 2003; Trigwell \& Prosser, 1991). This perspective was used to develop a theoretical framework compatible with e-portfolio-based learning in higher education.

This research explored how higher education students used e-portfolios in their learning by bringing together a number of related research perspectives: constructivism, SAL, and the 3P model of learning which is part of SAL The main perspectives in the research including SAL, and the $3 \mathrm{P}$ model of learning illustrated how students perceived and understood the role of e-portfolios in their learning and 
how this influenced their approaches to learning. The 3P model of students' learning (presage, process, and product) was used to structure different variables in this study. Prosser and Trigwell (1999) drew on the 3P model focusing on variation experienced by students in the 'what' and 'how' of their learning experiences. The variations have been shown to be closely related to the quality of their ultimate product or learning outcomes and the level of their academic achievements. These findings imply that students entering the learning context of a well-established e-portfoliobased unit will not automatically experience high-quality learning. What is more likely is that those students with a more complete understanding of e-portfolios requiring higher conceptions of the e-portfolios, and higher perceptions of the teaching and learning context may develop a deep approach toward the e-portfoliobased learning. This approach also promotes understanding, and is related to high quality learning outcomes (Prosser \& Trigwell, 1999). SRL focused on students' motivation for using e-portfolios and how they monitored, evaluated and regulated their learning using e-portfolios.

\section{Research Methodology}

The mixed method research paradigm is used in this research. In general, mixed methods research represents research that collects, analyses, and interprets quantitative and qualitative data in a single study that investigates the same underlying phenomenon (Leech \& Onwuegbuzie, 2007). It merges qualitative and quantitative approaches in various ways. The goal of mixed methods research is to merge the strengths of quantitative and qualitative approaches (Johnson \& Onwuegbuzie, 2004). 
The researcher interviewed students in two different phases of their study in the e-portfolio-based unit. The data aimed to investigate the effect of the participants' conceptions of e-portfolios, and their perceptions of the teaching and learning context on their approaches to learning and their learning outcomes. In this research PSTs completed a questionnaire at the end of the semester.

\section{Ethical Considerations}

An ethical awareness assisted the researcher in building this approved research. Ethics was the fundamental principle which helped the researcher to uphold things that are valued. The research was given full ethical approval by the ethics committee of the University in which the study was undertaken, and the ethical clearance (H0012981) was obtained from the university in June 2014 (as shown in Appendix $1.1)$.

Throughout the data collection, analysis, and interpretation of results the researcher followed all the ethical procedures presented in the ethics application and attachments. This research brought no harm to the participants. All the participants recruited were students at a university in Australia, and their participation in the research was voluntary. The researcher had no connection with the Unit. They were able to independently make responses to the questions according to their own beliefs. There were no sensitive personal or cultural issues included in the research questions. Participants would thus be neither offended by the questionnaire nor the interviews. They could withdraw their participation at any time without any effect on their study. No data was collected or used without the participants' consent. The participants were PSTs studying a Unit titled getting ready for the profession in the Faculty of 
Education. They used e-portfolios to present their teaching philosophy to their lecturer. They also addressed the teaching standards through the use of e-portfolios. The participants included examples of assessments, and feedback as artifacts when necessary. Although there were both online and face-to-face modes of teaching for the unit, only face-to face students were invited to participate in the research. The questionnaires were distributed amongst the participants at the end of the tutorial session in week nine, and those who were interested in participating in the interviews filled consent forms.

Data storage was organised with full ethical consideration. The participants' responses to the questionnaires were non-identifiable, and no specific individual could be identified by anyone including the researcher as the paper-based questionnaire did not ask students any personal information. The questionnaires were answered anonymously and all the collected data was treated confidentially. Responses to the interview questions were re-identifiable data; however, their confidentiality was well protected. The interview transcripts erased all references to any particular named participant, so only the researcher knew the information. The researcher used the photocopier in the Faculty of Education; so no other people had access to the confidential information. The participants' names were erased from the initial data and were replaced by pseudonyms such as participant 1,2 , etc. No individual's name was used in any publication arising out of the research. Both recorded interviews and paper instruments were stored securely. All records were kept in a password-protected computer, and then deleted one week after the close of the project. The paper data was stored in a locked filing cabinet in the chief investigator's office. The data analysis and subsequent thesis were stored on 
password-protected servers. All data will be destroyed after a period of five years by placing them in sealed bags, which will then be removed and shredded by a contractor employed specifically to remove confidential waste from the university.

\section{Limitations of the Research}

The data was gathered at a university in Australia. All of the participants were face-to-face students; online students were not invited to participate in the study. Also, all the participants were studying in the same unit at the Faculty of Education. Thus, the generalisation of the outcomes of the research needs to be treated with caution. However, many of the findings can be generalised to exist in universities across Australia. Appropriate workload and assessment scales were measured according to only two items each. Therefore, lack of items in these scales is another limitation of the research. Further to this, the lack of student interaction was a limitation of the ways in which e-portfolios were used. Because of lecturer's concerns that inexperienced pre-service teachers might include inappropriate comments, and that reflecting in an open forum might be stressful for some, the eportfolios remained private for the duration of the semester and were only visible to participating staff members (not to other students or beyond the university). Thus, the participants were not able to reflect in a collective sense or comment on each other's work. However, the participants mentioned that there were informal interactions and exchange of ideas outside of the classroom in terms of writing teaching philosophy. 
Another limitation of this research is that this research did not provide more targeted analysis connecting the characteristics of the actual e-portfolios with the participants' responses.

\section{Structure of the Thesis}

This chapter introduces the focus of this research as investigating PSTs perceptions of the role of e-portfolios in higher education. Research questions and aims are identified. Justification of the research, and theoretical consideration are presented. Research methodology, ethical consideration and the limitations of research are discussed.

Chapter 2 reviews the related literature about e-portfolio definition, types of eportfolios, the benefits of e-portfolio implementation, and the activities students may be engaged in when using e-portfolios. The chapter also discusses key models of technology adoption for designing e-portfolios in the higher education context. Then the theoretical framework is introduced for the use of e-portfolios. Different variables are introduced in the theoretical framework, which contributes to clarifying how students may approach deep learning and higher learning outcomes when using e-portfolios.

Chapter 3 outlines different elements of the research such as epistemology, research paradigm, and research method. The link between the various elements of the research is discussed. The research instruments and their reliability and validity in different phases of the research are outlined. Finally, data analysis techniques are discussed. 
Chapter 4 presents the findings and interpretations of the interviews. These findings reveal four main themes: students' conceptions of e-portfolios, their perceptions of the teaching and learning context, their approaches to learning, and their outcomes.

Chapter 5 discusses the results of the quantitative phase of the study. The associations between different aspects of the participants' learning are explored and the results are presented.

Chapter 6 draws together the findings of the study. Research questions are revisited, and a reflection of the research process is presented. The chapter concludes with a discussion of the challenges of e-portfolio implementation in the context of higher education and the researcher's recommendations are stated. The link between different variables is presented related to the theoretical framework such as prior knowledge, students' approaches to learning and their outcomes, as well as selfregulated learning.

\section{Conclusion}

While there are many reports about the process of learning through eportfolios, there is much less research on the students' experience of e-portfolios, what they report they learn through e-portfolios and how they go about approaching learning when using e-portfolios in the process of becoming a teacher. Therefore, it is important to examine how students are interested in using this tool before focusing on the positive impact of e-portfolios on teaching (Tzeng \& Chen, 2012). Variations in conceptions of e-portfolios do not just relate to how the students approach their studies, but also to the quality of their learning outcomes. It is also necessary to 
understand whether students perceived the functions of e-portfolios to be important (Tzeng \& Chen, 2012). A PST can describe how meaningful the process of learning through e-portfolios is, particularly if they are completing an e-portfolio to fulfil academic requirements (Parker et al., 2012). As a result, by investigating the participants' experience of e-portfolios, this thesis identifies reasons for variation in the quality of learning outcomes when using e-portfolios. Overall, the research focuses on the examination of the participants' learning experiences in a wellestablished e-portfolio-based unit in a university in Australia. It emphasises the participants' perspective by understanding key aspects of their conceptions of the eportfolios, their perceptions of their learning situation, how they are approaching their learning, and what they have learnt through e-portfolios. The links between these aspects of the participants' learning in this research are mainly informed by SAL and the 3P model of learning. SRL is also used as a complementary perspective to examine the effect of motivation on learning through e-portfolios. Constructivism is applied as the research epistemology, and the next chapter discusses how constructivism is compatible with SAL, the 3P model of learning and SRL. 


\section{Chapter 2: Literature Review}

\section{Introduction}

This chapter aims to review the reasons for e-portfolio implementation by PSTs in higher education. Moreover, it provides a literature background for the research, and reviews literature related to e-portfolios. The process of designing eportfolios and their implementation is closely reviewed. Concepts associated with enhancement of conceptual ideas through e-portfolios are each discussed in depth to provide a conceptual foundation for this research. Furthermore, the ways in which eportfolios are adopted by PSTs is taken into consideration.

\section{A Shift from Traditional Portfolios to E-portfolios}

Educational portfolios contain work that a learner has selected, to show improvement and change over time (Barrett, 2001). There has been a transition from traditional portfolios to e-portfolios as the use of the Internet has become more widespread. Challis (2005) asserted that there are more reasons for the transition, and he believes e-portfolios are different from traditional portfolios in four ways. First, it is easier to manage material in terms of reflection, rigorous selection, and analysis. Second, there is a difference regarding storage of data due to the reduced size. Availability to a broad audience is the third difference. It is possible to communicate online through a wider range of materials including digital media such as video and sound clips when using e-portfolios. Particularly, e-portfolios provide learners with opportunities to present materials using digital media such as audio recordings, graphics, databases, video and word processing software (Milman \& Adamy, 2009). A number of researchers (Chang, Tseng, Yueh, \& Lin, 2011) claimed that e- 
portfolios present advantages over traditional portfolios regarding access, management, interactivity, real-time functionality, and presentation method. However, the most notable advantage of e-portfolios is their facility for solving storage problems associated with traditional paper-based portfolios (Gathercoal, Love, Bryde, \& Mckean, 2002).

\section{Definition of E-portfolios and the Development Process}

Abrami and Barrett (2005) asserted that e-portfolios are digital containers, which are capable of storing visual and auditory content. The tool may be identified as an electronic platform, which is used to structure, store and retrieve information, including text, graphics, audio and video materials (Butler, 2006). According to Andre (2010), an e-portfolio has a number of significant features including: a personal repository, a personal diary, and feedback and collaboration systems. It offers the user absolute control, and can record linked abilities, events or plans.

In the process of creating e-portfolios, the learners' development, critical thinking, decision-making and problem-solving skills, as well as negotiation with educators about the contents of portfolios, all facilitate learning (Baturay \& Daloğlu, 2010). Barrett (2001) claimed that designing an e-portfolio can be daunting, but it becomes less difficult when viewed as a series of stages that accommodate different goals and activities. Taking the process of e-portfolio development into consideration, there are two main stages. The first stage was data collection and organisation of e-portfolios. This stage included designing, arranging, and presenting the content of e-portfolios, and they are the most time consuming and challenging tasks for learners (Tsai, Lowell, McDonald, \& Lohr, 2004). The next stage was 
designing the tabulation for navigation. Tabulation of e-portfolios refers to arranging the content in a way which allows easy access to information by its viewers (Chang et al., 2011). Kuo (2004) suggested several types of data tabulation according to a learner's field of study, content items, the student's work, or chronological order.

Danielson and Abrutyn (1997) outlined another process for developing eportfolios that emphasise reflection as an essential factor. The process begins with the selection, which involves reviewing and evaluating, and demonstrating achievement of specific standards. The second step is reflection, which encourages teachers and students to become reflective practitioners, evaluating their own growth over time, and their achievement of the standards, as well as identifying the gaps in their development. The next step is projection (or direction), in which students and teachers compare their reflections on the standards and performance indicators, and set learning goals for the future. This is the stage that turns e-portfolio development into professional development and supports lifelong learning. The last stage is presentation, in which teachers and students share their e-portfolios with their peers. This is the stage where appropriate public comments can be made to encourage collaboration and commitment to professional development and lifelong learning.

Ivers and Barron (1998) asserted that the e-portfolio development process has five stages: 1) Assess/Decide: The emphasis is on needs assessment of the audience, the presentation of goals, and the appropriate tools for the final portfolio presentation. 2) Design/Plan: The emphasis is on organising or designing the presentation. This involves determining audience-appropriate content, software, storage medium, and presentation sequence. 3) Develop: Materials for the presentation are gathered and organised into a sequence (hyperlinks can be used) for 
the best presentation of the material, using an appropriate multimedia-authoring program. 4) Implement: The developer presents the e-portfolio to the intended audience. 5) Evaluate: The focus is on evaluating the presentation's effectiveness in light of its purpose and the assessment context.

\section{Types of E-portfolios}

A number of researchers have asserted that the purpose of using e-portfolios defines their characteristics, and a key factor to the successful integration of an eportfolio system is identifying its purpose (Ritzhaupt, Singh, Seyferth, \& Dedrick, 2008). Therefore, e-portfolios have been categorised differently according to the

purposes they serve. For instance, McPherson (2007) divides e-portfolios differently according to the needs they meet. These are presentation e-portfolios, learning eportfolios, and work e-portfolios. Presentation e-portfolios present professional achievements. Learning e-portfolios focus on the learning process. The students collect and choose materials to present a body of work that shows their progress over the course of their education, and then they reflect on this work making significant connections around personal and educational goals (Mason, Pegler, \& Weller, 2004).

McDonald (2012) argued that with regard to various objectives in the academic environment, there are three main types of e-portfolio. First, documentation or 'working' e-portfolios show a collection of the student's work over time representing the learner's growth. This kind of e-portfolio may include the elements of learning from brainstorming activities to drafts and the completed product. Second, process eportfolios document all phases of the learning process with special emphasis on 
reflection. This type of e-portfolio facilitates reflection, which is an important strategy for learning (Greene, 2011).

The last one is the biographic e-portfolio, which is a record of achievement. This type of portfolio may have examples of a student's work experience, which is collected over a period of time and arranged chronologically.

In this research PSTs used summative e-portfolios. They did not receive formal feedback from peers, and peers were unable to see other students' e-portfolios. The participants' final products were considered for evaluation.

\section{Social Media as a Platform to Design E-portfolios}

Social media is used to define a variety of technologies that emphasise social aspects of the Internet as a channel for communication, collaboration, and creative expression (Dabbagh \& Reo, 2011). Social networking for academic purposes (SNAP) includes commenting on blog posts, asking and answering questions, and sharing ideas on a discussion forum (Kirkwood, 2010). For example, resourcesharing tools such as Twitter, blogs, Wiki software, Facebook and YouTube enable social networking (Dabbagh \& Reo, 2011; Kitsantas \& Dabbagh, 2010). A study done by Griffith and Liyanage (2008) highlighted that Australian students use Web 2.0 facilities such as wikis, blogs, discussion boards, instant messaging and they can complement to support what is taught in a traditional classroom setting. It provides the opportunity for personal learning environments (PLEs) as an effective platform for students' learning (Dabbagh, \& Kitsantas, 2012). PLEs empower learners to take charge of their own learning as they are required to select tools and resources to 
create, organise and package learning content to learn effectively (McGloughlin \& Lee, 2010; Rubin, 2010).

Many researchers attempt to find out why today's students are attracted to learning through social media. Some researchers, such as Boyd (2008), suggested that technology provides teenagers with the opportunity to create a favourable profile. Using features of social media in an online teaching and learning platform in e-portfolios help students to create their own profiles. When e-portfolio platforms are equipped with social networking tools, such as weblogs and wikis, they support the functions of community practice (Gray, 2008).

Students who are competent in using e-portfolios can access a wider range of online communication through social media networks to achieve meaningful learning (Babaee, 2012). Woo and Reeves (2007) supported the idea that it is possible to use online interaction to promote meaningful learning. Meaningful interaction in webbased learning includes: Offering alternative perspectives with one another while undertaking some authentic tasks, adding to evolving ideas, responding, negotiating, and arguing points (Lapadat, 2002). The advent of technology has led to social media based e-portfolios, which have a significant influence on learners' performance as they allow students to develop self-monitoring, self-regulation and self-assessment skills (Babaee, 2012). These aspects of learning are associated with a deep approach to learning and higher learning outcomes.

\section{Enhancing Web-based E-portfolios}

According to Gathercoal, Love, Bryde and Mckean (2002) web-based eportfolios encourage collaboration and creative thinking, because learners can 
collaborate with anyone in the world. They also support graphics, digital videos, sound, text and other presentation media. Participation in peer assessment through the use of web-based learning environments encourages the formation of positive attitudes towards lifelong learning (Nevgi, Virtanen, \& Niemi, 2006). The participants in this research use a web-based e-portfolio called MyLo on the University website.

\section{PebblePad based E-portfolios}

According to Welsh (2012), one of the tools which can be used to create an eportfolio is PebblePad. This method is commonly used as a personal digital repository in which students store evidence of performance-based competencies. In

addition, PebblePad supports reflection and acts as a personal and communal learning environment in which students can present evidence of their achievements through collaboration with others. PebblePad e-portfolios provide a sustainable learning environment, which is constantly being updated and refreshed. Skills such as reflection, self-regulation and formative assessment implementation are supported in this type of platform (Welsh, 2012).

\section{Facebook-based E-portfolios}

Although Facebook was not designed as an environment to construct and manage learning experiences, it is a suitable platform to encourage lifelong-learning, user-managed open learning and collaborative learning (Cerdà, 2010). Other valuable features of Facebook are the liking, tagging and sharing functions (Babaee, 2012). These can be useful for collaboration among peers, because when using a network users share ideas, and the nature of these interactions allows students to develop the necessary competencies for collaborative work. Facebook's 'like' function provides 
a forum for feedback and peer interaction. However, a study conducted by a number of researchers (Madge, Meek, Wellens \& Hooley, 2009) revealed that Facebook was not used for formal teaching purposes, and it was used informally for learning purposes. Cerdà (2010) also supported this claim, as he believes unlike other systems organised around courses, Facebook is an open platform, which is not a learning environment either in its underlying concept or the design of its tools.

\section{Wiki and Weblog-based E-portfolios}

Wikis have greatly enhanced many of the established methods of teaching, including collaboration. They are most effective when learners can be more autonomous, and autonomy gives students a feeling of ownership and responsibility for their own learning (Albert \& Kussmaul, 2008). It is possible for anyone to edit a Wiki, and this is a good opportunity for the teacher to edit students' work.

A weblog or blog is a web application, which contains periodic posts on a common web page, and these posts are often presented in reverse chronological order. It is a spontaneous online journal, which is an extremely popular communication tool on the Internet (Bhattacharya \& Chauhan, 2012). Traditional classroom tools, such as diaries and journals, which help develop autonomy, can be effectively combined within a blog (Bhattacharya \& Chauhan, 2012). They have had a great effect on the learning environment, as they support learners' self-reflection and self-evaluation (Simsek, 2010). Yang (2008) distinguished weblogs from typical web-based portfolios, labelling the weblog-based portfolio a 'blogfolio'. In a blogfolio, learners can post their assignments and the teacher is able to provide them with fast online feedback. Posting to a weblog encourages learners to perform well 
and to be more interested in accuracy, as their work can be viewed by a worldwide audience (Motallebzadeh \& Babaee, 2009).

There are a number of reasons why weblog technology has integrated so well with education. First, weblogs are considered to be a means of significantly reducing the technical barriers to effective web publishing (Yang, 2008, p. 179). Another reason is the ease of using the technology. In contrast to the production of personal websites, a weblog does not need specific software (Montero-Fleta \& PérezSabaterb, 2010). The ease of posting creates more confidence, enthusiasm and interest among learners. Furthermore, blogging strengthens social networks and learning communities, where users can easily exchange ideas and thoughts (Motallebzadeh \& Babaee, 2009).

\section{Challenges of Using Social Media in Education}

Critics of e-learning consider online classrooms as neutral spaces devoid of human connection, interpersonal relationships, and interaction with educators or peers. It is challenging for educators to use social media effectively to provide opportunities for learners to make emotional connections with peers just as they do in the face-to-face classroom (Baird \& Fisher, 2005). An important factor to address the issue of lack of interpersonal relationships in an online environment is to support learners to construct relationships with their peers (Baird \& Fisher, 2005). Student collaboration is the key factor in creating a constructivist learning environment, allowing students to interpret data and use their individual life experiences (Goldman-Segall, 1998).

Other challenges in integrating social media and learning include time constraints and technical difficulties (Lockyer \& Patterson, 2008). To address these 
challenges Lockyer and Patterson (2008) emphasised the need for subject designers and educators to put time and effort into planning the use of the Web 2.0 technologies prior to the start of the academic session. They believe that students may not want to implement a technology in their formal learning, when it may take time to master. The support of educators is required so that the time to learn is not considered to be a burden. They also suggest that educators need to support their students by helping those who are new to such technologies.

\section{Enhancement of Conceptual Ideas through E-portfolios}

E-portfolios may enable students to develop competencies which have not been fully mastered. The following paragraphs discuss the role of e-portfolios in the enhancement of aspects of effective learning for students. These aspects of students' learning are associated with adoption of a deep approach to learning and higher learning outcomes.

\section{Reflection through E-portfolios}

A critical component of an educational portfolio is the learner's reflection on the individual pieces of work as well as an overall reflection on the story that the portfolio tells (Barette, 2001). In order to achieve the full benefit of e-portfolios, it is essential to train learners to reflect on their work (Baturay \& Daloğlu, 2010). Without reflection, e-portfolios are merely a cumulative collection of work while reflection provides accurate information about learners' competency in many areas of learning. Through using e-portfolios, learners may select the best piece of work and reflect on why it is the best evidence, and they are able to make choices that will be beneficial (Janisch, Liu, \& Akrofi, 2007). Barak's (2005) research found that 
students are able to identify and take responsibility for their own learning through a process of reflection.

\section{Autonomous Learning through E-portfolios}

One of the most significant factors maximising students' achievement and accomplishment is autonomy. Autonomy is not only a set of behaviours, but a capacity to do something in a given situation (Holec, 1980). Autonomous learners make decisions, set goals, solve problems, take risks and develop their own learning strategies. They reflect critically and act independently (Little, 1991). They are known as 'active learners' who participate in classroom activities creatively and have the ability and passion to work collaboratively. Autonomy may provide the opportunity to transform learning from teacher-centered to student-oriented learning. There are some strategies to foster autonomy, but these strategies do not automatically enhance autonomy. Increased control over learning is one of the factors supporting self-determination, and consequently motivation and learner autonomy (Chan, 2001). Other important factors to improve autonomy include: Selfassessment, self-regulation, self-access learning, technology, and implementing eportfolios.

Chau and Cheng (2010) stated that e-portfolios provide opportunities for learners to construct knowledge, refine understanding, share with peers and teachers, and learn socially, personally and autonomously. They are used to enhance students' application of meta-cognitive strategies, but not every student is ready for autonomous learning. To integrate e-portfolios into autonomous learning, Yang (2003) suggested that teachers should introduce the concept of autonomous learning 
to students, offer guidelines to help students develop their e-portfolios, and allow eportfolio sharing and checking.

\section{Enhancing Collaboration through E-portfolios}

Collaborative and constructivist methods, which employ a range of media including text and video, contribute to increased flexibility in the learning process (Friesen \& Anderson, 2004). Therefore, every learning situation should include collaboration, which is construction of knowledge between students and the teacher and between the students themselves (Hunt \& Pellegrino, 2002). E-portfolios are an innovative trend in technology-based education. They elevate and motivate students' engagement in learning, foster active participation and constructive interaction in online discussions, and allow learners to develop positive feedback through eportfolios (Harun \& Jhee, 2012). They enhance collaboration, and exposure to other learners' e-portfolios promotes inspiration and innovation. Having a higher level of technology skills, mature technology integration or close collaborators are all indicators of high levels of e-portfolio use (Barrett, 2007).

Although the lack of interaction is a major disadvantage in Internet-based classroom activities, e-portfolios provide a learner-centered environment in which feedback from teachers and peers can create a more interactive setting (Yang \& Xu 2008). By contrast, Gordin, Grueneberg, Laff, Martinez, and Lam (2004) argued that in regards to e-portfolios, the collective value that other students may bring to the work is not taken into account. They believed that e-portfolios have shortcomings as their format is most often based on the individual creation of work. Wang (2009) investigated the collaborative versus individual use of e-portfolios, and his study revealed that those students who collaborated showed more significant improvement 
in their confidence to perform technology-related tasks than students in the individual portfolio group. Motallebzadeh and Babaee (2009) found that weblogbased e-portfolios helped to enhance interaction, collaboration and sharing as users had the opportunity to receive online feedback in a timely manner. They also emphasised that the potential for teachers to post private messages to learners made this learning environment even more interactive.

\section{Developing Organisational Skills through the use of E-portfolios}

\section{Implementation}

A number of researchers (Kirkham et al., 2009) stated that the use of eportfolios enhances the quality and range of data that students may use, and this tool has the potential to enhance the self-organised learning process associated with enhancement in learning processes. They claim that e-portfolios give more depth to the learning processes as they provide space for both distributed and live data integration. Students may find that through using e-portfolios they learn how to develop organisational skills, because of the necessity to organise files from the very beginning of the course (Lin, 2012). They need to review their articles in a meaningful way so that their final product shows what they have learned throughout the course (Lin, 2012).

\section{Providing Assessment, self-assessment and Feedback through E-portfolios}

Although a large number of educators agree on the advantages of using various alternative assessment approaches, implementing them is difficult because educators are uncertain how to combine quality assessment with daily practice (Corcoran, Dershimer, \& Tichenor, 2004). In order to combine assessment with daily practice it is crucial to adopt innovative teaching methods that integrate IT literacy 
into assessment. In regards to modern learners in the changing world, technology in learning plays a significant role in achieving this goal. Internet and web-based technologies have a big impact on modifying traditional methods of assessment by including new ways of measuring students' ability and knowledge (Rastgoo \& Namvar, 2010). As a result of integration of technology into assessment, web-based learning is implemented. In a web-based context the assessment process is carried out through the Internet, where participants undertake a variety of activities such as self- and peer-assessment, peer portfolio reviews and teacher evaluation (Chang \& Tseng, 2009). E-portfolios are assessment tools, which collect evidence about learning outcomes, such as student development, reflective thinking, and academic achievement (Chang, Liang \& Chen, 2013).

\section{Assessment through the Use of E-portfolios}

In Oskay, Schallies and Morgil's (2008) view, e-portfolio assessments are considered as a powerful, valid and trustworthy approach. The value of e-portfolio assessment is its role in aligning teaching and assessment in order to facilitate productive learning (Huot, 2002; Klenowski, 2000). In regards to assessment, there are two types of e-portfolios as described by Cooper and Love (2001). First, formative e-portfolios include samples of students' work collected throughout the semester to show changes over a period of time. Formative assessment focuses on judgments about the quality of students' work, and emphasises how successfully something has been done or is being done. This type of the assessment focuses on feedback in order to promote learners' competence (Royce, 1989). Formative portfolios can show the process of learning for a special learner, and it may be used as a report to parents or guardians. Second, e-portfolios may include proof of 
students' skills. The range and depth of their skills are called summative e-portfolios. Summative e-portfolios have learning outcomes, and they do not focus solely on the process of learning.

\section{Self-assessment through the Use of E-portfolios}

Successful students regularly engage in self-assessment in the process of their learning (Kavaliauskiene, 2004a). Fielke and Quinn (2011) discussed the influence of e-portfolios on self-assessment. They suggested that one tool that has been identified as important for supporting development of self-assessment is the eportfolio because through the use of e-portfolios learners get an opportunity to think about their own progress, and then they may find ways to change or improve. Eportfolios facilitate self-assessment (Fielke \& Quinn, 2011), which is one of the typical characteristics of successful learners, because reflection on the process of changes contributes to their improvement (Kavaliauskiene, 2004b).

\section{Feedback Provision through the Use of E-portfolios}

In tertiary education, feedback has a greater role than simply correcting errors. It is crucial in guiding and developing student learning through identifying gaps between performance and the required standard (Sadler, 1989). It also serves different important purposes in aiding learners' intellectual development, such as correction of errors, or developing new ways of understanding (Lea \& Street, 1998).

The most common complaint about feedback is the delay in the return of learners' work. Engagement is greater if students receive feedback when it is still important to them, and in time for them to learn from it or seek further assistance (Gibbs \& Simpson, 2004). Therefore, it is beneficial to consider a continuum 
between instruction and feedback in order to connect them (Hattie \& Timperley, 2007).

In order to address the abovementioned issues, e-portfolio platforms are recommended by Chuang (2010) to provide feedback. They are easy to use; they give students a sense of editorship and promote discussion (Chuang, 2010). The possibility of providing peer feedback and teacher feedback through e-portfolios enhances collaboration and interactivity, which enhances interaction (Chang et al., 2013). There is a requirement to encourage dialogue through feedback (Hyatt, 2005), and the social features of e-portfolios in some platforms allow dialogue and conversations.

\section{E-portfolios in the Teacher Education Context}

Research has considered the role of e-portfolios in teachers' professional development from various perspectives (Trent \& Shroff, 2013). First, PSTs spend too much time on theory and too little time on developing actual practices (Barone, Berliner, Blanchard, Casanova, \& McGowan, 1996). Second, some teacher education programs may not prepare students for the realities of the classroom (Goodlad, 1990; Ottenbreit-Leftwich et al., 2012). This may be because of the lack of alignment between the way technology is used in pre-service teaching programs and the way in which teachers use technology to enhance the teaching and learning process (Ottenbreit-Leftwich et al., 2012).

It is possible to incorporate e-portfolios into teacher education programs to address these issues. PSTs' may achieve better understanding of teaching competencies in terms of classroom practices through reflecting on their e-portfolios 
(Kabilan \& Khan, 2012). In Robbins' (2004) teacher training program, PSTs focus on a reflection cycle including: selecting, describing, analysing, appraising and transforming, and they use this cycle to create their e-portfolios.

A number of researchers (Borko, Michalec, Timmons, \& Siddle, 1997; Evans, Daniel, Mikovch, Metze, \& Norman, 2006; Hicks et al., 2007; Penny \& Kinslow, 2006; Zubuzaretta, 2004) emphasised the enhancement of reflection and professional development for PSTs through the use of e-portfolios.

\section{Assessment of PSTs through the Use of E-portfolios}

Traditional assessment of PSTs causes anxiety because long examinations are used as a method of assessing the learner's level of competence (Ghosh \& Agravat, 2009). The use of e-portfolios as a means of authentic assessment is gaining popularity in teacher education (Lin, 2012) as they remove the challenges of traditional methods of assessment. Teacher education programs in many parts of the world employ e-portfolios (Ntuli, Keengwe, \& Kyei-Blankson, 2009). E-portfolios used in the assessment of PSTs reflect the teaching values of the candidates. For example, PSTs are assessed against teacher education program guidelines when using e-portfolios (Sunal, McCormick, Sunal, \& Shwery, 2005). As a result, PSTs may use e-portfolios to represent their unique conceptions of what it means to teach by analysing, discussing, and evaluating their own teaching practices and professional growth (Dana \& Tippins, 1998). Kabilan and Khan (2012) investigated the use of e-portfolios by PSTs, and found that student teachers appreciated eportfolios as a tool for learning and self-assessment because their performance and achievement could be tracked over a period of time. It was also found that the use of 
e-portfolios as a monitoring tool enables PSTs to identify their strengths and weaknesses.

\section{Developing Teaching Competence through the use of E-portfolios}

PSTs are becoming increasingly aware that by using e-portfolios they can express their knowledge about learning and teaching in explicit terms (Lin, 2012). However, the question of how to effectively integrate e-portfolios into teacher training programs needs to be considered to take advantage of e-portfolios for developing teaching competency (Bowers, 2005). It is important to evaluate the level of implementation of e-portfolios by PSTs in their learning in order to determine whether this practice leads to teaching competencies (Kabilan \& Khan, 2012). Through using e-portfolios PSTs evaluate their teaching practice, and they become aware of their philosophy of teaching and learning (Lin, 2012). In regards to teaching competencies, Kabilan and Khan (2012) identified six competencies emerging from PSTs' use of e-portfolios. 1) developing understanding of an effective teacher's role; 2) developing teaching approaches/activities; 3) improving linguistic abilities; 4) comprehending content knowledge; 5) gaining ICT skills and; 6) the realisation of the need to change mindsets .

\section{The Impact of Using E-portfolios on PSTs' Identity}

Identity refers to our understanding of who we are and who we think other people are (Danielewicz, 2001). Individuals create a self-presentation on e-portfolios as a means of exploring or developing their identity (Hallman, 2007). PSTs ask themselves questions to find out who they are and who they want to be as beginning teachers, and they see creating an e-portfolio as a task that is worthwhile for them (Barrett, 2007). The occupation aspect of identity is the most relevant to whether 
students will likely use an e-portfolio (Tzeng \& Chen, 2012). It is important for PSTs to know who they are as teachers, and to identify their theories of teaching. Eportfolios provide PSTs with the opportunity to showcase their capabilities, and they can contribute to the construction of the PSTs' identities as modern teachers through active engagement such as uploading, sharing, viewing, receiving feedback, and decision making about the planning and delivery of lessons (Trent \& Shroff, 2013).

\section{Using E-portfolios to Prepare for the Teaching Profession}

Since e-portfolios allow PSTs to present their best work on the Internet, future employers can see what is important to them, and this can improve those preservice teachers' marketability (Lin, 2012). Dalton (2007) stated that one of the most advocated functions of e-portfolios is their ability to enable students to make career decisions or to find employment. Creating an e-portfolio system should begin with services that help learners to prepare and to present themselves for careeradvancement opportunities (Dalton, 2007). For example, e-portfolios provide a digital résumé, which can create a more favorable impression when applying for a job (Penny \& Kinslow, 2006). The World Wide Web offers the opportunity for PSTs to introduce themselves at the international level, where they can add their photographs or videos of their teaching and state their ideas and values concerning education (Lin, 2012). Most students are uncertain about their future career, and those who need to make a commitment have the most positive attitude towards using an e-portfolio system (Tzeng \& Chen, 2012). In other words, most students welcome an e-portfolio system that can help them to successfully make the transition from learning to the profession (Lumsden, 2007). 


\section{E-portfolios and Institute for School Teaching and School}

\section{Leadership (AITSL)}

The Australian Institute for Teaching and School Leadership (AITSL) in consultation with teachers, have defined the standards in terms of the domains of teaching including professional knowledge, practice and engagement (2014) to define quality teacher standards for teacher registration. Parallel to this initiative in improving the quality of teaching, a national policy titled the Digital Education Revolution was developed to boost technology enhanced-learning (Smart, Sim, \& Finger, 2013). Within this national policy initiative, teachers are being encouraged to use Information and Communication Technologies (ICT) (Smart et al., 2013). Therefore, e-portfolios are used for demonstration of graduate teachers' development of the teaching standards. E-portfolios have been implemented in PSTs' education and to prepare them in licensure with a teacher registration body (Napper \& Smith, 2006). These type of e-portfolios include evidence of assessment such as lesson plans, presentations, reflections to show how PST process information and develop professional skills gained from their pre-service course" (Napper \& Smith, 2006, p. 2). For example PSTs at the University of Tasmania use e-portfolios to address each standard with evidence explained and attached to demonstrate how they meet the standard. E- portfolios may facilitate the development of content and pedagogy skills and facilitate communication between teachers and administrators (Shepherd \& Skrabut, 2011). There is research with evidence that portfolios are useful tools for the process of accreditation and job seeking (Smart et al., 2013).

\section{E-portfolios and the Development of Graduate Attributes}


Qualities, skills, and understandings that are agreed by a university community to be transferred to students during the time they study at that University are called graduate attributes (Bowden et al. 2000). E-portfolios facilitate reflection, recording and articulation of the university experience and as a result have the potential to embed the graduate attributes into the curriculum (Lambert \& Corrin, 2007). The main feature of e-portfolios is the facility to enable students to store and update records of their achievements both in terms of the development of discipline specific skills and the acquisition of graduate attributes (Luca et al, 2003). The emphasis of most e-portfolio implementation is on helping students to understand their own personal development and identify areas where improvement is needed (DiBiase, 2002). Further to this, Bridgstock (2009) argues that students must not only maintain and develop knowledge and skills that are specific to their own discipline, but must also possess 'generic' skills, and attributes that are transferable to many occupational situations and areas. These generic skills are defined as 'those transferable skills which are essential for employability at some level for most' (Kearns, 2001, p. 2). Generic skills are known as 'core skills', 'key competencies', 'transferable skills' or 'underpinning skills' (Mayer, 1992). A research conducted by Lambert and Corrin (2007) indicated that the ability to reflect on graduate attributes and professional skills were students' outcomes of using the e-portfolios. Reflections, self- evaluation and personal development are central themes to eportfolio development (DiBiase, 2002). For example, Oliver (2013) asserted how Curtin University's Curriculum (2010) focused on embedding graduate attributes through three strategies. The first was embedding graduate attributes in degree programs according to constructive alignment of outcomes and assessments. The 
second strategy was reviewing on evidence including perceptions of graduates, employers on the importance of graduate attributes and the extent to which they were developed. The third strategy was a university-wide e-portfolio system enabling students' self- and peer-assessment of graduate attributes.

\section{The Use of E-portfolios by PSTs for Certification}

Last but not least, many teacher education institutions list e-portfolios as a requirement for teacher certification and the creation of portfolios is seen as a necessary skill for both university students and PSTs (Chang et al., 2011). The participants of this research are PSTs using e-portfolios to indicate their teaching philosophy and to meet teaching standards.

\section{Developing ICT Skills}

E-portfolios play an important role in teacher development, as they can demonstrate evidence of teachers' ICT abilities and assist in their development of positive attitudes towards the use of ICT (Abrami \& Barrett, 2005). In terms of using technology, teachers need to develop knowledge that enables them to transfer technological potentials into solutions to pedagogical problems (Zhao, 2003). Lin (2012) also believed that PSTs use the IT skills developed by using e-portfolios for other actions such as modifying Web pages, adding hyperlinks, uploading documents, scanning, changing file formats, and cropping and sizing pictures.

\section{Conclusion}

This chapter investigated the extent and efficacy of e-portfolios for demonstrating PSTs' development of the teaching standards. This chapter defined eportfolios and introduced different types, including the presentation e-portfolio, 
outcome e-portfolio, documental e-portfolio, assessment e-portfolio, process eportfolio, record e-portfolio, work e-portfolio, course e-portfolio, reflective eportfolio, structured e-portfolio, and e-learning portfolio (Carlson, 1999; Cole, Ryan, \& Kick, 1995; Danielson \& Abrutyn, 1997; Greenberg, 2004; Tillema \& Smith, 2000). The most relative e-portfolio-based activities that underpin e-portfolio implementation in higher education have been introduced. Literature review also revealed that the majority of research and publications have emphasised familiarisation with and facilitation of the e-portfolios with a focus on selfassessment, collaborative learning, independent learning, and reflective learning. However, conducting research to investigate the use of e-portfolios for PSTs from a theoretical perspective defining the process of their development remains to be explored.

To address the gap in the literature, a theoretical framework compatible with e-portfolio-based learning was developed. The theoretical framework suggests that students' perception of the teaching and learning context is an important factor in how they learn (Prosser \& Trigwell, 1999). A number of key researchers in the area of higher education have emphasised the significant role of context on students' learning (Biggs, 1987; Prosser \& Trigwell, 1999; Ramsden, 1992). The reason for this emphasis is that different perceptions towards learning contexts encourage students to approach learning differently. Variations in their conceptions of eportfolios and perceptions of teaching and learning context do not just relate to how they approach their studies, but also to the quality of their learning outcomes. Therefore, within the theoretical framework of the study, this research explores whether the selection of learning activities discussed in this chapter was affected by 
what students think an e-portfolio is, and how they perceive the teaching and learning context.

Overall, the research examines the effect of the PSTs' perceptions of the teaching and learning context on their approaches to learning and their learning outcomes. Summative e-portfolios were used in the e-portfolio-based unit in this study. The research aims to investigate whether the use of e-portfolios can enhance learning for PSTs in the Australian educational context. It examines how PSTs conceived e-portfolios, and how they experience learning through them. The research examines whether the theories discussed can be applied to a university context or not. 


\section{Chapter 3: Research Methodology}

\section{Introduction}

The previous chapter identified the related literature and theories around eportfolios in higher education. These theories help to explore how PSTs in a university in Australia use e-portfolios in their learning by bringing together related research perspectives: Constructivism, SAL, the 3P model, and SRL. In the current chapter, the research aims and questions are discussed. The basic elements of research process including epistemology, theoretical perspective, methodology, and methods are presented according to Crotty (1998).

\section{Research Questions}

The research questions are:

Research Question 1: How do PSTs perceive the role of e-portfolios in their studies? Sub questions include:

- How has e-portfolio-based learning changed students' perceptions?

- Which factors lead to adopting deep approach to learning when using eportfolios?

- Which factors lead to choosing surface approach to learning when using eportfolios?

Research Question 2: How do PSTs implement e-portfolios to facilitate high quality learning in the context of higher education? The sub-questions include:

- What is the role of e-portfolios in effective learning?

- How do students gain knowledge through using e-portfolios? 


\section{Basic Elements of the Research}

Crotty (1998) introduced the basic elements of research including epistemology, theoretical perspective, methodology, and methods. He believes epistemology is the theory of knowledge embedded in the theoretical perspective and the methodology we have chosen. The following diagram illustrates Crotty's (1998) four basic elements of the research.

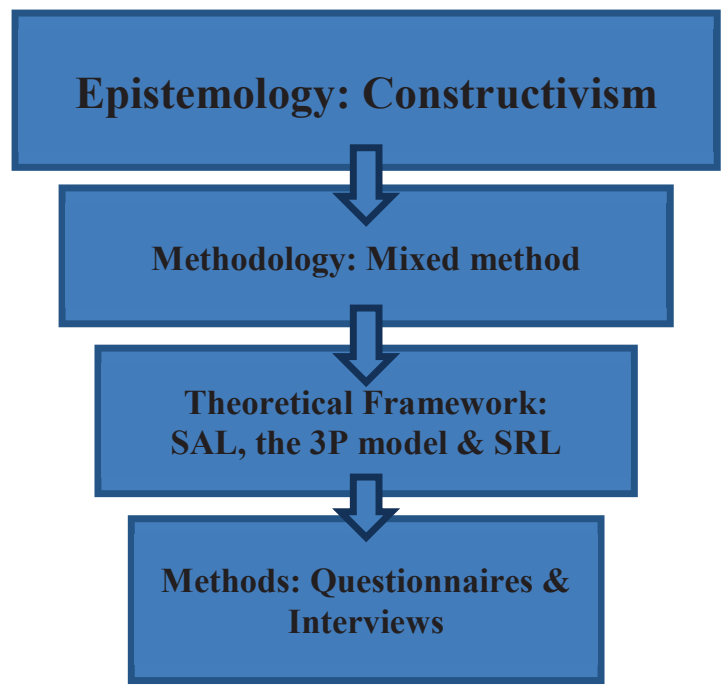

Figure 1. Crotty's (1998) four basic elements of the research.

This research uses Crotty's (1998) model to frame the research. The following paragraphs describe each research element in this thesis in detail. The first element introduces constructivism as the epistemology of the research. The second element is methodology describing mixed methods including qualitative and quantitative phase of the research, and what they explore. The third element describes the theoretical framework of the research, and finally, the research method is introduced. It introduces the participants in this research, and discusses the design of the interview questions and questionnaire in detail. 


\section{The First Element: Constructivism as the Epistemology}

According to Crotty (1998), epistemology shows how we know what we know. It concerns deciding what kind of knowledge is possible and how to ensure that the gained knowledge is adequate and legitimate (Crotty, 1998). In this research, constructivism is adopted as the epistemology. It is not a prescriptive theory of learning to say how human beings should learn, rather it is an adaptive theory of learning defining the way people learn or develop (Richardson , 1997). Constructivist theorists (e.g. Crotty, 1993; Richardson, 1997; Schunk, 2008) believe that meaning is not discovered, but constructed in human beings' minds. In terms of knowledge construction, Crotty (1998) asserted that construction of meaning and its transition occurs within a social context through engagement by human beings with the world they are interpreting. Both Schunk (2008) and Crotty (1998) argued that in this understanding of knowledge, even in relation to the same phenomenon, individuals may construct meaning in different ways. The reason is that people's construction may be true to them but not necessarily to others (Schunk, 2008). As a result, situation is an important factor in interpreting the world and constructing knowledge. This is because people produce knowledge based on their belief and experience in a given situation (Cobb \& Bowers, 1999), which differs from person to person. In regards to the way people construct knowledge in their minds, there are different perspectives. The following paragraph discusses different approaches in constructivism.

\section{Constructivist Approaches}

Constructivism has different perspectives in regards to the way people construct knowledge in their mind. Taking different focuses of constructivism into 
consideration, there are two different constructivist approaches including psychological and social constructivism. Richardson (1997) discussed social and psychological constructivism as two types of approaches focusing on different ways of constructing knowledge.

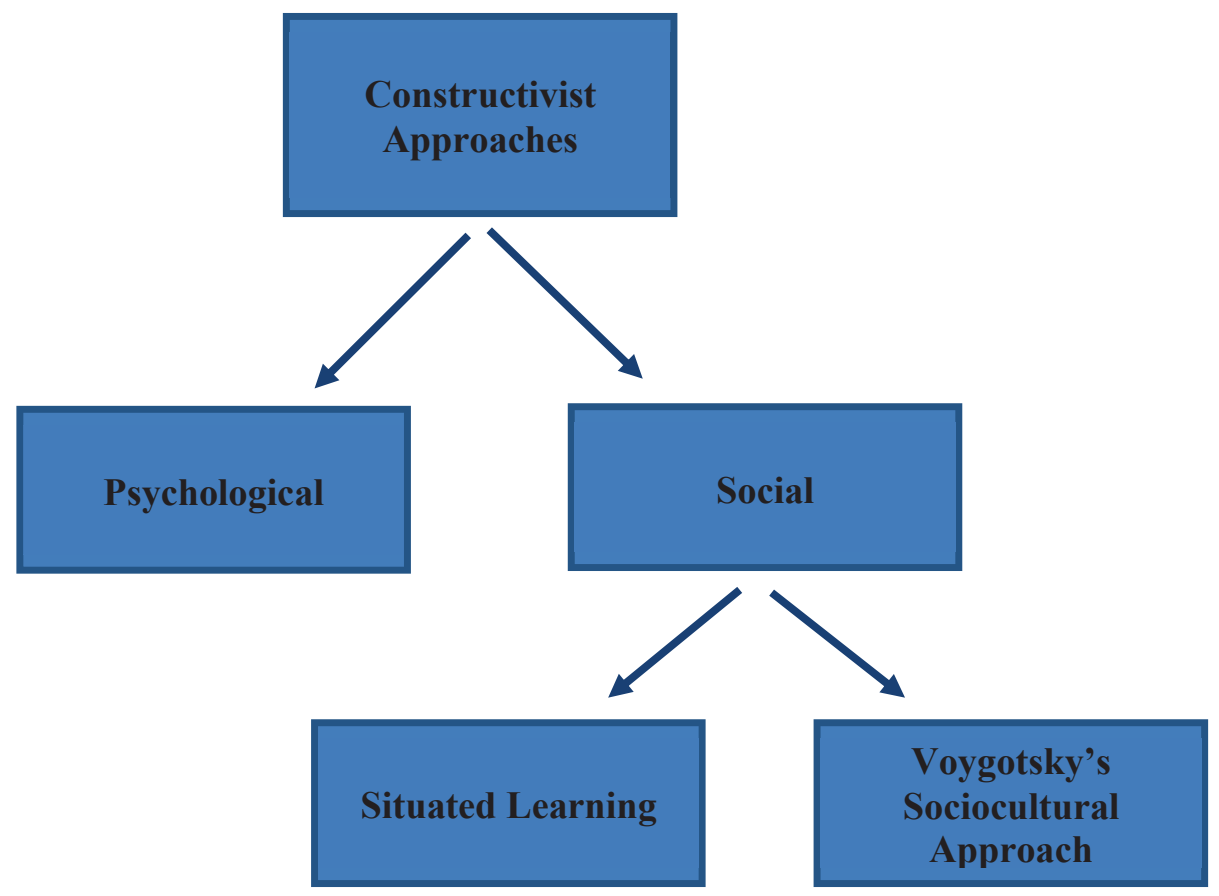

Figure 2. Constructivist approaches.

Psychological approach refers to constructing knowledge individually, and it emphasises the role of individuals as the ones who construct knowledge. Richardson (1997) asserted that students go through the following process for individualistic meaning making. Firstly, learning is possible for them through reconstructing their existing understanding by restructuring their cognitive map. In order to do so teachers play the role of a facilitator by creating an environment in which students undergo a certain number of cognitive tasks. Secondly, reconstructing students' cognitive map is possible through challenging their concepts and thinking process through questioning their beliefs, turning beliefs to hypotheses and examining those 
hypotheses. The criticism for this approach is that social elements of learning are ignored as the relationship between students and formal learning is not supported, and it separates individuals from social elements (Richardson, 1997). Psychological constructivism is not adopted for this research, as its assumptions do not match the theoretical framework of the research. The main reason is that it ignores the importance of context, as psychological constructivists believe that similar cognitive mapping happens for all students. Concept maps clarify how students construct knowledge within their minds. This approach supports the idea that students engage in tasks, and they change the way they think. The change is not because of the context, and students form the same perspectives.

Social constructivism is categorised into two groups including situated learning and Vygotsky’s sociocultural approach (Richardson, 1997). Situated learning refers to the relationship between a person and his or her mind (Green, 1989), and relates to the construction of knowledge by a person in transaction with the environment and social context (Richardson, 1997). This approach defines how people learn when they are in transaction with the environment and the social context, such as in a school setting. This theory emphasises the role of situation and context in learning. The classical information processing model (sensory, registers, working memory, long term memory) ignores the social environment, while cognitive information processing emphasises the importance of situation once environmental inputs are received (Schunk, 2008). Vygotsky's sociocultural approach discusses the role of individuals and the effect of social collaboration, and interactions in their learning. The theory emphasises the interaction of social, cultural, historical and individual factors as the key factors in people's development 
(Schunk, 2008). Interaction with people in the environment stimulates developmental processes and improves cognitive growth (Schunk, 2008). Followers of this theory believe that the development of people relies on social interactions (Richardson, 1997). Vygotsky's theory says that development cannot be disconnected from that context, and the way in which learners interact with their peers, objects and institutions, transforms their thinking. Therefore, supporters of this approach focus on the importance of context.

\section{Adopted Constructivist Approach in this Research}

Social constructivism, including situated and sociocultural constructivism, has been adopted as the epistemology of this research. A core premise of constructivism is that cognitive processes, inducing thinking and learning, are situated or located in the physical and social context (Anderson, Reder \& Simpson, 1996). As mentioned before, students' context of learning and their perceptions towards this context are key factors in their learning. The situated learning approach is aligned with SAL and the 3P model of learning focusing on context and students' perceptions. As e-portfolio-based learning is the situation in which students are located, this research explores their perceptions in that context.

In Vygotsky's sociocultural approach, social interaction allows the sharing of cultural meanings within the group, but then meaning is internalised by the individual (Schunk, 2008). Therefore, individuality is not ignored in this theory. In this research the participants had their own perceptions of the context, and these perceptions vary from one student to another. Therefore, this approach as part of social constructivism fits the theoretical framework of the current research explained in detail in chapter two. 


\section{The Second Element: Methodology}

According to Crotty (1998) the second element of research is methodology, which is the strategy, plan of action, process or design lying behind the choice and use of particular methods. Methods are chosen according to methodology, and there should be rationale for the choice of methods and the particular forms in which the methods are employed (Crotty, 1998).

This research is relational research indicating how students learn when using e-portfolios. The methodology in this research includes both qualitative and quantitative methods. The qualitative methodology seeks to describe a view of the e-portfolio-based teaching and learning context as experienced by individual PSTs, enabling a richer and more accurate description to be captured. The quantitative methodology provides some empiricism in the investigation.

In the qualitative phase of the research, the semi-structured nature of the discussion between student and researcher allows a clarification of the ideas behind the words used by the participants so that a deeper understanding of the context can be revealed. In particular, different aspects at different points in time of the students' experience are considered. Pre-interviews conducted at the beginning of the semester before having exposure to the e-portfolios and postinterviews were conducted after 9 weeks of study in the unit to explore PSTs' conceptions of the e-portfolios, perceptions of the teaching and learning context, approaches to learning, and perceptions of their learning outcomes.

To strengthen our understanding, quantitative methods are used alongside the qualitative phase which offers a different lens through which we can understand the PST's' experience of e-portfolio-based teaching and learning 
context. An important advantage of the quantitative approach is the provision of quantitative estimates of the relative strengths of relationships amongst different aspects of PSTs' learning experience in the e-portfolio-based learning context.

The quantitative method involved the development of questionnaires for a sample of 73 undergraduate and postgraduate PSTs in which they reported their learning experiences of e-portfolio-based learning regarding their conceptions of an e-portfolio, perceptions of clarity of goals, quality of teaching, and appropriateness of assessment and workload.

The qualitative and quantitative research instruments are designed to address the research questions in this thesis. The following paragraph discusses the link between the research questions and data collection through the instruments. Some examples are presented below to reflect how research instruments are used to respond to the research questions.

RQ1. How do PSTs perceive the role of e-portfolios in their studies? Sub questions include:

- Pre-interview Q1. What do you think an e-portfolio is?

- Post-interview Q3. How did e-portfolio help you engage with learning activities? How? Why?

- Questionnaire Q24. I learn through the e-portfolio by rote, going over and over them until I know them by heart even if I do not understand them.

- Questionnaire Q30. E-portfolios enhance my active involvement in learning in this Unit. 
RQ2. How did e-portfolio help you engage with learning activities? How?

Why?

- Pre-interview Q4. Do you think you will reflect on your learning when using the e-portfolio?

- Post-interview Q5. What sort of thing do you think you learnt through using the e-portfolio?

- Questionnaire Q19. I find that at times studying using the e-portfolio gives me a feeling of deep personal satisfaction.

- Questionnaire Q21. I find that I have to do enough work in the e-portfolio so that I can form my conclusion before I am satisfied.

\section{The Third Element: The Theoretical Framework}

Crotty (1998) mentioned that the second element, a theoretical perspective, is an approach to understanding and explaining society and the human world. $\mathrm{He}$ asserted that the theoretical perspective brings a number of assumptions to our chosen methodology. In chapter two, the theoretical framework for this research was introduced as a combination of SAL, the 3P model that is part of SAL, and SRL. However, the main perspectives are driven from SAL and the 3P model of learning. The assumption is that this combination of theories clarifies how students learn through e-portfolios in higher education. Therefore, this assumption was examined in detail.

This study aims to examine e-portfolio based learning in the context of a theoretical framework with a major focus on SAL and the 3P (Presage, Process, Product) model of learning, which is part of SAL. This research also takes 
assumptions of SRL into consideration to examine the role of motivation in students' learning through e-portfolios. Constructivism, the epistemology of the research, supports assumptions of both perspectives. The following paragraphs describe how these perspectives are linked, and how they support e-portfolio-based learning.

The theoretical framework helps to gain a deeper understanding of how students use e-portfolios to achieve better learning outcomes. SAL illustrates how individual students experience or perceive different teaching and learning contexts and how the perceptions of those contexts influence their approaches to learning. SRL focuses on students' motivation for using e-portfolios and how they monitor, evaluate and regulate their learning using e-portfolios. The 3P model of students' learning is used to structure different variables in this study. Both SAL and SRL are located under the umbrella of constructivism, as it supports the assumptions and principles involved in both of these theories of learning.

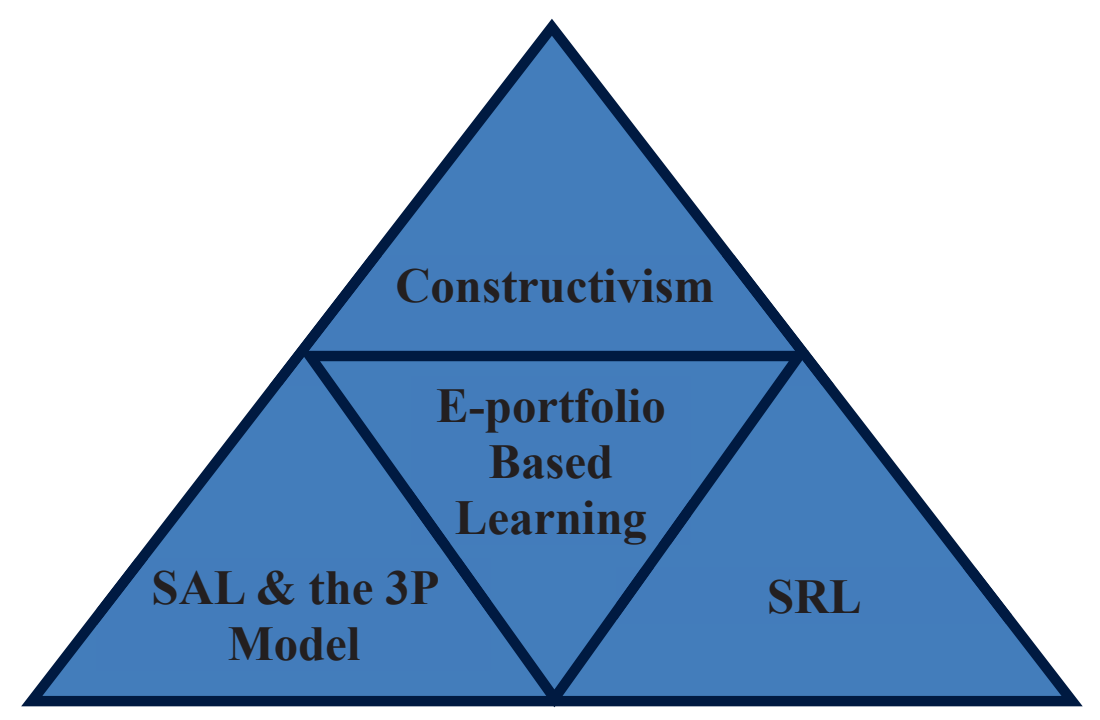

Figure 3. Theoretical framework for learning through e-portfolios 


\section{Students’ Approaches to Learning (SAL)}

Different learning contexts encourage students to choose different learning approaches (Biggs, 1987; Prosser \& Trigwell, 1999). SAL discusses how individual students experience or perceive the teaching and learning context. Different learning contexts and perceptions of those contexts affect students' learning outcomes. Thus all students may experience the same context, but they perceive it differently depending on their prior experiences. Biggs and Tang (2011) asserted that surface and deep approaches to learning are not personality traits, but they are a reaction to teaching. Biggs and Tang also believed that a high workload, lack of motivation, or irrelevant topics lead to students adopting a surface approach to learning, whereas effective learning activities such as formative feedback, self-monitoring, and metacognitive control involving self-assessment and reflection encourage students to adopt a deep learning approach.

\section{Surface Approaches to Learning}

A number of researchers (Biggs \& Tang 2011; Prosser 2004) identified the main reasons for students selecting a surface approach to learning. They believe the contributing factors are: accomplishing tasks with minimal trouble, rote memorisation, low cognitive level, meeting the course requirements, assessment demand, tasks that are not integrated, focusing on discrete elements, and seeing little relationship to other courses. Recognising relationships to other courses promotes multi-structural understanding. Unrelated sets of ideas and procedures, which are not coherent in the mind of learners, lead to rote learning and to adopting a surface approach to learning (Prosser, 2004). 


\section{Deep Approaches to Teaching and Learning}

There is a direct link between approaches to teaching and learning. A deep approach to teaching, which includes conceptual change and student-focused strategies, encourages students to adopt a deep approach to learning (Prosser \& Trigwell, 1999). Coherent and related understanding encourages students to undertake tasks rationally (Prosser, 2004). In this situation, students' understanding of the subject matter is relational and related while in surface learning their understanding is multi-structural and unrelated (Biggs, 1999). Previous studies have shown that a deep approach to learning allows higher quality learning outcomes (Prosser \& Miller 1989; Ramsden 1992). Strategies associated with a deep approach include: interaction with content, relating new ideas to previous knowledge, relating concepts to everyday experiences, and relating evidence to conclusions (Prosser, 2012). Biggs and Tang (2011) also identified strategies that are associated with adopting a deep approach to learning, such as reflection, comprehending the main ideas, hypothesising, and arguing. For example, clarity of goals and criteria, having some freedom and choice in how and what to learn, leads to students developing a deep approach to learning (Prosser, 2004).

\section{The 3P Model of Learning}

The 3P model of learning explains how learning occurs in the context of higher education. This learning model, which is part of SAL theory, examines how different variables have been used in this study. In this research, the 3P model of learning investigates how students learn through different variables, such as prior knowledge, perception, and self- regulated e-portfolio based learning. The 3P model clarifies how high quality learning starts from linking prior knowledge to current 
knowledge. The model was first outlined by Trigwell and Prosser (1997). This model has greatly facilitated understanding of university students' learning experiences.

The 3P model emphasises that students select their approach to learning according to the context of their situation. They construct perceptions towards their own learning, and these perceptions are the key factors in how students learn at university. Therefore, there is a direct relationship between students' prior experiences of teaching and learning, and their present context and their perceptions of teaching and learning (Prosser, 2004). Different variables of this model will be discussed separately in the following paragraphs.

\section{Prior Knowledge}

Meaningful learning comes from integrating current knowledge into previous knowledge (Biggs, 1982). Prior knowledge refers to students' characteristics, their previous experiences, and their new knowledge (Entwistle \& Ramsden, 1983). Using prior knowledge involves linking known concepts and the learner's background and personal attitudes to new meanings and concepts (Ausubel, Novak, \& Hanesian 1968).

Ausubel et al., (1968) investigated the effect of prior knowledge on learning outcomes. To do so they targeted two groups of students attempting to use meaningful learning strategies to investigate the relationship between their learning outcomes and their prior knowledge. Both groups of students tried to use meaningful learning strategies, but those students with poorly developed prior knowledge did not achieve high grades. In contrast, those students with well-developed prior knowledge 
experienced a positive effect on their grades. This study showed that incorporating new knowledge into prior cognitive structure leads to meaningful learning.

One of the key variables investigated in this thesis is prior knowledge of learning. There are a number of researches emphasising the variation in prior knowledge in a subject (Johansson, Marton, \& Svensson, 1985; Prosser \& Millar, 1989; Prosser, 1996). These studies have identified associations amongst the quality of students' conceptions and approaches that students bring to a course, and the quality of the conceptions, approaches and outcomes they report at the end of the course. For example, Prosser (1987) focused on the effect of students' levels of prior knowledge on their learning outcomes. He believed that a reasonable level of prior knowledge was required to achieve learning. A high level of prior knowledge provides conditions for adopting a deep approach to learning (Entwistle \& Ramsden, 1983), which is associated with high quality learning outcomes. Research has demonstrated students' prior knowledge of subject matter and their prior understanding of key concepts as well as the nature of that subject matter are vital to their subsequent approaches to study and learning outcomes (Prosser \& Trigwell, 1999).

\section{Process}

Process includes perceptions of the context, approach, outcome and conceptions of e-portfolios. These variables are discussed below.

Perceptions of the Context

Prosser (2004) defined perception as the experience of something, which is abstract, for example, a particular assessment task. Research has shown that students' 
perception of context is a key factor in how they learn (Prosser \& Trigwell, 1999). Students adopt different learning approaches according to their perceptions of the context. A key factor in students' learning research is that the learning and teaching issue is not how lecturers have designed and constructed their subjects and courses, butrather how their students perceive and understand the way they have designed and structured them (Prosser \& Trigwell, 1999; Ramsden, 2002). Researches have shown that students in the same learning situation will experience that teaching and learning context in different ways. It is important to first understand what sorts of things students focus on when engaged in studying, and second what effect this variation has on the quality of the students' learning. The research conducted by Ramsden and Entwistle (1981) identified five major categories for students' perceptions of learning context (Entwistle \& Ramsden, 1982; Entwistle, 1991; Ramsden \& Entwistle, 1981; Ramsden, 1991). These five categories are good teaching, clear goals, appropriate workload, appropriate assessment and freedom in learning. These five areas form the aspects of Ramsden's course experience questionnaire (CEQ) (1991), which was developed from an earlier version by Entwistle and Ramsden (1983) - the Course Perceptions Questionnaire. In this thesis a CEQ questionnaire was used to explore the students' perception of the quality of teaching, clarity of goals, and appropriateness of assessment and workload.

In this study e-portfolio-based learning is the context of teaching. For example, when the quality of teaching is good, the goals and assessments are clearly defined, and students are learning in an independent climate, they are more likely to adopt a deep approach to learning (Prosser, 2012). In particular, in this thesis, 
perceptions of teaching and learning context mean students' perspectives of quality of teaching, clarity of goals, and appropriateness of assessment and workload.

Approach

Process includes students' approaches to learning including a surface or deep approach to learning. For example, in a research conducted by Marton and Säljö (1976) a group of students who were engaged in a reading task described what they had read in four qualitatively different ways. Marton and Säljö (1976) looked for reasons behind the variation in what the individual student involved in the experiment said about their approaches about their reading tasks. The researchers identified two approaches which different students adopted for that task: a surface approach, which was characterised by a focus on the words in the text while a deep approach where the focus was on the meaning of the text. In particular, when the students were assessed for their understanding of the text at the end of the test, the most complete descriptions of the text were achieved by students who had adopted a deep approach to learning, whereas the least meaningful outcomes came from students who adopted a surface approach.

\section{Outcome}

What students learn and the quality of their learning is called product or outcomes, and these outcomes are influenced by students' preconceptions, learning approaches and perceptions (Prosser, 2004). Dunkin and Biddle (1974) contended that prior knowledge factors fed into process factors which in turn 
produced the product. A high quality learning outcome has been described as the type of learning that remains after lesser quality outcomes have been forgotten (Prosser \& Trigwell, 1999). Another important reason for the emphasis on high quality learning outcomes is that lecturers realise that only those students with a sophisticated complete understanding of a subject can effectively and efficiently remember what they have learnt and then successfully apply in other new contexts. Prosser and Trigwell (1999) suggested that being able to link different elements learned in a subject and applying those links in a new context is associated with higher learning outcomes. . In other words, this type of learning outcome, which includes a more complete ways of conceiving of something, is of a higher quality than an outcome involving limited conceptions.

\section{Conceptions of the E-portfolios}

Conceptions of learning have been identified by educational researchers to be an important aspect of students' learning outcomes. In this research, students' conceptions refer to PST's understanding and definition of the e-portfolios. Students enter the learning environment with variation in conceptions of this tool, and therefore, in this research this variation is distinguished as higher and lower conceptions. For example, those students who merely use e-portfolios to collect evidence of learning have lower conceptions of the tool while others who are aware of the potentials of the tool regarding facilitating reflective learning, evidence-based learning and critical thinking have higher conceptions of e-portfolios. For example, those students who have lower conceptions of the e-portfolios may only focus on the 
physical aspects of e-portfolio implementation such as collecting evidence of learning while others may be aware of the potentials of the tool in terms of facilitating reflective learning, and evidence-based learning and critical thinking. As a result, those students who have higher conceptions of the e-portfolios are highly likely to use the tool to achieve reflection, and to link their prior knowledge of their teaching philosophy to their new knowledge through reflection and critical thinking when putting their philosophy of teaching in their e-portfolios. In this thesis, conceptions of e-portfolios refer to the participants' perspectives of the e-portfolios. What they think of the tool, and why and how they use the tool.

\section{Self-regulated Learning Theory (SRL)}

Pintrich (1999) asserted other important requirements of learning in higher education. He believed that it is necessary to encourage students to be highly selfregulated learners through goal setting, monitoring, regulating, and controlling their cognition, motivation, and behavior. SRL is a learning theory describing how students learn in the context of higher education. This theory is used as a complimentary theory in this study, and SAL and the 3P model of learning form the major parts of the theoretical framework.

Pintrich (2004) introduced four phases for SRL including: (1) planning, (2) monitoring, (3) controlling, and (4) reflecting. He asserted that the phases are not structured linearly or hierarchically and that monitoring, controlling and reflecting can occur simultaneously. In order to plan their learning, students are required to set goals, activate their perceptions, and gain knowledge about the tasks as well as the context. The second phase includes monitoring the process of doing tasks, using metacognitive activities, being aware about the tasks, and context. Controlling 
involves controlling tasks and context as well as regulating tasks and context. The last phase is having different perceptions and reflections on oneself, tasks and context. Research conducted by Printrich (2004) has revealed that there is a close relationship between SAL and SRL theories of learning.

\section{Similarities and Differences between $S A L$ and $S R L$}

These theories of learning share a number of similarities, but they are different in terms of their focal points. SAL focuses on student perceptions about context and their approach to learning when using e-portfolios, while SRL includes motivational, affective, and social contextual factors (Printrich, 2004). The following paragraphs explain the similarities and differences.

Similarities between SAL and SRL

A number of authors have argued for a relationship between SRL and SAL (Case \& Gunstone, 2002; Heikkila \& Lonka, 2006). A shared assumption between SAL and SRL is that learners are viewed as active participants in the learning process and they construct their own meanings, goals, and strategies from the information in the external environment and their own minds (Pintrich, 2004). This assumption is shared with advocates of the SAL perspective (Biggs, 1993; Vermunt, 1996). According to Pintrich (2004), both SAL and SRL focus on goal setting for learning, and context is considered as a highly effective factor in the process of learning. Both theories allow students to play a constructive and active role as they set goals and control their learning. SRL and SAL theories promote an idea, which follows from a cognitive perspective. A number of researchers (Heikkila, Niemivirta \& Nieminen, 2010) are of the opinion that both SAL, SRL share common basic 
assumptions in terms of cognitive and attribution strategies which derive from cognitive psychology. For example both theories include motives or motivation in their framework. SAL describes both what students do and why they do it and if their intention is to understand they are more likely to adopt a deep approach to learning. In a similar fashion, SRL includes the idea of 'the will and the skill' (Pintrich \& De Groot, 1990).

Another similarity is that both theories of learning focus on the role of context as an important factor affecting students' learning. Most students recognise that context influence their learning (Heikkila et al., 2010) and the focus of educational research has been shifting from the investigations of mainly cognitive processes to examining cognition in interaction with motivation (Rozendaal, Minnaert, \& Boekaerts, 2005). In spite of the similarities between SAL and SRL, they conceptualise and measure learning differently.

\section{Differences between SAL and SRL}

Printrich (2004) asserts that there are a number of differences between these two theories of learning. He compares two different theories of learning in higher education: SAL and SRL. He argues that these two theories share some common features and are dissimilar in some respects. He believes that SAL focuses on the cognitive aspect of learning, while SRL relies on psychological theories of learning such as motivation, affects and cognition. Although SRL and SAL each define students' learning in higher education, a combination of these two theories covering cognitive and psychological perspectives provides a more complete picture of how students learn when using e-portfolios. SRL and SAL theories can be outlined under 
the umbrella of constructivism, as it shares a number of learning activities and principals common to these two theories.

Another main difference is that SAL does not consider self-efficiency or expectancy, and it reflects a limited view of motivation. Secondly, SAL discusses approaches to learning including deep and surface approaches. In contrast, SRL relies on an analytical approach that can generate many different constructs and categories of student motivation and learning (Printrich, 2004). Regulation of cognitive, motivational, behavioral and contextual features are emphasised in SRL. These factors are best measured at the level of domain, especially at course level or at microanalysis level in terms of specific task. In contrast, SAL focuses on individual differences.

\section{Applying Constructivist Principles to SAL and SRL}

In regards to students' learning, Schunk (2004) identified a number of constructivist assumptions. She claims that research has shifted on learners, and as a result, rather than examining how knowledge is acquired, the focus is on knowing how it is constructed. Constructivism defines how students learn, and how the learning activities which are involved in this theory of learning, are aligned with SAL and SRL. For example, constructivist theory suggests that prior knowledge helps students to construct knowledge. It asserts that students reconceptualise information, and self-regulative activities promote their learning.

Most constructivist approaches criticise traditional approaches to teaching because the traditional method does not promote the link between prior and new knowledge, and it does not help students to internalise and understand concepts. The reason for this is that information acquired from traditional teaching is usually not 
well integrated with other knowledge held by students (Richardson, 1997). The 3P model of learning addresses these issues by suggesting that learning occurs when students link their prior knowledge to their current knowledge. Constructivism supports this idea as it proposes that individuals create their own new knowledge based upon the interaction of what they already know and believe and the phenomenon or idea with which they are engaged (Richardson 1997; Schunk 2004). They believed that learning is a transaction between prior knowledge and current knowledge, and students need to construct the structure of their new knowledge in such a way that the new knowledge is relative to their pre-existing knowledge.

SAL suggests that students choose deep or surface approaches to learning according to their perceptions. In regards to students' perceptions, Schunk (2004) argued that traditional approaches to teaching only involved the transmission of knowledge to students, whereas constructivist teaching becomes a vehicle for changing students' perceptions about the world they engage in. Schunk believed that conceptual change was a central principle in the development of meaning, and cognitive reorganisation or conceptual change occured when students try to overcome obstacles that arise as they engage in learning activities. Conceptual change develops a formal constructive approach to learning, which defines learning as a process of personal construction of meaning. In such an environment, teachers create a situation in which students actively participate in activities that enable them to make their own individual constructions. For example, group work; problemsolving and open discussions all contribute to learning.

In regards to SRL, constructivist theories suggest that people construct knowledge according to their beliefs and experiences, which differ from person to 
person. Constructivist theories assume that students are taught to be self-regulated and take an active role in their learning by setting goals, and monitoring and evaluating their own progress (Brunning, Fisher \& Ronning, 1997).

Constructivist principles, such as knowledge building, active and selfdirected learning, and collaborative learning and practice, can all be applied to support e-portfolio based learning (Ligorio \& Sansone, 2009). Constructivism supports the belief that meaning is constructed by learners, and the nature of the learning activities, focus on students having metacognitive control, formative feedback, appropriate motivation, interconnected knowledge, and opportunities for social learning (Biggs \& Tang, 2011). Metacognitive control refers to selfmonitoring, reflection, self-assessment, self-management, and lifelong learning. All these learning activities are possible through e-portfolio implementation.

\section{E-portfolio in the Context of Theoretical Framework}

The following paragraphs explain how the theoretical framework is related to e-portfolio based learning and how SAL and SRL theories define e-portfolio based learning. The learning activities involved in these theories form the e-portfolio based learning activities.

\section{SAL and E-portfolio-based Context}

The theoretical framework of the study explores the relationship between learning and e-portfolio technology. SAL focuses on students' learning outcomes according to their perceptions. In this regard, Prosser (2000) asserted that when students use technology-enhanced strategies in order to learn, a number of factors affect their learning. Student learning outcomes depend on the realisation that even if technology meets the teacher's aims, it has nothing to do with learning outcomes. He 
emphasises that learning achievement depends on students' perceptions towards the aims of the new technologies in their learning. The way students adopt different approaches to learning in the technology-enhanced environment affects their outcomes. For example, students' perceptions of the e-portfolios, assessment and their workload associated with using the new technologies, course design, and teaching methods are all important factors that influence their achievements. In regards to developing e-portfolios, if students face time constraints and high workload, they may adopt a surface approach to learning. Another important factor, which is emphasised in SAL, is learning outcomes. SAL suggests that students may achieve high quality learning outcomes if they can find a rational and coherent link between what they learn. Taking learning outcomes into consideration, Biggs (2011) criticised the tertiary learning environment where the lecturer provides declarative knowledge to students, because students need to put their theoretical knowledge into practice before graduation. Therefore, in order to resolve this issue, he recommends the use of e-portfolios as they have the potential to bridge the gap between theoretical and functional knowledge. This link creates a coherent set of ideas from theory to practice, and it supports higher quality learning outcomes.

\section{SRL and E-portfolio-based Context}

One of the most constructive processes for learning is self-regulation. Selfregulated learning involves having plans and using metacognitive and cognitive strategies (Sorić \& Palekčić, 2009). Pintrich (1999) asserted that it is necessary to encourage students to be highly self-regulated learners through goal setting, monitoring, regulating, and controlling their cognition, motivation, and behaviour. The three phases of self-regulation include: forethought, performance, and self- 
reflection (Zimmerman, 2000). In particular, approaching the learning tasks in a mindful and confident manner, setting goals, and developing a plan for attaining those goals are characteristics of highly regulated learners (Alexiou \& Fotini, 2010). Zimmerman and Pons (2012) stated that self-regulated strategies include: goal setting, planning, self-evaluation, record keeping and monitoring, rehearsing and memorising, and reviewing records. However, Meyer, Abrami, Wade, Aslan, and Deault (2010) argued that a main feature of self-regulation is metacognition, meaning the awareness, knowledge and control of cognition. They assert that the three processes that make up metacognitive self-regulation are planning, monitoring, and regulating.

In order to enhance metacognition, a number of researchers (Gipps, 2002; Zellers \& Mudrey, 2007) believe that e-portfolios can be used. Findings of research conducted by Cheng and Chau (2013) supported this idea as they investigated the relationship between learners' self-reported use of SRL strategies and their eportfolios. The results of the study revealed that five SRL strategies including elaboration, organisation, and critical thinking, metacognitive self-regulation, and peer learning were significantly positively correlated with the e-portfolio scores of the participants. Moreover, the results indicated that there were statistically significant differences in the use of the five SRL strategies between high and low eportfolio achievers. Both findings represent that cognitive skills (e.g. elaboration, organisation, critical thinking), metacognitive control strategies (e.g. self-regulation) and collaborative learning strategies (e.g. peer learning) are likely to be important to e-portfolio development. 
Research conducted by Alexiou and Paraskeva (2010) supported the idea that e-portfolios facilitate self-regulate learning by approaching the learning tasks in a mindful and confident manner, setting goals proactively, and developing a plan for attaining those goals. The main reason for this claim is that students are required to set goals, standards and criteria when creating their e-portfolios and achieving learning outcomes. These criteria act as a guideline for students to monitor their learning progress, use self-assessment strategies, and provide formative feedback for their peers. These activities provide the opportunity for changing, adopting and improving self-regulated activities in the course of learning. As a result, a collaborative learning environment is possible through the use of e-portfolios. In the collaborative climate, both peer-assessment and lecturers' ongoing formative feedback allow students to monitor their learning. In addition, having an online audience including peers, the lecturer, and possible employers encourages students to feel more responsible and motivated for their own learning. Therefore, the use of eportfolios facilitates both affective and cognitive aspects of learning. Barrett (2007) also believed that e-portfolios have great potential for helping students to become more cognitively active in their learning, and this encourages students to select a deep approach to learning (Biggs \&Tang, 2011).

\section{Learning Activities Aligned with the Theoretical Framework}

The following table illustrates the learning activities which are possible through e-portfolio adoption. All these activities are aligned with SAL, SRL and constructivist theories of learning defining how students learn in the context of higher education. Diverse learning activities illustrated below are possible through using e-portfolios. 
Table 1

E-portfolio-based Learning Activities Aligned with the Theoretical Framework

\begin{tabular}{ll}
\hline SAL Activities & SRL Activities \\
\hline Formative feedback & Motivation \\
Monitoring & Goal setting \\
Reflection & Reflection \\
Prior knowledge & Prior knowledge \\
Student-focused & Metacognitive \\
Conceptual change & Coping strategies \\
Self-assessment & Self-efficiency \\
& Interactions \\
\hline
\end{tabular}

Activities such as conceptual change, freedom of choice, relating concepts to everyday experiences, and relating previous knowledge to new knowledge encourage students to adopt a deep learning approach. In addition, quality of teaching, clear goals and assessment, and independent climate affect students' perceptions. Factors such as setting goals, activating perception, gaining knowledge, monitoring the learning process, and using metacognitive strategies are all used in SRL. E-portfolios support these learning activities.

\section{The Fourth Element: Method}

The fourth element of research is method. Methods are techniques for data collection and analysis, and they include planned techniques or procedures to be used. Particular activities for gathering and analysing data are the research methods, and these techniques and procedures are used to gather and analyse data related to the research questions or hypotheses (Crotty, 1998).

These following paragraphs discuss the method of the research, the participants, the design of the interview questions, and the design of the modified 
questionnaire, and the sequence of activities. Data collection methods for this study were in the form of pre- and post- interviews and a survey. The survey questionnaire aimed to examine a certain number of variables across a large number of participants, while the semi-structured interviews examined a smaller number of participants over a large number of variables and conditions (Huxley, 1995).

The student population for this thesis comes from the undergraduate and postgraduate PSTs studying in the Faculty of education at a University in Australia with sample size (N) of 73 for the quantitative phase of the study. Fifteen participants from the same population participated in the pre-interviews at the beginning of the term, and 13 of them attended the post-interviews at week 9.

The research protocol used in this thesis was approved by the Human Research Ethics Committee. Participants were assured that responses were confidential, voluntary and unrelated to any of their assessments during the program. Each participant was assigned a pseudo name that was used for data entry and analysis to maintain confidentiality of responses. All students who indicated willingness to participate in the research signed a consent form.

Participants There are some interesting conceptual issues regarding the link between e-portfolio implementation and the participants' perceptions and their progress. PSTs who were studying in an e-portfolio-based unit in a University in Australia were invited to participate in the research. The students were PSTs studying a Unit titled Preparing for the Profession in the Faculty of Education. They used e-portfolios to present their teaching philosophy to the lecturer. They also addressed the teaching standards through the use of e-portfolios. The participants included examples of assessments, and feedback as artifacts when necessary. The 
platform used to create e-portfolios was Desire to Learn. Although there were both online and face to face modes of teaching for the unit, only face to face students were invited to participate in the research. The questionnaires were distributed amongst the face- to-face students, and those who were interested in participating in the interviews filled a consent forms. The problem of inviting all of the students and having mixed sample is that if there is a change in the participants' learning, it is not possible to exclude the possibility that the change is explained by whether the students are face-to-face or online.

To conduct pre- and post-interviews, the participants were divided into three groups of high, mid, and low according to their GPAs. Fifteen students participated in the pre-interviews; however, only 13 participated in the post- interviews. Seven participants in the high group gave consent to participate in the interviews, and five participants from the middle group agreed to respond to the interview questions, and only three low participants were involved in the interviews. All the face-to-face participants were invited to complete a questionnaire in week 9 of their study in the e-portfolio-based unit. 
Table 2

Participants of the Semi-Structured Interviews

\begin{tabular}{lccl}
\hline Number & \multicolumn{3}{l}{} \\
\cline { 2 - 4 } & Gender & GPA & Level \\
\hline 1 & F & 5.40 & High \\
2 & F & 5.93 & High \\
3 & F & 5.93 & High \\
4 & F & 5.54 & High \\
5 & F & 5.54 & High \\
6 & F & 5.42 & High \\
7 & M & 5.83 & High \\
8 & F & 5.15 & Mid \\
9 & F & 4.75 & Mid \\
10 & F & 4.96 & Mid \\
11 & M & 4.70 & Mid \\
12 & F & 5.33 & Mid \\
13 & M & 4.50 & Low \\
14 & F & 4.50 & Low \\
15 & F & 4.62 & Low \\
\hline
\end{tabular}

\section{Design of the Interview Questions}

Interview questions were prepared in relation to the research contents prior to the interviews. The semi-structured interviews gave the researcher an opportunity to gain a much deeper understanding of the rationale behind the participants' interpretation of the e-portfolios in their learning practice. In order to reply to the research questions, the interview items were developed according to the theoretical framework of the research. Thus, the pre-interview items explore the characteristics of the participants including their pre-conceptions of e-portfolios (the 3P model) preperceptions of e-portfolios (the 3P model), their prior approach to learning (SAL), prior knowledge (the 3P model), and their motivation (SRL) when using e-portfolios as well as their learning outcomes (the 3P model). There were slight differences in 
pre- and post- interview questions in order to investigate how the participants'

perceptions towards learning changed before and after using e-portfolios. Here are the interview questions.

Table 3

Links between Interview Questions and Research Questions

\begin{tabular}{lll}
\hline The Interview Questions & \\
\cline { 2 - 3 } & Link to the & Link to the \\
Theoretical & Research \\
& Framework & Questions \\
\hline
\end{tabular}

1. What do you think an eportfolio is?

Conceptions of e- 1 portfolios: SAL, the 3P model

2. What do you think your

Perceptions of 1 role, as a student would learning: SAL be when using an eportfolio?

3. What do you think your Perceptions of teacher's role would be when using the eportfolios?

- How do you think eportfolio will fit in this Unit?

- What sort of things you will do when using an e-portfolio?

- Do you think you will reflect on your learning when using the e-portfolio?

- Do you think eportfolio will promote your independent learning?

4. Do you think e-portfolio SRL

promote your motivation to learn? 
5. What sort of thing you think you will learn through using eportfolio?

- What do you think you will learn about being a pre-service teacher by using eportfolios?

- What do you think you will learn about being a pre-service teacher by using eportfolios?
SAL: perception of 2

learning

\section{Design of the Modified Questionnaire}

The quantitative survey used in this thesis contained three questionnaires designed to identify quantitative differences in conceptions of e-portfolios, approaches to study, and perceptions of the teaching and learning context. Firstly, the questionnaire was piloted with the PSTs enrolled in the e-portfolio-based unit at the beginning of the semester. After data analysis, and modification of the questionnaire according to the results, the final questionnaire was distributed amongst the same participants after nine weeks of their exposure to the e-portfolios. The following table represents a number of examples for the changed items. 
Table 4 Original Questionnaire Items and Reasons for the Change

Item No Changes

Q11. The aims and objectives of this Negative statements changed to course are NOT made very clear positive

Q26. Too many staff ask us questions Non applicable questions omitted just about facts

Q22. I do not find using this course E-portfolio-based learning replaced very interesting so I keep my work to the word this course to contextualise a minimum the items

The following table presents the different parts of the questionnaire.

Table 5

Different Parts of the Questionnaire

\begin{tabular}{ll}
\hline Parts & To Examine \\
\hline Part A & The participants' background \\
Part B & $\begin{array}{l}\text { The participants' conception of e-portfolios and their } \\
\text { prior knowledge } \\
\text { The participants' perceptions of teaching and learning } \\
\text { context } \\
\text { Part C } \\
\text { Part D participants' approaches to learning when using e- } \\
\text { portfolios }\end{array}$ \\
\hline
\end{tabular}

Part A, the demographic part, asked a number of questions related to the participants' background, for example, their gender, year level, and degree of familiarity with e-portfolios. Part B included seven items related to the participants' conceptions of e-portfolio implementation and their prior knowledge. Part $\mathrm{C}$ was a modified Course Experience Questionnaire (CEQ), and Part D was a questionnaire investigating the participants' approaches to learning. 
Part B, the conceptions of e-portfolios was originally designed by Wilson, Lizzio and Ramsden (1997). The CEQ evolved from a theory of teaching and learning in which students' perceptions of curriculum, teaching and assessment are key determinants of their approaches to learning and their learning outcomes (Entwistle \& Ramsden, 1983; Marton \& Saljo, 1976). The original work related to the CEQ carried out at Lancaster University in the 1980s (Wilson et al., 1997). Then, Ramsden (1991) designed the first CEQ30. It was a combination of sources including analysis of open-ended student feedback, the course perceptions questionnaire (Ramsden \& Entwistle, 1981), a subsequent school experience questionnaire (Ramsden, Martin, \& Bowden, 1989), experiences of studying and higher education questionnaire (Entwistle \& Tait, 1990) were used to developed the first CEQ30 (Wilson et al., 1997). It was also increasingly employed as a measure of the quality of teaching in universities in the UK (Wilson et al., 1997). A research conducted by Byrne and Flood (2003) reported the reliability and construct validity of the CEQ in an Irish context as well. The questionnaire was also used to measure perceived teaching quality in Australian higher education context, and according to a number of researchers (e.g., Trigwell \& Prosser, 1991) it was broadly confirmed in Australian higher education context as well. The CEQ was modified over time as the dynamic nature of higher education has changed tremendously. Finally, three versions of the CEQs including CEQ36, CEQ30, and CEQ23, each with a different number of items and scales have been developed (Wilson et al., 1997). According to them, CEQ36 includes items to measure the perceptions of clear goals, good teaching, generic skills, appropriate assessment, independent learning, and appropriate workload. CEQ30 includes five scales of good teaching (8 items), clear goals and standards (5 
items), appropriate workload (5 items), appropriate assessment (6 items) and emphasis on independence (6 items). CEQ23 has been reported as the most widely used (Byrne \& Flood, 2003). It includes the scales of good teaching (6 items), clear goals and standards (4 items), appropriate workload (4 items) and appropriate assessment (3 items) and generic skills (6 items). This research adopted CEQ30 from Wilson et al. (1997). The reason is that the absolute minimum participants are five for each item. In order to solve the issue of lack of participants' issue, the questionnaire was reduced according to the result of face validity. Further to this, two scales, namely the generic skills and emphasis on independence, were dropped in the modified questionnaire. The generic skills scale was dropped because it was an outcome not a perceptions scale, and independence because it is often not included in studies of this kind.

Part D, is a modified SAL questionnaire, adopted from Biggs, Kember, and Leung (2001), and it asked the participants to provide information about their approaches to learning. All the adopted items of the instruments in both parts $\mathrm{C}$ and D were modified to fit into an e-portfolio-based context.

Generally speaking, the analysis of quantitative data was conducted in three stages. In the first stage, exploratory factor analyses were conducted on each of the questionnaires to confirm the construct validity of each scale. The reliability of each scale was then confirmed in stage two through the use of Cronbach's coefficient of reliability. The third stage saw associations between the scales explored through a correlation analysis and a second order exploratory factor analysis of the scales. 


\section{Qualitative Data Analysis: The Grounded Theory}

The data collected from the semi-structured interviews were analysed through grounded theory. This is an appropriate design when the theory is incomplete or not available to explain a process (Creswell, 2007). The core belief of the theory is to find the correlation between the concepts, to lay a hierarchy in the data through the use of an inductive method to code, and to analyse data to obtain research findings (Lu, Le, \& Babaee, 2013). In the current research, the grounded theory contributes to examining what deep and surface learning occurs when using e-portfolios. The theory was applied through an inductive method to code and analyse data to obtain research findings. Rather than a hypothesis, the researcher generated a theory from the participants' responses to the questions in the research instruments. The researcher developed this theory by interpreting the communication gained through the interviews with the participants. In particular, the participants' views were explored to find out the meaning of their approaches to learning through the grounded theory. Therefore, the definitions of them have not been pre-determined. The audio taped interviews were transcribed. The researcher read through the participants' responses line by line, and identified themes and categories grounded in the data. Firstly, first-order concepts were identified. Then, the variables related only to the core variables were found, and finally a story line was written. The initial data was studied, themes and concepts were compared and contrasted, and then, they were synthesised into different categories. The steps of analysing the data through grounded theory including open coding, axial coding, and selective coding (Ryan \& Bernard, 2000) are discussed below. 


\section{Open Coding}

Open coding is the initial stage of the data analysis. In order to undertake this step, recommendations made by a number of qualitative researchers (e.g., Creswell, 2007; 2009; Fan, 2011; Fei, 2007; Glaser, 1992) were applied. Firstly, the first-order concepts and substantive themes were identified, developed, analysed and compared. The researcher remained open to the raw data, and finally, the themes were placed into core categories.

\section{Axial Coding}

In contract to open coding, axial coding allows the analyst to limit coding to only those variables that relate to the core variable in sufficiently significant ways to be used in a parsimonious theory, and the core variable becomes a guide to further data collection (Glaser, 1978). Thus, the researcher can make detailed comparisons between the concepts in this stage in order to construct higher-order concepts (Sarantakos, 2005). The constant comparisons between the concepts allow the researcher to make visible links between open codes and to group them into themes according to these interconnections (Fan, 2011). These links between axial codes in turn improve the researchers' understanding of the meanings represented in the data.

\section{Selective Coding}

The final stage is the selective coding process. In this stage, the writer uses the axial codes to write a "story line" through connecting and linking them together into higher levels of abstraction (Creswell, 2007). 


\section{The Main Challenge of Grounded Theory}

A number of researchers (e.g., Allan, 2003; Bitsch, 2005; Glaser, 1978;

Strauss \& Corbin, 1998) stressed possible challenges for grounded theorists. In order to achieve a valid analysis, the main challenge of grounded theory is addressed in this research. Coding by microanalysis consists of analysing data word-by-word through coding the meaning found in words or groups of words (Strauss \& Corbin, 1998). The process is very time consuming as each interview contains much data, and it requires precise study of the transcription to find the relevant information to the research topic (Allen, 2003). This may cause confusion as dividing interview data into words may lead to the analysis getting lost within the data. Further to this, finding codes can be difficult as the researcher may not be sure what they are looking for.

In order to address the issue, the researcher needs to identify the key points in the interview data and concentrate the analysis on these, and there has to be some agenda for research by interviews to keep the research projects scoped (Allen, 2003). However, it is recommended that grounded theory investigators need to have no preconceived ideas when they collect and analyse data. It is proposed to make the process of research data collection and analysis explicit through writing, and to provide enough information to let others see how findings are followed from data analysis (Gasson, 2004). As Gasson (2004) recommended, this research used the following steps: all analysis documents were saved, the research journal was maintained, and literature sources were explicitly acknowledged and integrated. The epistemology, theoretical framework of the study presented in this chapter, and the results of analysis from the qualitative phase of the research were applied to form the 
agenda for the qualitative data analysis to provide the most appropriate responses for the research questions.

\section{Reliability and Validity for the Qualitative Phase}

Reliability and validity need to be redefined in qualitative research as notions like trustworthiness, generalisability, rigor, authenticity, conformability, transferability and credibility are required to ensure validity and reliability in qualitative research design (Allen, 2003; Lu et al., 2012). In particular, the validity in qualitative research is concerned with whether the findings of a research project can explain what has happened under investigation (Henn, Weinstein, \& Foard, 2006). There can be no validity without reliability, and as a result, demonstration of validity is sufficient to establish the reliability (Lincoln \& Guba, 1985).

Internal validity requires all the parts of the theory to explain the data (Strauss \& Corbin, 1998). The criteria of credibility and authenticity may be replaced with internal validity (Miles \& Huberman, 1994). Bitsch (2005) proposed a number of techniques to ensure credibility in qualitative research including: prolonged engagement, persistent observation, peer debriefing, negative case analysis, member checks, and triangulation. Further to this, to ensure dependable and authentic findings and rigor, as well as minimising the impact of subjectivity on the process, it is necessary to establish clear and repeatable procedures for research, and to reflect on the position that researchers takes when they perform them (Gasson, 2004). In the current study, the researcher tried to remain as objective as possible in the course of conducting the interviews and data analysis. Triangulation occurred through employing the mixed methods methodology, and a case study conducted for two 
students who deviated from the common pattern to investigate the reasons behind their alternative approaches to study in the unit.

In qualitative research transferability parallels external validity and generalisability, and it refers the degree to which research results can be applied to a context apart from where they were gained (Bitsch, 2005). Gasson (2004) believed that transferability refers to determination of the extent to which findings can be employed in other contexts or with other participants, and the similarity between sending and receiving context. In this research participants were invited to participate in the interviews according to purposeful sampling to ensure transferability. Participants who gave consent for the interviews were divided into three groups of high (seven participants), mid (five participants), and low (three participants) according to their GPAs.

\section{The Links between the Four Elements of the Research}

The research methodology and methods should be chosen according to the research questions; it is important to know what theoretical perspective lies behind the methodology in question and what epistemology informs this theoretical perspective (Crotty, 1998). The epistemology in this research includes two main assumptions, which are compatible with the theoretical framework of the research. The first important assumption is that context and situation play an important part in interpreting the world and constructing knowledge. Crotty (1993), for example, as a constructivist theorist emphasised the role of context, and claimed that people learn through constructing meaning within a social context. The second interesting assumption of constructivism is that even people who are learning in the same 
context may have different understandings and interpretations of that context, so they learn differently (Crotty, 1993 \& Schunk, 2008). This is because people produce knowledge based on their beliefs and experiences in a given situation (Cobb \& Bowers, 1999), which differs from person to person. It is obvious that even in relation to the same phenomenon, different people construct meaning in different ways as people's construction may be true to them but not necessarily to others (Schunk, 2008). These two assumptions are closely related to SAL and the 3P model of learning discussed in chapter two. The reason is that SAL, and the 3P model define how students learn as the effect of their engagement with the context, and their individual perceptions towards the context. For example, even if the students are studying in the same class, with the same lecturer, they learn differently as they construct different perceptions towards the context and the learning environment. Therefore, these two assumptions of constructivism are closely related to the main perspectives adopted for the research.

In this research, a mixed methods paradigm was adopted to collect data. Data collection methods included using pre- and post-interviews and a questionnaire. The questionnaire and interview questions were situated in the context, and the instruments were compatible with the epistemology and the theoretical framework of the research. The instruments asked some questions related to the participants' views and the items were situated within their work on e-portfolios in that particular unit. Therefore, the instrument fitted a situated learning approach. Both instruments explored the role of the participants' interactions with peers, the lecturer, and tutor in the unit. Therefore, Vygotsky's sociocultural approach was taken into consideration. The following figure indicates the key variables in the research design. 


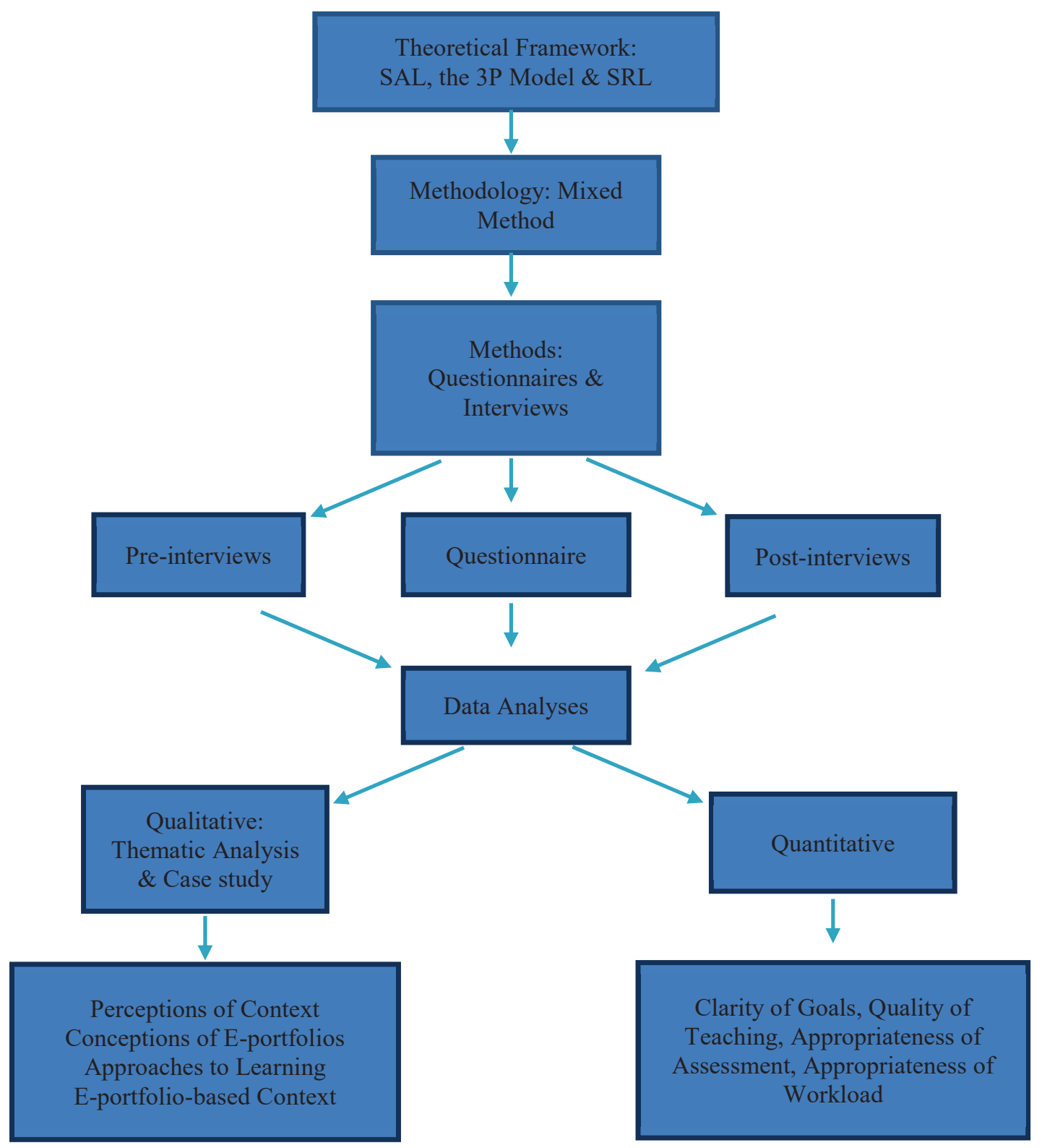

Figure 4. Key variables in the research design.

\section{Conclusion}

This chapter discussed how the theoretical framework, research methodology and the research method have been chosen according to the research epistemology. The link between the basic elements of research is clarified. The mixed methods research design was outlined, and the process of qualitative and quantitative data analysis is introduced. 
In this research the methodology is mixed methods paradigm. The goal of mixed methods research is to merge the strengths of quantitative and qualitative approaches within a mixed methods research approach (Johnson \& Onwuegbuzie, 2004), and it helps to connect the quantitative and qualitative research (Onwuegbuzie \& Leech, 2004). Creswell (2007) defined mixed methods research as a research design or methodology, in which the investigator collects, analyses, mixes, integrates or connects both quantitative and qualitative data in a single study or a multiphase program of inquiry. The results obtained through the combined methods can be more fruitful and improve understanding of the phenomena under study and promote fresh ideas about them, in order to give answers to questions that are difficult to answer by using a single method (Greene, Caracelli, \& Graham, 1989; Tashakkori \& Teddlie, 2003, 2010). Therefore, this research used both qualitative and quantitative research design to answer to all of the research questions and sub questions. The PSTs' conceptions of e-portfolios, their perceptions of teaching and context, their approaches to learning, and learning outcomes were examined through the interview questions.

For the quantitative phase of the research, validated questionnaires examining different aspects of student learning experiences were used. PSTs were asked to respond to the 36-item questionnaire. The methodology of using only face-to-face enrolled students addressed the potential challenges as all participated in the questionnaire and only those who approved were interviewed. The questionnaire questions evaluated the quality of teaching, clarity of goals, appropriateness of assessment and workload. Therefore, qualitative and quantitative research designs 
were used to respond to all of the research questions and sub-questions. The following chapters discuss the results of data analysis in this research. 


\section{Chapter 4: Qualitative Data Analysis}

\section{Introduction}

The current chapter explores the extent to which aspects of the participants' conceptions and perceptions of the context of teaching and learning affects adoption of different approaches to learning. The qualitative phase of the study investigated eportfolio-based learning in order to gain a deeper understanding of influential factors for students to adopt or alter their approaches to learning when implementing their eportfolios. In order to achieve this goal the researcher investigated key factors in the participants' approaches to learning when using e-portfolios through conducting two interviews, one at the beginning and one at the end of a unit of work, in the final semester of their degree. The first interviews were conducted in week 2 of their study in the unit, and it was called pre-interview in this research. The post-interviews occurred in week 11 of their study. The qualitative phase of the study explored the reasons behind adoption of learning approaches, and the relationship between key terms such as reproductions, reflections, motivation, perceptions and conceptions of the e-portfolios, and their learning outcomes. Fifteen students participated in the preinterviews before their exposure to e-portfolios. The exposure to e-portfolios occurred during tutorials in the unit titled "Preparing for the Profession". Although the same participants were invited to participate in the next round, only 13 students took part in the post-interviews.

Grounded theory was used to analyse the qualitative data. Grounded theory is a general methodology for developing theory, which is "grounded" in data (Glaser \& Strauss, 1967). The theory involves the construction of theory through the analysis of 
data. Four categories were generated from the participants' responses to the interview questions through the use of grounded theory. The themes and categories were formed through the use of grounded theory and related to how the participants perceived the role of their e-portfolios in their learning process.

\section{Structure of Chapter 4}

Categories, and themes generated from the participants' responses to the semi-structured interviews are described below. The relationships between the categories are discussed, and, finally, in order to respond to the research questions, a case study was conducted to investigate the reasons behind the participants' shift in approaches to learning in the context of higher education.

\section{Data Analysis}

At the end of the coding process, four categories were generated from the participant's responses. The list of categories and main themes are presented below.

Table 6

Categories and Main Themes in the Pre and Post- Interviews

\begin{tabular}{ll}
\hline Categories & Themes \\
\cline { 2 - 2 } $\begin{array}{l}\text { 1. Participants' conceptions of e- } \\
\text { portfolios }\end{array}$ & $\begin{array}{l}\text { About collecting evidence, applying for a } \\
\text { job, meeting teaching standards }\end{array}$ \\
$\begin{array}{l}\text { 2. Participants' perceptions of the } \\
\text { teaching and learning }\end{array}$ & Their role, and their lecturer's role \\
$\begin{array}{l}\text { 3.The participants' Approaches to } \\
\text { learning }\end{array}$ & Surface or deep approach to learning \\
$\begin{array}{l}\text { 4. Learning outcomes } \\
\text { Achieving teaching standards, reflecting } \\
\text { on teaching skills, learning about e- } \\
\text { portfolios }\end{array}$
\end{tabular}




\section{Category 1: Students' Conceptions of the Use of E-Portfolios}

This category discusses what the participants think of e-portfolios. A significant number of participants were actively involved in the adoption of eportfolios. According to the variation in the definition of the tool, they used eportfolios to achieve different goals. Therefore, this category comprised two themes according to the variation in the participants' definitions of e-portfolios as well as the goals they tried to achieve. Their responses showed that pre-conceptions of the eportfolios were limited to a collection of online evidence to meet the teaching standards, and to apply for jobs. Their post-conceptions of the e-portfolios also remained consistent with two students responding as follows:

Pre-perception: E-portfolio is like an online resume of my qualifications, sample of works, examples of what I'm going to do like applying for a job. Then, I present not only verbally and through my resume I give online visual example to employer. (Participant 1)

Post-perception: It's an online document of what I'm doing and documenting the standards as a teacher. (Participant 2)

\section{Category 2: Students' Perceptions of the Use of E-portfolios}

The interview questions related to students' perceptions of the e-portfolios tended to emphasise an important theme including their role and their lecturer's role.

\section{Students’ Role}

Students responded to the following questions:

In the pre-interview - What do you think your role would be when using the e-portfolio? In the post-interview they were asked - What was your role when you used the e-portfolio? 
There was almost no variation in emphasis in the participants' pre-and postperceptions of e-portfolios. The students' pre and post-perceptions mainly focused on themes including task fulfilment, evidence collection, and preparation of an online resume to apply for a job as well as reflection to develop the e-portfolios.

Pre-perception: Within the unit I think my role is just for an assessment. We use it to demonstrate that we can present ourselves as professionals to seek work. (Participant 4)

Post-perception: (My role involved) development of my own e-portfolio, so I have criteria to address and to find evidence to address these criteria so if a potential employer wants to have a look, I save evidence so I guess my role is to collate it in a way that people would understand and read it. (Participant 3)

Post-perception: (My role) was to independently create an e-portfolio based upon my own teaching aspirations to use it for a job and to show skills.

\section{(Participant 5)}

Pre-perception: (my role is) to work and build on it and produce something to present something outside of the University. I think my role would be construct it, and refer back to work I have done before and create it what represents the kind of teacher I am. (Participant 7)

Only three students indicated that the pre-perceptions of their role involved reflection while post-perceptions of e-portfolios showed that only one student mentioned that her role is to reflect on the e-portfolio.

Pre-perception: I get together some of my past work and put it in there so that I can use it when I come out. Maybe it's a way for me to reflect on the 
last four years. I can prepare myself for being able to answer questions when I get into the workforce. (Participant 6)

Pre-perception: We have to look at justifying part of the curriculum and we go back into our work in four years. I guess I would reflect on what I have learned and how maybe my knowledge has changed form then, how it has grown as a students and as a professional. (Participant 1)

\section{Lecturer's Role}

Responses in this category demonstrated that in the pre-interviews nine participants perceived the role of the lecturer as a guide, supervisor, and facilitator. In particular, students perceived that their main duty was showing the students how to develop and use the e-portfolios. Comments made included the following:

Probably it is like a supervisor role so it gives us a bit of guidance and gives us feedback and lots of background how to use it, it's straightforward how to use it. (Participant 8)

Teaching how to use it; basically, how to upload evidence and to access it later. (Participant 9)

She sets up the template so everyone had to use the same template and she instructed on how to use the e-portfolio. (Participant 10)

I guess give us advice on whether it's appropriate professionally. I guess give us advice on it if it reflex the individuals who are creating it rather than just putting what we think the person want to see. I don't know. (Participant 1) However, in their post-perceptions, only three of the participants mentioned that the lecturer had the role of supervisor or facilitator when using the e-portfolios. 
They are basically just the facilitators. They guide us through they give us lectures and a few tutorials and things based on how to utilise the e-portfolio, but they didn't really say what was expected and what we need to put in there. It is based on finding something based on the criteria, and then pop it in, and how to use the e-portfolio but not what to put in the e-portfolio. I think being a teacher we get told about scaffolding all the time and so to have some sort of examples how to structure what to put in, not exactly what to put in but how to structure what to put in. (Participant 11)

We were meant to have some tutorial allocated to the computer lab to practice and to learn the skills of using e-portfolio, and we didn't do this. We stayed in the classroom and did other activities we didn't talk about eportfolios, so the tutor didn't have a role either. (Participant13)

She provided a lot of PowerPoint presentations and she really took steps in how to upload information and what sort of things to upload, so all kind of information was useful. Tutorials she set up were enough for me. (Participant 12)

I actually did a lot of reflection on the teaching experiences that I have included so I reflected on teaching and my learning in the professional context not in the university context. I didn't reflect on the learning in the university classroom I reflected on the teaching practice I had in my practicum and also in my volunteering. One example is I organized an excursion to going to the museum and for e-portfolio I finished up reflections about that excursion to upload as one of the attachment s and in that way eportfolio helped me in my teaching and learning. It was not e-portfolio which 
helped me to reflect it was the assessment task using e-portfolio has. I have reflected on 8th of standards and I have done that by how I demonstrated each standards and based on my current company and then I uploaded it in the e-portfolio, I did the reflection before using the e-portfolio so I don't think that the e-portfolio helped me with that. (Participant 7)

\section{Category 3: Students' Approaches to Learning}

This section presents the participants' general approaches to study both prior to and after their engagement in the e-portfolio-based unit. Baturay and Daloğlu (2010) asserted that in order to achieve the full benefit of e-portfolios, it is important to train learners to reflect on their work as it provides accurate information about their competency in the areas of learning. Without reflection, e-portfolios are only a cumulative collection of work. The surface approach to study is reproduction and collection of evidence for the sake of doing the assignment (Babaee, Swabey, \& Prosser, 2014). A deep approach to learning is associated with active engagement, conceptual change, identification of the strengths and weaknesses of the students in meeting the teaching standards, and setting clear goals to develop teaching competency (Babaee et al., 2014).

The participants were asked to respond to the questions at the beginning of their exposure to e-portfolios in the second session of the unit and also after nine weeks of exposure to e-portfolios. They were asked what sort of things they will do when using an e-portfolio in this unit. Responses from the students indicated that this category included four themes: reflection, self-assessment, independent learning, and motivation. All of these are related to self-regulated learning through e-portfolios. Variations in emphasis were apparent in the students' responses in the pre and post- 
interview. These differences were used to group similar responses into the categories and to describe the relationships between them.

\section{Reflection}

Students' prior approach to learning showed that 13 participants in the preinterviews mentioned that they will reflect on their e-portfolios.

I look back at the kind of student I was four years ago, to see the development through the personal development, skills and pedagogy. I could write the kind of changes to do with the kind of teacher I want to be. (Participant 7) Yes, I think you will discuss what you have learned through certain activities maybe the whole unit and what you could use assessment tasks and rubrics as evidence. (Participant7)

Yes, probably refining the material. So I suppose, yes. (Participant 8) Yes (I reflect on my e-portfolio). Like I said before looking at the past assignment and realising what I know now and what I didn't know then and maybe agreeing and dis agreeing what I've done in the past. (Participant 1) As can be seen in the participants' responses, although they all mentioned reflection, they used the word reflect to indicate different meanings. For example, participant 7, perceived the importance of reflection to change her conceptions of teaching, and to improve the kind of teacher she would like to be. In contrast, participant 8 used the term reflection to refine the material. It may be associated with the physical aspect of the use of e-portfolios and importing material.

However, post- approaches to study represented that from the 13 students who participated in the post-interviews, nine of them mentioned that they reflected on their e-portfolios. Again, they used the word 'reflection' to indicate different 
meanings. Here are some examples showing the range of the variation in their responses in the post-interview:

Yes, I (reflected) to incorporate ICT, I reflected about linking evidence from different website and videos and pictures and these things. It's a great tool. (Participant 12)

I think you reflect when you are doing the work because we have to provide evidence of things we are matching with criteria. I'm reflecting back on my works in 4 years in uni and it is a good form of reflection. (Participant 6) No, I wouldn't say I reflected on my learning. This unit was designed around e-portfolio it was just one assessment task not around e-portfolios. (Participant 3)

Yes I did to incorporate ICT. I reflect about linking evidence from different website and videos and pictures and these things. It's a great tool. (Participant 9)

Participants' responses implied that these students used the term reflection to achieve different goals. It seems that the participant 6 reflected on his teaching practice to enact a change for the best while both participants 12 and 3, appeared to reflect on production and development of the e-portfolio in terms of designing and creating the tool, and the important factors that are associated with deep learning have been missed.

\section{Self- assessment}

Ten participants in the pre-interviews mentioned that they would undertake self-assessment, and nine of them in the post-interviews reported that they did complete a self-assessment through the use of a rubric. 
I used the rubric criteria but not much of self-assessment. I am still working on the assignment and I will do self-assessment. (participant 11)

\section{Independent Learning and Motivation}

The comparison between the participants' prior and post approach to learning indicated that after the use of e-portfolios most of them believed that e-portfolios encouraged both independent learning and motivation as they perceived it as an individual tool which motivated them to get involved in the activities. In the preinterviews 13 students mentioned e-portfolios encourages independent learning and motivation and in the post-interviews 11 students mentioned this.

Pre-interview: Yes, I think so. It is very personal so everybody is going to have different responses compare to an essay, which people eventually do the same thing, but because we all have different experiences we write different things in an e-portfolio. I guess we need to go and find examples ourselves, and no one will tell us what to do. If it is about doing things yourself, trying to find things to back up what you are saying. (Participant 11) Post-interview: I think so. Rather than writing everything down you need to decide what to do, and it's not a specific thing and the choice of document and what to upload is personal. (Participant 7)

It's an independent task, individual task, and the task is an individual and because it is in an e-portfolio it makes it an individual thing. Therefore it was independent. (Participant 2) 


\section{Category 4: Students' Learning Outcomes}

This section presents a variety of responses from the participants' about their pre and post-conceptions of the learning outcomes in the e-portfolio-based context after nine weeks of exposure to the tool. The main perceptions about the learning outcomes in both pre- and post-interviews around the possible achievements, and the things they could learn about being PSTs in the e-portfolio-based context were similar.

This category describes four qualitatively different themes the participants reported about their learning outcomes in the pre and post-interviews. These themes include: addressing the selection criteria, learning about e-portfolios, applying for a job through meeting the teaching standards, and reflection on teaching skills. These differences were used to group similar responses into themes after they completed a semester in the e-portfolio-based teacher education unit. A large number of the participants mentioned that the use of e-portfolios contributed to their development as PSTs in many ways. However, variations in emphasis were apparent in their responses.

A few participants reported conceptual change, progress, development and identification of their weaknesses and strengths in the journey of preparation for the teaching profession while a larger number of students mentioned mastering IT skills, collecting evidence, and doing the task as their main achievements when using an eportfolio in the unit. The four themes and the participants' comments are discussed below. 


\section{Theme 1: Addressing selection criteria}

Four of the participants mentioned they would use the e-portfolios to address selection criteria in both rounds of the interviews:

Pre-interview: I think the most important thing to learn, (is that) I have to understand the standards required and after graduation and have some development and we become professional teachers. I think as a pre-service teacher we have to obey the standards and we have to see if we can meet the standards. E-portfolio helped my self-reflections, my thinking about thinking and my reflective practice as an independent learner. (Participant 15) Post-interview: The e-portfolio contributed to keeping a good documentation and tracking your individual progress against (the) standards and identifying the gaps in the collection of evidence. (Participant 4)

To me is an electronic version of the documents you can use it to demonstrate like weather we have to demonstrate all the standards required as a graduate student for the job interview, or online data base for your own work, weather the initially or putting online artifacts or some examples of selection criteria by linking it to our e-portfolio. (Participant 3)

\section{Theme 2: Learning About the E-portfolios}

The participants' responses to the pre-and post-interviews showed that one of the learning outcomes in both rounds of e-portfolios involved becoming familiar with e-portfolios in order to apply for a job. Ten participants mentioned this as a learning outcome in the pre-interview and 11 participants mentioned this in the postinterview. 
Post-interview: I don't really know. Beside how to use e-portfolio which is basic I can't think of anything particular. Rather than a way to link everything and it's relate to applying for jobs not from the e-portfolio.

(Participant 10)

Post-interview: I have a better understanding of what an e-portfolio is. (Participant 3)

\section{Theme 3: Applying for a Job Through Meeting the Teaching}

\section{Standards}

In the pre-interviews only three participants mentioned that they would learn how to apply for a job through presenting their e-portfolios, but in the postinterviews six of them said that they would do so.

Pre-interview: Taught me how to professionally make it, to show to employers and how to go about it. It's when I finish it I can have a good look at it. (Participant 7)

Pre-interview: I suppose to use if effectively so knowing how to navigate it and knowing what sort of information is expected to be put in the e-portfolio. Using it wisely so knowing what is it expected in each section, and getting to know e-portfolios. (Participant 1)

Pre-interview: Within the Unit I think my role is just for an assessment. We use it to demonstrate that we can present ourselves as professional to seek work. (Participant 3)

Post- interview: More effective way to keep all your past pieces of work like an online resume. It is easier to access it. It's always there and it's handy, 
you can change it and alter it, and they will be very handy - I like it. (Participant 8)

Post- interview: I learned the importance of keeping good documentation and digital copies, and I learned the system that we make sure that we put effort on something which remains available. (Participant 4)

\section{Theme 4: Reflection on Teaching Skills}

In both pre-and post- interviews five participants mentioned that their learning outcome would be reflected in their teaching practice through the use of the e-portfolio:

Pre-interview: Hopefully, it will make me aware of all of the different aspects of what (being) a teacher is going to be like. Because I'm sure there are a plenty of parts of the job that may not get covered in the unit, and maybe putting this e-portfolio together and seeing what other students think is important, or what other teachers think is important, to put in there.

(Participant 10)

Pre-interview: I think (the learning outcome would be) changes of teaching and how doing and how going on pracs and doing assignments and doing units, and how our thoughts of teaching and the kind of teaching we'd like to do has changed, the way we construct lessons. The planning side of things and writing down the changes and having it in a digital form it is very easy. (Participant7)

Post-interview: I was reflective of what we have done in the last four years. The assignments layer and I were reflective of meeting the assignment and getting a teaching job. I have collected things to back it up. It was working 
and learning what I have done to be a teacher. It helped in the way of getting job and providing an e-portfolio helps. I learnt about whether I've met those standards and what requires you need an e-portfolio when you apply for a teaching job, and it helped me to know what I need to prepare when I graduate, and when I get a teacher. We used it a little bit and the purpose of it is clearer. It's a good stepping-stone for the other e-portfolios you do online. That's good. (Participant 2)

Pre-interview: yes (I would reflect on my e-portfolio). I guess having to look in depth to the standards on the way that I achieve them, I have be looking that what I've learned during the semester and during the Unit, and on my placement and I try to put all together and try to think about what worked and what hast not worked. (Participant 6)

Table 7 indicates the frequency of the participants' responses.

Table 7

Frequency of Responses Related to the Participants Responses to the Interviews

\begin{tabular}{lcc}
\hline Frequency of Distributions & & \\
\cline { 2 - 3 } & Pre-interviews & Post-interviews \\
\hline Learning How to Apply for jobs & 3 & 6 \\
Reflecting through E-portfolios & 13 & 9 \\
Students' Role as Reflectors & 3 & 1 \\
Lecturers' Role as Facilitator & 9 & 3 \\
Self-assessment & 10 & 9 \\
Independent Learning and Motivation & 13 & 11 \\
Address Selection Criteria & 4 & 4 \\
Learning about E-portfolios & 10 & 11 \\
\hline
\end{tabular}




\section{The Relationship amongst the Categories}

Qualitative analysis indicated that the following four categories were generated from the participants' responses: students' conceptions of the e-portfolios, their perceptions of the teaching and learning context, their approaches to learning, and their learning outcomes. Taking these categories into consideration, variations of high or low understanding of the context of teaching and learning played an important role in formation of different approaches to learning and in turn, on learning outcomes. To discuss the associations between the categories precisely, responses from two very different participants (one a surface learner, the other a deep learner) in the unit are presented in the following tables.

Table 8

The Relationship Between the Categories: Example of a Student who Adopted a Surface Approach to Learning

\begin{tabular}{lll}
\hline $\begin{array}{l}\text { Relationship } \\
\text { between categories }\end{array}$ & Themes & Quotations \\
\cline { 2 - 3 } Lower Conceptions & Data collection & Online data for you work \\
Lower perceptions & Passing assignment & $\begin{array}{l}\text { We try to get pass the assignment } \\
\text { like an online resume so } \\
\text { collecting best piece of work and } \\
\text { uploading it for the assignment. }\end{array}$ \\
Surface approach to & Motivation to get a & $\begin{array}{l}\text { Yes it will be marked and I want } \\
\text { a good mark. It will be a hardy } \\
\text { tool and I will be proud of myself }\end{array}$ \\
good grade & No self-assessment & No self-assessment yet \\
Learning Outcomes & & I cannot think of any
\end{tabular}


All the participants who adopted a deep approach to learning had higher pre and post-conceptions and pre and post-perceptions of the e-portfolios. Table 8 presents quotations from a student who adopted a deep approach to learning in this particular unit. It clarifies that the participants' high conceptions and perceptions of the e-portfolios encouraged adoption of a deep approach to learning.

Table 9

The Relationship Between the Categories: A Student Who Adopted a Deep Approach to Learning

\begin{tabular}{lll}
\hline $\begin{array}{l}\text { Relationship } \\
\text { between } \\
\text { categories }\end{array}$ & Themes & Quotations \\
\cline { 2 - 3 } $\begin{array}{l}\text { Higher } \begin{array}{l}\text { conceptions } \\
\text { of the }\end{array} \\
\text { e-portfolio }\end{array}$ & $\begin{array}{l}\text { Development } \\
\text { of the tool }\end{array}$ & $\begin{array}{l}\text { From what I know it is a collection of } \\
\text { resources and stuff that you put together } \\
\text { like an online or a digital form. I used it in } \\
\text { last year and we used it just to upload our } \\
\text { assignments and pictures and text. It was } \\
\text { very complex but once I was there, and I } \\
\text { produced it, it was easy to read. It was } \\
\text { really user friendly. I saved a lot of time } \\
\text { rather than flicking through pages. }\end{array}$ \\
&
\end{tabular}

Students' role (My role was) to work and build on it and produce something to present something outside of the University. I think my role

Higher perceptions of the eportfolios would be construct it and refer back to work I have done before and create it what represents the kind of teacher I am.

I look back at the kind of student I was four years ago and I see my personal development and skills and pedagogy. I could write the kind of changes to do with the kind of teacher you want to be, and we did it in our first year so observing the way that we do that to develop and through talking with other people.

I tried to do (self-assessment) for most things to make sure that it reaches the 
Self-assessment criteria and also that it works and that functional and it really makes sense to do that before even thinking about showing that to anybody else.

Independent learning

Deep

Approach to Learning

$\begin{array}{cl}\text { Motivation } & \begin{array}{l}\text { Already I have been thinking about what I } \\ \text { can do, or it and what needs to be included, } \\ \text { so it's already getting me more motivated. }\end{array} \\ \text { I think it shows the way that you need to } \\ \text { reflect through your work in the semester } \\ \text { Reflection, } \\ \text { and looking back over things you have } \\ \text { done and seeing the kind of progression } \\ \text { from first to 4rth year and looking } \\ \text { forwards to becoming a teacher. I think } \\ \text { changes of teaching and how you are doing } \\ \text { and how going on PRACS and doing } \\ \text { assignments and doing units, and how our } \\ \text { thoughts of teaching and the kind of } \\ \text { teaching we like to do has changes, the } \\ \text { way we construct lessons. The planning } \\ \text { side of things and writing down the } \\ \text { changes and having it in a digital form it is } \\ \text { very easy. (E-portfolio) taught me how to } \\ \text { professionally make it to show to } \\ \text { employers and how to go about it. It's } \\ \text { when I finish it I can have a good look at } \\ \text { it, and its bits a pieces. But when it comes } \\ \text { to gather everything I linked, I have to find } \\ \text { documents to show that I've worked } \\ \text { through is to achieve standards, so to say } \\ \text { that already on the way of doing that and } \\ \text { like looking back what kind of teacher you } \\ \text { were gives you a perspective of how you } \\ \text { want to improve. By Improvement I mean }\end{array}$

I suppose it would help students to learn and to find different things they can do. It goes through semester so you can build it on and you can go back and forth to it rather than just sitting down a few weeks before and writing it all. You can work on it and add things. 

and I am changed now. and how I do differently now, a and changes in the lesson plans because I am now more experienced in the class room.it makes it a lot easier to look back and this is what I am achieving in 2-3 years' time.

Participant 8 showed a deeper understanding of the e-portfolio-based context due to her use of the tool for learning and professional development as a PST. She commented that the tool contributed to her changing her conceptions of teaching and to being more reflective; the kind of teacher she would like to be in the future. These conceptions and perceptions are associated with a deep approach to learning.

\section{Findings}

Participants were asked to respond to the interview questions before and after their exposure to e-portfolios, to share their pre- and post-conceptions and perceptions of the e-portfolios, their prior approaches to study, as well as their postapproaches to study. They also responded to questions related to their pre and post learning outcomes. The participants' responses identified categories and themes for the pre- and post- interviews. A variation in emphasis was apparent in the participants' responses. At the end of the coding, four categories were generated: perceptions of e-portfolios, conceptions of e-portfolios, and approaches to learning, and learning outcomes. Five major themes were generated from the participants' responses: showcasing through e-portfolios, guidance, deep approach to learning (e.g., reflection and growth, conceptual change, collaboration, clear goals), surface approach to learning (e.g., reproduction, doing the assignment), and learning 
outcomes (knowing weaknesses and strength, reflection, conceptual change on teaching, using e-portfolios, and ITC skills). These categories and themes were intended to indicate particular aspects of the participants' experiences. The researcher observed these categories moving closely towards a grounded theory on how the participants perceived the role of e-portfolios in their learning process, and how these perceptions affected their approaches to learning and their learning outcomes. The results of the qualitative analysis confirmed that the participants' perceptions of the context affected their experience of the teaching and learning and also their adoption of their approaches to learning. There was a positive association between the higher conceptions of e-portfolios and a deep approach to learning. The qualitative analysis also indicated that two participants altered their approaches to learning before and after use of the e-portfolios. A case study was conducted to investigate the reasons behind their shift.

\section{The Case Study of Two Deviant Cases}

A case study was conducted to identify the influential factors in changing approaches to learning in the context of higher education when using e-portfolios. The qualitative analysis of 13 participants indicated that two of the participants showed a deviation from the common pattern as they altered their approaches to learning after nine weeks of exposure to the e-portfolios. Therefore, this section presents the results of a case study, which explored the variation in these two PSTs' approaches to learning when undertaking the unit of work and implementing eportfolios. The results of the case study indicated that a number of contextual variables seemed to influence them to adopt either a surface or a deep approach to 
learning. The current research explored the extent to which aspects of the participants' perceptions of the context of teaching and learning affected adoption of different approaches to learning.

The combination of data from pre- and post- interviews showed that two cases were clearly different since they indicated a deviation from the common pattern. They were the only cases which shifted their adopted approaches to learning after nine weeks of exposure to the e-portfolios. It was important to apply a clear strategy to investigate the purposes and the rationale behind this transition to answer the research questions. An exploration of these two cases was important as the research questions were investigating the perceptions of participants' use of eportfolio- based learning, and the factors leading to the adaption of a deep or surface approach to learning when using e-portfolios.

\section{Transition from Surface to Deep Approach: Participant 5}

As is illustrated in Table 10, the responses indicated that participant 5's preperceptions and conceptions of e-portfolios mainly focused on showcasing purposes, and there was a single focus on the development of an e-portfolio to present work. Participant 5 believed that there were other possible options for this purpose.

I use it effectively so knowing how to navigate it, and knowing what sort of information is expected to be put in the e-portfolio. They don't motivate me to learn. I personally withdrew from it as I said I have got all this stuff anyway. (Participant 5)

After nine weeks of exposure to the e-portfolio, participant 5 showed a shift from a surface approach to a deeper approach to learning as the post-perceptions and 
conceptions stressed reflection, conceptual change, growth and development rather than developing an e-portfolio to complete the task.

It was the assessment-based learning activity that we had to do in a course of time. It's quite reflective, and it helps you reflect on your previous learning as well because you can think about where your strengths and weaknesses lie, and then play on those, and they are supported with the criteria that you need to mee. It helps a bit to change my ideas. It makes you think about where you need perhaps some more research or professional development in the areas you feel a bit less strong I suppose. (Participant 5)

Participant 5 claimed that she reflected on her four years of study to find out about her weaknesses in order to overcome them, and it helped her to change her ideas, and her teaching philosophy. These learning activities are associated with a deep approach to learning, and in turn with achieving higher learning outcomes. Table 10 represents her responses to the pre- and post- interviews as well as showing generated themes and categories according to her responses.

Table 10

Participant 5: Categories, Themes, and Comments Showing Shift from a Surface to Deep Approach to Learning

\begin{tabular}{|c|c|c|}
\hline \multirow{2}{*}{ Categories } & \multicolumn{2}{|c|}{ Themes and comments } \\
\hline & Pre-interviews & Post-interviews \\
\hline $\begin{array}{l}1 \text { Conceptions } \\
\text { of E- } \\
\text { portfolios }\end{array}$ & 1) Showcasing & 1) Showcasing 2) Sharing \\
\hline $\begin{array}{l}2 \text { Perceptions } \\
\text { of E- } \\
\text { portfolios: } \\
\text { Students' } \\
\text { Role }\end{array}$ & $\begin{array}{l}\text { 1) Navigating } \\
\text { the e-portfolio } \\
\text { 2) Archiving } \\
\text { information }\end{array}$ & $\begin{array}{l}\text { 1) Creating an e-portfolio based on my } \\
\text { own teaching aspirations to showcase } 2 \text { ) } \\
\text { assessment pace learning activity } 3 \text { ) helps } \\
\text { you reflect on your previous learning } 4 \text { ) } \\
\text { thinking about where your strengths and }\end{array}$ \\
\hline
\end{tabular}


weaknesses lie and then play on those 5) picking things and show what you know 6) good evidence with or good back up 7) changing my ideas 8) thinking about where you need perhaps some more research or professional development

Lecturer's 1) Guidance 1) The facilitator and guide 2) how to Role utilise the e-portfolio 3) they didn't really say what was expected 4) on finding something based on the criteria 5) who to use the e-portfolio but not what to put in the e-portfolio

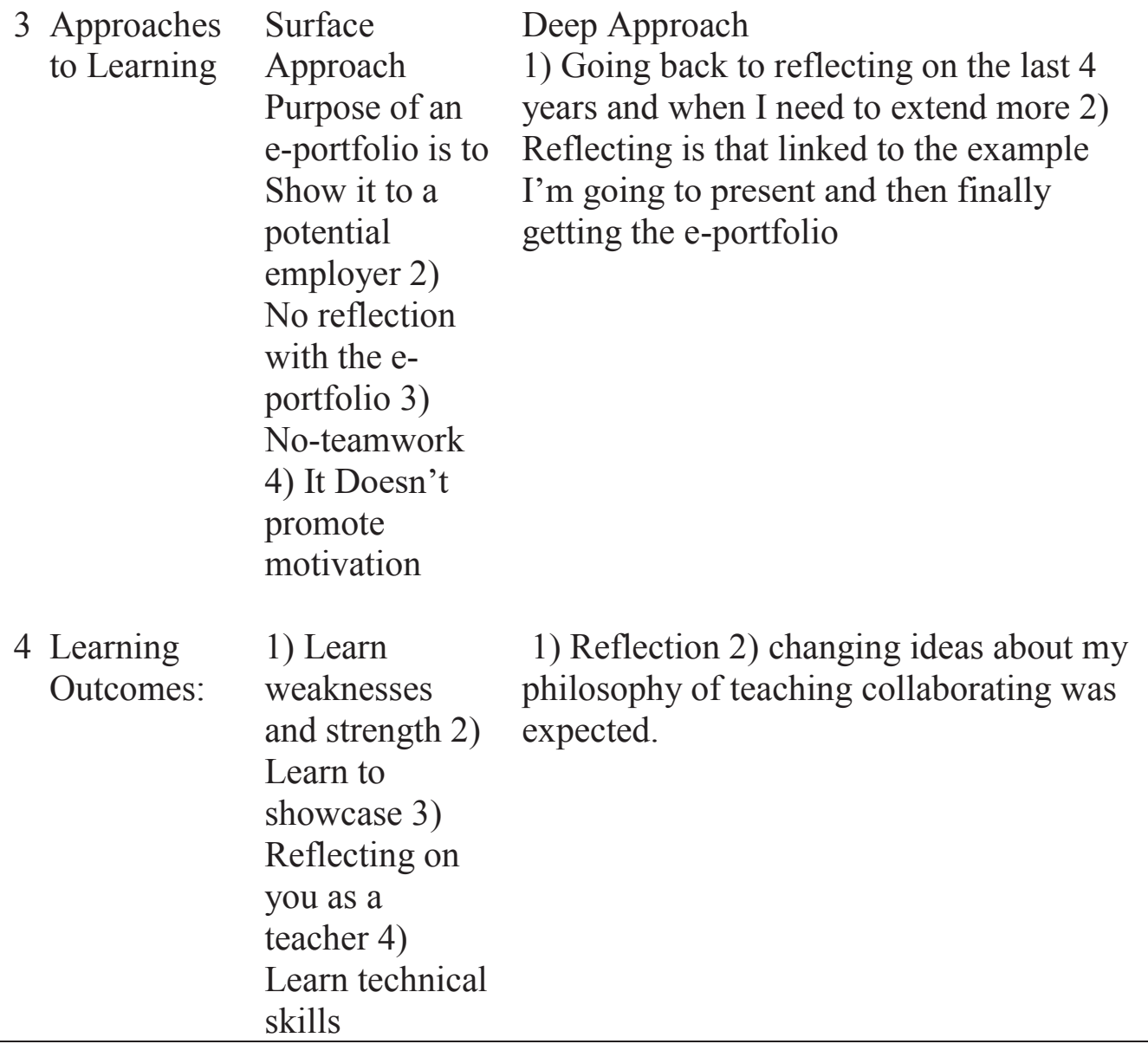




\section{Transition from Deep to Surface Approach}

In the pre-interview, participant 6 mentioned that she thought of the eportfolio as a résumé to be shown to potential employers, and asserted that her role was to reflect on her last four years of study:

We have to look at justifying part of the curriculum, and we go back into our work in four years. I guess I would reflect on what I have learned and how maybe my knowledge has changed from then, how it has grown as a student an as a professional. We had our first assignment to create our own philosophy of teaching which I think is a really good, especially if that is something we can use when we come out when we go to apply for a job or when we have an interview and somebody may say "why do you want to be a teacher?" and to have something prepared, and to understand your own beliefs is a probably good practice. (Participant 6)

In her post- learning outcomes, she changed her views on the e-portfolios.

She believed e-portfolios did not help her to be engaged with learning activities, and she delivered everything into her e-portfolio in the last two weeks. However, she still believed that e-portfolio implementation fitted into the unit. She claimed it prepared her for the profession, and it gave her a good tool after graduation; she described her role as an organiser and editor. Although she believed in reflection, she believed the e-portfolio did not help her to learn.

Reflection, like going to past assignments and reflecting on your beliefs as a professional. You have to put them in a format. I don't think an e-portfolio will help so much. Reflection helped me identify what has changed since I wrote it, but e-portfolio has nothing to do with my teaching philosophy. E-portfolio 
doesn't provide anything new, and it doesn't change my philosophy of teaching. Maybe it facilitates it. Reflection makes me aware of my values and beliefs as a teacher and prepares me for entering the workforce. (Participant 6)

She did not think the e-portfolio promoted her independent learning or her motivation to learn, and the only thing she learned through the e-portfolio was organising documents and keeping evidence of learning. She also asserted that she did not learn anything about being a PST through the use of her e-portfolio. Therefore, it indicated a change of her perceptions and a shift in her learning approach. Table 11 shows the categories and themes drawn from her responses to the interviews. It also illustrates how perceptions and conceptions of the participant 6 changed after nine weeks of exposure to the e-portfolios.

Table 11

Participant 6: Categories, Themes, and Comments Showing a Shift from a Deeper to Surface Approach to Learning

\begin{tabular}{|c|c|c|}
\hline \multirow[t]{2}{*}{ Categories } & \multicolumn{2}{|c|}{ Themes and comments } \\
\hline & Pre-interviews & Post-interviews \\
\hline $\begin{array}{l}1 \text { Conceptions of } \\
\text { E-portfolios }\end{array}$ & 1) Showcasing & 1) Showcasing 2) Sharing \\
\hline $\begin{array}{l}2 \text { Perceptions of } \\
\text { E-portfolios: } \\
\text { Students' Role }\end{array}$ & $\begin{array}{l}\text { 1) Navigating the e- } \\
\text { portfolio 2) } \\
\text { Archiving } \\
\text { information }\end{array}$ & $\begin{array}{l}\text { 1) Creating an e-portfolio based } \\
\text { on my own teaching aspirations } \\
\text { to showcase 2) assessment pace } \\
\text { learning activity } 3 \text { ) helps you } \\
\text { reflect on your previous } \\
\text { learning 4) thinking about } \\
\text { where your strengths and } \\
\text { weaknesses lie and then play on } \\
\text { those 5) picking things and } \\
\text { show what you know } 6 \text { ) good } \\
\text { evidence with or good back up }\end{array}$ \\
\hline
\end{tabular}




\begin{tabular}{|c|c|c|}
\hline Lecturer's Role & 1) Guidance & $\begin{array}{l}\text { 7) changing my ideas } 8 \text { ) } \\
\text { thinking about where you need } \\
\text { perhaps some more research or } \\
\text { professional development } \\
\text { 1) The facilitator and guide 2) } \\
\text { how to utilise the e-portfolio } 3 \text { ) } \\
\text { they didn't really say what was } \\
\text { expected 4) on finding } \\
\text { something based on the criteria } \\
\text { 5) who to use the e-portfolio } \\
\text { but not what to put in the e- } \\
\text { portfolio }\end{array}$ \\
\hline $\begin{array}{l}3 \text { Approaches } \\
\text { to Learning }\end{array}$ & $\begin{array}{l}\text { Surface Approach } \\
\text { Purpose of an e- } \\
\text { portfolio is to Show } \\
\text { it to a potential } \\
\text { employer 2) No } \\
\text { reflection with the e- } \\
\text { portfolio 3) No- } \\
\text { teamwork 4) It } \\
\text { Doesn't promote } \\
\text { motivation }\end{array}$ & $\begin{array}{l}\text { Deep Approach } \\
\text { 1) Going back to reflecting on } \\
\text { the last } 4 \text { years and when I need } \\
\text { to extend more 2) Reflecting is } \\
\text { that linked to the example I'm } \\
\text { going to present and then } \\
\text { finally getting the e-portfolio }\end{array}$ \\
\hline $\begin{array}{l}4 \text { Learning } \\
\text { Outcomes: }\end{array}$ & $\begin{array}{l}\text { 1) Learn weaknesses } \\
\text { and strength 2) } \\
\text { Learn to showcase } 3 \text { ) } \\
\text { Reflecting on you as } \\
\text { a teacher 4) Learn } \\
\text { technical skills } \\
\end{array}$ & $\begin{array}{l}\text { 1) Reflection } 2 \text { ) changing ideas } \\
\text { about my philosophy of } \\
\text { teaching collaborating was } \\
\text { expected. }\end{array}$ \\
\hline
\end{tabular}

Participant 6's pre-conceptions included her expectation to receive advice on whether the process of e-portfolio development was appropriate professionally, and advice as to whether the e-portfolio reflected the individual who was creating it rather than just including what she thought the tutor wanted to see. These expectations were associated more consistently with a deep approach to learning. However, she changed her ideas in the post- interviews. She expected to receive help to navigate through the e-portfolio and advice on what to include in the e-portfolio. 


\section{The Reasons behind the Shift in Approach to Learning}

Some associations behind the shift in the participants' approaches to learning according to the data analysis are discussed below. The aspects of participants' learning in the context of teaching and learning and the possible influential factors that may affect adoption of approaches to learning are identified according to the participants' responses. Interestingly, most of these factors are related to the context of teaching and learning.

\section{Pre-perceptions and Conceptions of the Context (The 3P Model)}

In these particular cases, the responses to the pre-interview indicated that variables such as the participants' pre-perceptions on the context of teaching and learning plays a key role in adoption of different approaches to learning, and in turn in to their learning outcomes. Taking the technology-based context of teaching and learning into consideration, Prosser (2000) remarked that in such an environment, students' learning outcomes depend on their perceptions towards the aims of the new technologies in their learning. For example, participant 5's pre-perceptions and conceptions of the e-portfolio showed that she mainly perceived the e-portfolio as a tool to apply for a job, and therefore, her learning activities were limited to navigating the e-portfolio to use it for the purpose of showcasing. Apparently, the pre-perceptions of participant 5 did not include considering reflection as a learning activity. Such learning perceptions and conceptions of the e-portfolios are associated with a surface approach to learning.

\section{The Level of Students' Prior-Knowledge}

Prosser (1987) focused on the effect of students' levels of prior knowledge on their academic achievement, and he asserted that a reasonable level of prior 
knowledge is required to achieve learning. Prior knowledge refers to students' characteristics, their previous experiences, and their new knowledge (Entwistle \& Ramsden, 1983). Using prior knowledge involves linking known concepts and the learner's background and personal attitudes to new meanings and concepts (Ausubel et al., 1968). Participant 5, in the pre-interview, mentioned that: “e-portfolios don't motivate me to learn. I think just because we haven’t used them enough throughout the course, and then all of a sudden we need to know how to navigate it. We need to know how to upload things. I personally withdrew from it”.

It showed that she stressed the existence of an appropriate level of preknowledge to build her new knowledge on, and in her study in the unit, it seems that her adoption of a surface approach to learning was associated with not having the appropriate level of pre-knowledge.

\section{Post-perceptions of the Context (The 3P Model)}

Participant 5 showed a shift from a surface approach to a deep approach to learning. Her responses to the post- interview indicated that her perceptions and conceptions of e-portfolios were changed after having nine weeks of meaningful exposure to the e-portfolio, and it seems that this change is associated with her adoption of a deeper approach to learning. She employed learning strategies, which included reflection, collaboration, and conceptual change. Further to this, she was more motivated to learn. For example, her pre-conceptions of e-portfolios indicated that she initially perceived the e-portfolio as a tool to apply for a job, but after having exposure to the tool she changed her mind. She appeared to use the e-portfolio as a tool to change her conceptions of teaching, and to find her strengths and weaknesses; these activities are associated with a deep approach to learning. 


\section{Good Teaching (The 3P Model)}

Quality of teaching may influence students in their approach to learning. It can be seen that students' expectations of lecturers' activities can be affected by the approach to learning that they adopt, and in turn, lecturers may affect students learning outcomes by choosing different teaching strategies. For example, setting clear goals for the students from the beginning of the semester may guide them in the right direction. In regard to this, Participant 5 mentioned that they needed to create their e-portfolios according to the criteria provided for them, and then, she expected her lecturer to play the role of a facilitator, and she maintained this perception in the post- interview. In both interviews, participant 5 described her pre-perceptions of the lecturers' role as a guide and facilitator.

\section{Perceptions on Integration of E-portfolios into the Unit (The 3P}

\section{Model)}

Although participant 5 mentioned that the use of the e-portfolio fitted into the unit, she believed that e-portfolios were not well integrated with the unit as there were two separate focuses in the lectures and the tutorials, and the goals in these two different sets of teaching were not correlated with the expectation of the assignment. I can't imagine how else, with modern technology and everything, we would have done it unless we have a physical portfolio to showcase. The unit, like all of the content and weekly lectures, didn't align with the expectation of the assignment, but then in the tutorial everything was focused on creating the eportfolios, and so it almost fell like we had two focuses in the week. The lectures would say how to do an interview, and then the tutorial would say how to make the e-portfolios, and it wasn't correlating. I suppose so. There 
was heavy focus on the e-portfolio but how to upload things, how to implement it and how to use it. (Participant 5)

In this unit, the participants' pre- and post- conceptions were involved with implementation of the e-portfolios mainly for the purpose of applying for a job; therefore, the nature of such e-portfolios required students to showcase their abilities and strengths to be more attractive to future employers. In such an environment students were not encouraged to reflect on their philosophies of teaching, their teaching strategies, and their learning outcomes. As participant 5 mentioned, in the tutorial sessions they received lessons on uploading things and navigating the eportfolios, and these techniques were mostly related to technical aspects of using the e-portfolios. According to her claim, since the lectures did not clarify the potential of e-portfolios for the students, the possibility of learning through using e-portfolios was not emphasised. As a result, it seems that they did not receive enough advice in terms of the dynamic and reflective nature of the e-portfolios, which could help them to do ongoing reflection on the process of their learning. Further to this, the participants did not receive any feedback until the end of the semester as the eportfolios were mainly used for the purpose of summative assessment. Both participants did not use the tool during the semester; they started importing documents at the end of the semester, therefore they lost the chance to monitor the progress of development of their teaching philosophies, and to respond to the teaching standards gradually according to their learning during the unit. Apparently, the nature of the unit encouraged them to use the tool only for showcasing purposes. In this research, the participants received feedback for their e-portfolios at the end of the semester. The rubric included in this thesis was not used to assess the 
students' summatively. Students were assessed by their lecturer (not the researcher) at the end of the semester according to several criteria including, but not limited to, their final e-portfolios. The researchers did not access the final results. Students' perspectives on their learning outcomes were examined through interviews by the researcher.

However, even in such an environment of teaching and learning, participant 5 intended to use the e-portfolio as a reflective tool to think of her philosophy of teaching, and she was able to make a conceptual change in her teaching beliefs. She monitored her strengths and weaknesses during her four years of being a PST in only two weeks as she developed her e-portfolio, and in such a short time she provided responses to the eight teaching standards according to her gradual growth in regards to her four years of study at the University. It confirms the productive nature of eportfolios in the higher education context, and it reaffirms the provision of an appropriate context to apply the tool.

\section{Conclusion}

The results of the qualitative phase of the study indicated that a number of contextual variables appear to influence students to adopt either a surface or a deep approach to learning. The qualitative phase of the research confirmed that the participants' perceptions and conceptions of the context of teaching and learning plays an important role on adoption of their approaches to learning and their learning outcomes.

The participants of this study were PSTs in their final year who were using eportfolios to prepare for the teaching profession. Interpreting findings indicated that 
2 of 15 cases showed a shift in their learning approaches during the semester. These two cases showed transition from their adopted approach to learning after the use of e-portfolios. The change in their learning approaches was considered critical for the current study, and as a result, the reasons behind this transition were explored. Another aim of the qualitative phase of the study was to identify the influential factors in adoption of the participants' approaches to learning in the course of their studying in the context of higher education. However, a full description of their learning was complex. Therefore, in this chapter the key aspects of the participants' learning that affected their approaches to learning were generated from their responses to the interview questions. For the first time, this research analysed the different perceptions of two PSRs in the same e-portfolio based context through the use of SAL, the 3P model of learning, and SRL theories of learning. Finally, qualitative analysis allowed the identification of a number of alterations in the development of the e-portfolios to encourage deep learning in the context of higher education. 


\section{Chapter 5: Quantitative Data Analysis}

\section{Introduction}

The previous chapter used qualitative methods to detail the results of an intensive study of a small number of participants. In this chapter, the result of a more extensive study of a larger number of participants will be detailed to complement the smaller intensive study. A questionnaire was one of the research instruments applied in this research. For this research, a combination of three questionnaires related to the participants' conceptions of the e-portfolios, their perceptions of the teaching and learning context, and their approaches to learning when using e-portfolios were used. The main purpose of the questionnaires was to examine the role of participants' conceptions of the e-portfolio and its relationship to perceptions and outcomes. The current investigation stressed the importance of the teaching and learning context as students entered the learning environment with individual conceptions towards the eportfolio- based learning, and it is expected that these conceptions were key factors in the adoption of a deep or surface approach to learning. This chapter examined how conceptions of the e-portfolios may affect the participants' experience of teaching and learning context, and also the adoption of particular approaches to learning.

After the participants had nine weeks of exposure to the e-portfolios, they were surveyed to share their experiences towards aspects of their learning environment including: their conceptions of the e-portfolios, their perceptions of the teaching quality, clarity of goals, and appropriate assessment and workload as well as their approaches to learning. At this stage of their study, it was expected that they had sufficient time to form meaningful impressions of e-portfolio implementation. 
All PSTs involved in the unit called "Preparing for the Profession" were invited to participate in the research. Seventy-three of them responded to the questionnaires. Having collected the responses from a sample of 73 final year students in both Master's and Bachelor degrees, quantitative analyses investigated empirical associations among the participants' conceptions of the e-portfolios, their perceptions of their learning and teaching environment, and the e-portfolio-based unit as well as their approaches to learning. This chapter examined the associations between the participants' conceptions of the e-portfolios, and their perceptions of clear goals, good teaching, appropriate workload and assessment as well as their approaches to learning. The results of this evidence-based study can be used to inform teacher educators as to how e-portfolios have been implemented in the context of higher education in Australia. The findings also identified the issues of designing and teaching e-portfolio-based learning in this context.

\section{Structure of the Chapter}

In Chapter 2, four basic elements of the research and their links to the current study were discussed in detail. The chapter presented how the research methods were chosen according to the research epistemology, the theoretical framework, and the methodology. Chapter 3 presented the research methodology. Chapter 4 discussed the qualitative phase of the research. In this chapter, the quantitative data are analysed, and the results are presented.

The participants' conceptions of the e-portfolio-based unit were investigated through their responses to the questionnaire. The conceptions of the e-portfolios were explored to identify what participants in this particular context thought of the eportfolios, and the use of them. Four different variables related to their perceptions of 
the context in the e-portfolio-based unit were investigated. To examine these different variables, the modified version of CEQ used in this research included items related to the participants' perceptions of good teaching, clear goals, appropriate assessment, and workload. In addition, their approaches to learning including deep and surface approaches were surveyed.
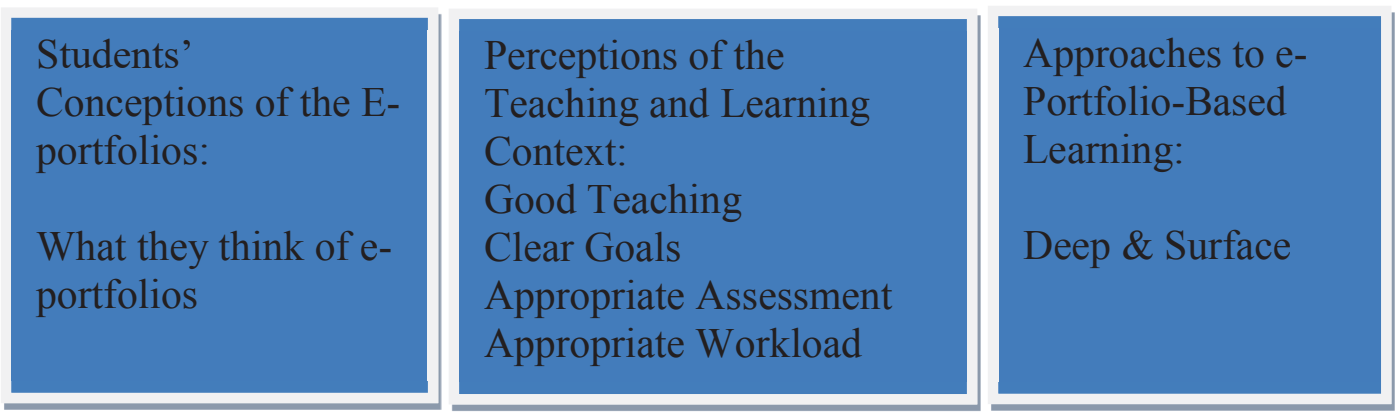

Figure 1. Aspects of students' perceptions investigated in Chapter 5.

Finally, the participants' responses were analysed using a qualitative analyses. As a result, the structural relationships between these different aspects were examined in depth. Chapter 5 is structured as below.

\section{Conceptions of the E-portfolios}

This section presents the factor analysis for the participants' conceptions of the e-portfolios using seven items. In this research factor analysis was used to identify variables that explain the pattern of correlations within a set of observed variables. The analysis identified one factor, including all seven items. 


\section{The Perceptions' of the E-portfolio-based Teaching and Learning}

\section{Context}

This section shows item factor analysis from the participants' responses to the modified CEQ. This part of the questionnaire was adopted from Wilson et al. (1997), and the items of this instrument were modified to fit into an eportfolio-based context. A factor analysis of all of the modified CEQ items was first performed. The result of this factor analysis identified 2 factors, the first including good teaching and clear goals and the second including appropriate assessment and appropriate workload.

\section{Approaches to Learning}

This section presents the factor analysis for the participants' approaches to learning using 12 items adapted from Biggs et al. (2001). The analysis confirmed that there are two factors of deep and surface learning related to approaches to learning.

\section{The Reliability}

The reliability reports the Cronbach's reliability alpha values and descriptive statistics of all scales measuring the students' conceptions of the e-portfolios, various aspects of their learning perceptions including clear goals, good teaching, appropriate assessment and workload, and their approaches to learning.

\section{The Pearson Correlational Analysis}

This section reports the correlation analysis showing the associations between the various scales of the participants' conception of the e-portfolios, their perceptions of the Unit (CEQ), and their approaches to study (SAL). 


\section{The Second Order Factor Analysis}

. This section discusses the results of the second order factor analysis.

While the correlation analysis shows associations between pairs of variables, the second order analysis groups variables together that seem to be related to each other and identifies those variables that do not seem to be related. In this research second order factor analysis was used to investigate these structural relationships between the variables investigated in the correlation analyses. Further to this, the second order factor analysis is conducted to examine the underlying structure of the scales.

\section{Motivation for Each of the Quantitative Analyses}

The following table shows the research questions and sub-questions and the link between them and the questionnaire items.

\section{Table 12}

Research Questions and Sub-questions and their Link with Questionnaire Items

\section{Research Questions and Sub-questions}

1. How has e-portfolio-based learning changed students' perceptions?

- Which factors lead to adopting deep approach to learning when using e-portfolios?
Link to the parts of the questionnaire Part D: Studen Q. 34 E-portfolios perceptions of enhance the sense of portfolios learning ownership in this Unit

Part C: $\quad$ Q.27 I work hard at student's my e-portfolio approaches because I find the to learning material interesting. 
- Which factors lead to choosing surface approach to learning when using eportfolios?

2. How do PSTs implement eportfolios to facilitate high quality learning in the context of higher education?

- What is the role of e-portfolios in effective learning?

- How do students gain knowledge through using eportfolios?

Part C:
student's
approaches
to learning
Part C:
student's
approaches
to learning

Q.18 My aim is to pass the e-portfolio while doing as little work as possible Q.23 I find most new topics interesting and use them in developing the e-portfolio and often spend extra time trying to obtain more information about them.

Part D:

Student's perceptions

of eportfolios Part B:CEQ

Q30. E-portfolios enhance my active involvement in learning in this Unit.

Q.4 I usually have a clear idea of where I am going and what's expected of me when using the e-portfolio

In order to answer the research questions item factor analysis was conducted for different parts of the questionnaire to categorize the variables in the research. The item level factor analyses were conducted to confirm the construct validity of the various scales in the study. The reliability of the scales was confirmed using Chronbach's Alpha. The association between the scales was explored using a correlation analysis and a second order factor analysis. 


\section{The Results of Data Analyses}

The following paragraphs discuss the results of quantitative data analyses. Exploratory factor analyses are conducted on each of the questionnaires to confirm the construct validity of each scale.

\section{Conceptions of the E-portfolios: Item Factor Analysis}

The conceptions of the e-portfolios scale developed in the pilot study were used in the main research. To assess validity for the main study, a factor analyses was used on the items. Hair, Black, Babin, Anderson and Tatham (2006) defined construct validity as "extent to which a set of measured variables actually present the theoretical latent construct they are designed to measure" (p. 776). They also suggested using factor analyses to examine the relationships for a large number of variables and to indicate whether the information can be summarised in a smaller set. As presented in table 13 all the seven items grouped in one factor.

Table 13

Item Factor Analysis for Students' Conceptions of E-portfolios

\begin{tabular}{cc}
\hline Item & Factor \\
\cline { 2 - 2 } Number & 1 \\
\hline 28 & 0.832 \\
29 & 0.818 \\
30 & 0.787 \\
31 & 0.746 \\
32 & 0.743 \\
33 & 0.736 \\
34 & 0.617 \\
\hline
\end{tabular}

No rotation because of a single factor; Kaiser-Meyer-Olkin Measure $(\mathrm{KMO})=.837$; Bartlett test $\mathrm{p}<$ .001 ; Eigenvalues $=4.888 ; 34.914 \%$ variance explained, and $n=71$.

Leech, Barrett and Morgan (2008) asserted that factor analysis provides the result of factor loadings, Kaiser-Meyer-Olkin Measure of Sampling Adequacy 
(KMO) test, and the Bartlett tests. They mentioned that KMO test represents whether or not each item is predicted by each factor and the measurement less than 0.50 is inadequate, while the Bartlett test reveals whether variables are correlated highly enough to provide a reasonable basis for factor analysis. In this test, the measures should have a significant value (Sig.) of less than .05 (Leech et al., 2005).

For the conceptions of e-portfolios, KMO and Bartlett's tests for sampling adequacy were, .837 and $p<.00$ respectively. Therefore, the findings supported the validity of the present part of the questionnaire for a sample of 73 undergraduate and postgraduate participants.

\section{Perceptions of the Unit: Item Factor Analyses}

In this research, the modified Course Experiences Questionnaire (CEQ) was employed as a measure of the participants' perceived quality of teaching, clarity of goals and appropriateness of workload and assessment. The modified CEQ survey, originally designed by Wilson et al. (1997), was revised for the participants in this research. It was employed, as a measure of the participants' perceived quality of teaching, clarity of goals, appropriateness of assessment and workload. These variables measured the quality of teaching in the e-portfolio-based unit in a number of important aspects of the teaching about which the participants had direct experience and were, therefore, validly able to comment. As a result, through the use of the modified CEQ, the participants' perceptions of the variables such as good teaching, clear goals, appropriate assessment, and workload were measured. For example, the items in the appropriate assessment scale investigated the participants' perceptions whether they believed the assessment procedure was a reproducing and surface, or deep approach to assessment. 
This section shows the results of the item factor analysis from the participants' responses to the modified CEQ using 11 items. The 11 items were selected following a series of item level factor analyses and tests of reliabilities of the CEQ scales in order to improve the construct validity and reliability of the final questionnaire. The result of the factor analysis of the 11-item version is shown in Table 16.

A number of researchers (Hair et al., 2006; Leech et al., 2005) claimed that the key to understanding the factor analyses results is computing the varimaxrotation containing factor loadings. Table 13 shows the results of the factor analysis with varimax- rotation. It identifies two factors, and the first includes items in the good teaching and the clear goals scales. The second includes items in the appropriate assessment and workload scales.

This result is consistent with a number of previous analyses of the CEQ scales (Prosser \& Trigwell 1999). It suggests that the good teaching and clear goal items are positively related while appropriate assessment and appropriate workload items are also related. The positive relationships may suggest that the students perceived that the teaching was good, were more likely to also believe that the goals were clear. Furthermore, investigator's examination of the content of the appropriate assessment and workload items confirmed that they fit together conceptually. Therefore, in the analyses the numbers of factors were limited to two. With regard to interpreting factor loadings, there has been some disagreement. Although a number of researchers (Leech et al. 2005) claimed that factor analysis loadings of 0.4 are considered high, some others (Hair et al., 2006) asserted that standardised loadings should be 0.5 or higher, and ideally 0.7 or higher. As can be seen in Table 14, all of 
the loadings were higher than 0.4. Therefore, the factor analyses confirmed that the items in the modified CEQ measured the participants' teaching and learning experience in the e-portfolio-based unit.

Table 14

Factor Analysis of the Modified CEQ Items

\begin{tabular}{ccc}
\hline \multirow{2}{*}{ Variables } & \multicolumn{2}{c}{ Factors } \\
\cline { 2 - 3 } Good teaching & Factor1 & Factor 2 \\
Q8) & & .000 \\
Q9) & .657 & .439 \\
Q10) & .678 & -.016 \\
Q12) & .656 & -.057 \\
Clear Goals & .622 & \\
Q1) & & -.198 \\
Q4) & .648 & -.480 \\
Q11) & .508 & -.272 \\
Appropriate Assessment & .744 & .499 \\
Q6) & & .619 \\
Q7) & .017 & \\
Appropriate Workload & -.108 & .779 \\
Q3) & & \\
Q15) & -.002 & \\
& -.011 & \\
\hline
\end{tabular}

\section{Scales Factor Analyses for the Modified CEQ}

As discussed above, result of the factor analyses and conceptual examination revealed that the modified CEQ contained four scales. The item factor analyses were performed to test the construct validity of each scale separately to explore whether the items in each scale measured what they were supposed to measure. Having 
computed factor analysis for each scale, the factor loadings for each scale were obtained separately. Tables 15 - 18 show the factor loadings.

Table 15

Exploratory Factor Analysis for the Good Teaching Scale

\begin{tabular}{lc}
\hline Item Number & Conceptions of Good Teaching \\
\cline { 2 - 2 } & Factor \\
\hline 8 & .825 \\
9 & .778 \\
10 & .724 \\
12 & .687 \\
\hline
\end{tabular}

No rotation because of a single factor and Kaiser-Meyer-Olkin Measure $(\mathrm{KMO})=.752$; Bartlett $\mathrm{p}<.001$; Eigenvalues $=2.283 ; 57.068 \%$ variance explained, and $\mathrm{n}=66$.

Table 16

Exploratory Factor Analysis for the Clear Goals

\begin{tabular}{cc}
\hline Item Number & Factor \\
\cline { 2 - 2 } & \\
\hline 1 & .769 \\
4 & .762 \\
11 & .882 \\
\hline
\end{tabular}

No rotation because of a single factor and Kaiser-Meyer-Olkin Measure $(\mathrm{KMO})=.613$; Bartlett $\mathrm{p}<.001$; Eigenvalues $=1.950 ; 65.013 \%$ variance explained, and $n=73$.

Table 17

Exploratory Factor Analysis for the Appropriate Assessment Scale

\begin{tabular}{cc}
\hline Item Number & Factor \\
\cline { 2 - 2 } & 1 \\
\hline 6 & .851 \\
7 & .851 \\
\hline
\end{tabular}

No rotation because of a single factor and Kaiser-Meyer-Olkin Measure $(\mathrm{KMO})=.500$; Bartlett $\mathrm{p}<.001$; Eigenvalues $=1.198 ; 93.939 \%$ variance explained, and $\mathrm{n}=73$. 
Table 18

Exploratory Factor Analysis for the Appropriate Workload

\begin{tabular}{cc}
\hline Item Number & Factor \\
\cline { 2 - 2 } & 1 \\
\hline 3 & .769 \\
15 & .788 \\
\hline
\end{tabular}

No rotation because of a single factor and Kaiser-Meyer-Olkin Measure $(\mathrm{KMO})=.500$; Bartlett $\mathrm{p}<.001$; Eigenvalues $=1.471 ; 49.050 \%$ variance explained, and $\mathrm{n}=73$.

As it can be seen all loadings in these scales are above .40 , and it approved that the items in this scale measure the participants' perceptions of good teaching, clear goals, appropriate assessment and workload appropriately.

KMOs for good teaching, clear goals, assessment and workload were .752, $.613, .500$, and .500 respectively, and they all were above 0.50 . The Bartlett's test showed that the Sig. for three of these scales was .000. Therefore, measures had significant factor loading (Sig.) of less than .05. It means that the variables in this scale were correlated highly enough to provide a reasonable basis for the factor analysis. However, Sig. for Workload is .001, which is less than .05. As presented, all the scales in the CEQ had standard factor loadings, KMOs and Sigs. It should be noted, however, that two of the scales had only two items each and results including these scales need to be treated with due caution.

\section{Approaches to Study: Item Factor Analysis}

This section presents the factor analysis for the participants' approaches to learning using 11 items adopted from Biggs et al. (2001). The analysis confirmed that there are two factors related to approaches to learning: deep and surface learning. Factor analysis was used to evaluate the validity of this part of the questionnaire. As a result, the deep approach to learning included six items while the 
surface approach to learning included five items. Table 21 shows the list of loadings. Table 19

Item Factor Analyses for Students' Approaches to Learning

\begin{tabular}{lll}
\hline Item Number & \multicolumn{2}{c}{ Factors } \\
\cline { 2 - 3 } & Factor 1 & Factor 2 \\
\hline Deep Approach & .512 & -.269 \\
17 & .523 & .148 \\
19 & .841 & .033 \\
21 & .638 & -.336 \\
23 & .537 & -.276 \\
25 & .616 & -.086 \\
27 & & \\
& & \\
Surface Approach & & .650 \\
16 & .080 & .556 \\
18 & -.134 & .778 \\
20 & -.276 & .650 \\
24 & -.124 & .510 \\
26 & -.039 & \\
\end{tabular}

Rotation $=2.137$; Kaiser-Meyer-Olkin Measure $(\mathrm{KMO})=0.572$; Bartlett $\mathrm{p}<.001$; Eigenvalue factor $1=$ $3.163 ; 28.754 \%$ variance explained; and $\mathrm{n}=62$.

The factor analysis indicated that KMOs for deep and surface approach to learning was 0.572 , and the Sig. was .000 . This approved the construct validity of this part of the questionnaire investigating the participants' approaches to learning. The reason behind this claim is that $\mathrm{KMO}$ is above 0.50 , and the Sig. scale is less than .05 . Further to this, factor loadings estimated for all items is above .5. Therefore, the evidence supported the validity of this part of the questionnaire. The following tables show scale factor analysis for approaches to learning. 
Table 20

Factor Analysis for the Deep Approach to Learning

\begin{tabular}{ll}
\hline Item Number & Factor \\
\cline { 2 - 2 } & \\
\hline 17 & .631 \\
19 & .427 \\
21 & .804 \\
23 & .667 \\
25 & .508 \\
27 & .619 \\
\hline
\end{tabular}

No rotation because of a single factor and Kaiser-Meyer-Olkin Measure $(\mathrm{KMO})=.602$; Bartlett $\mathrm{p}<.001$; Eigenvalues $=2.352 ; 39.197 \%$ variance explained, and $\mathrm{n}=69$.

Table 21

Factor Analysis for the Surface Approach to Learning

\begin{tabular}{lc}
\hline Item Number & Factor \\
\cline { 2 - 2 } & \\
\hline 16 & .818 \\
18 & .745 \\
20 & .563 \\
24 & .554 \\
26 & .553 \\
\hline
\end{tabular}

No rotation because of a single factor and Kaiser-Meyer-Olkin Measure $(\mathrm{KMO})=.635$; Bartlett $\mathrm{p}<.001$; Eigenvalues $=2.205 ; 36.742 \%$ variance explained, and $\mathrm{n}=69$.

The KMOs for deep, and surface approaches to learning were .602 and .635 respectively. The Sig was .000 for both scales.

\section{The Reliability of the Scales in the Questionnaire}

Now that construct validity of all three parts of the questionnaire has been confirmed, the reliability of the scales is discussed in detail. Hair et al. (2006) clarified what reliability was, and they suggested a common way to measure it. According to them reliability is different from validity as it relates not to how 
something is measured not what should be measured. They also asserted that the reliable measures are those, which will remain consistent in their values if multiple measurements are taken. They claimed that internal consistency is a more common method to measure reliability. According to them, it refers to the consistency among the variables in a scale, and individual items should be highly inter-correlated to measure the same construct. To make sure of this, they suggested reliability coefficient measurement to assess the consistency of the entire scales with Cronbach's alpha. In a reliable scale, alpha should be above .70; however, in journal articles, it is common to see one or more scales have lower alphas, for example, .60.69 (Leech et al., 2005).

Table 22 lists the reliability of each scale of the questionnaire using Cronbach's (1951) coefficient alphas. Alpha coefficients of the samples in this research demonstrated moderate to high levels of internal consistency for all scales Therefore, the reliability values were indicator of an acceptable level of internal consistency for all the scales except appropriate workload.

For all the scales but workload there is a range of plausible estimates of scale reliability, which are acceptable. Increasing the number of items increases the reliability value (Hair et al., 2006). The small number of items in the Appropriate Assessment and the Appropriate Workload scales may help explain the lower reliabilities of these scales. Since one issue in assessing Cronbach's Alpha is its positive relationships to the number of items in the scale (Hair et al., 2006) the low reliability value for this particular scale may be understood. Furthermore, the second factor analysis showed that relationship between appropriate workload and the other scales is consistent with the results of the previous research. Therefore, taking the 
lack of numbers issue and the results of previous research into consideration, the low reliability for this scale is understood.

Table 22

Reliability Estimates of the CEQ Scales

\begin{tabular}{ll}
\hline Variables & Cronbach's Alpha \\
\cline { 2 - 2 } & \\
\hline Conceptions of E-portfolios & .874 \\
Good Teaching & .752 \\
Clear Goals & .730 \\
Appropriate Assessment & .617 \\
Appropriate Workload & .545 \\
Deep Learning & .672 \\
Surface Learning & .658 \\
\hline
\end{tabular}

Table 22 lists the reliability of each scale of the questionnaire using Cronbach's (1951) Coefficient Alphas. Alpha coefficients of the scales in this research demonstrated moderate to high levels of internal consistency for all scales. Therefore, the reliability values were an indicator of an acceptable level of internal consistency for all the scales except appropriate workload, which was marginally acceptable.

Increasing the number of items increases the reliability value (Hair et al., 2006). Lack of number of items may be a reason for marginal reliability in the appropriate workload scale as this scale included only two items. Since one issue in assessing Cronbach's Alpha is its positive relationships to the number of items in the scale (Hair et al., 2006), the low reliability value for this particular scale maybe understood. Furthermore, the second factor analysis showed that relationship between appropriate workload and the other scales is consistent with the results of 
previous research. Therefore, taking the lack of numbers issue and the results of previous research into consideration, the low reliability for this scale is acceptable.

\section{Correlation Analysis of Aspects of the Participants' Learning}

The associations between the scales were explored through a correlation analysis. Pearson correlational analysis was conducted between the participants' conceptions of the e-portfolio, perceptions of the teaching and learning environment (measured by the scales of the modified CEQ) and reported approaches to learning (measured by deep and surface subscales of the SAL). Correlation coefficient shows "the strength of the association between any two metric variables when the Sig (- or + ) indicates the direction of the relationship" (Hair et al., 2006, p. 171). "The value can range from +1 to -1 , with +1 indicating a perfect positive relationship, 0 indicates no relationship and -1 indicating perfect negative or reverse relationship" (Hair et al., 2006, p. 171). The following table shows the Pearson correlation of the key aspects of the participants' conceptions of e-portfolios, their experiences in the e-portfolio based unit, and their approaches to study. The asterisks $(*, * *)$ or $P$ values indicate that 12 of these 21 coefficients were statistically significant.

The results of the correlation analysis revealed that there were substantial and statistically significant positive associations between conceptions of the e-portfolio with good teaching, clear goals, and the deep approach to learning $(.365, .420$, and $.442, \mathrm{p}<0.01$ respectively) while it showed a statistically significant negative correlation with a surface approach to learning $(\mathrm{r}=-.376, \mathrm{p}<0.01)$. However, surface approach to learning revealed statistically significant negative associations with appropriate workload $(\mathrm{r}=-.310, \mathrm{p}<0.05)$ and appropriate assessment $(\mathrm{r}=-.230$, $\mathrm{p}<0.05)$. However, these correlations need to be treated with due caution. The results 
also showed that there were statistically significant negative associations between a surface approach on the one hand and good teaching and clear goals scales on the other ( $r=-.325,-.331$, and $\mathrm{p}<0.05$ respectively). Table 23 presents the detailed information about the correlations. 


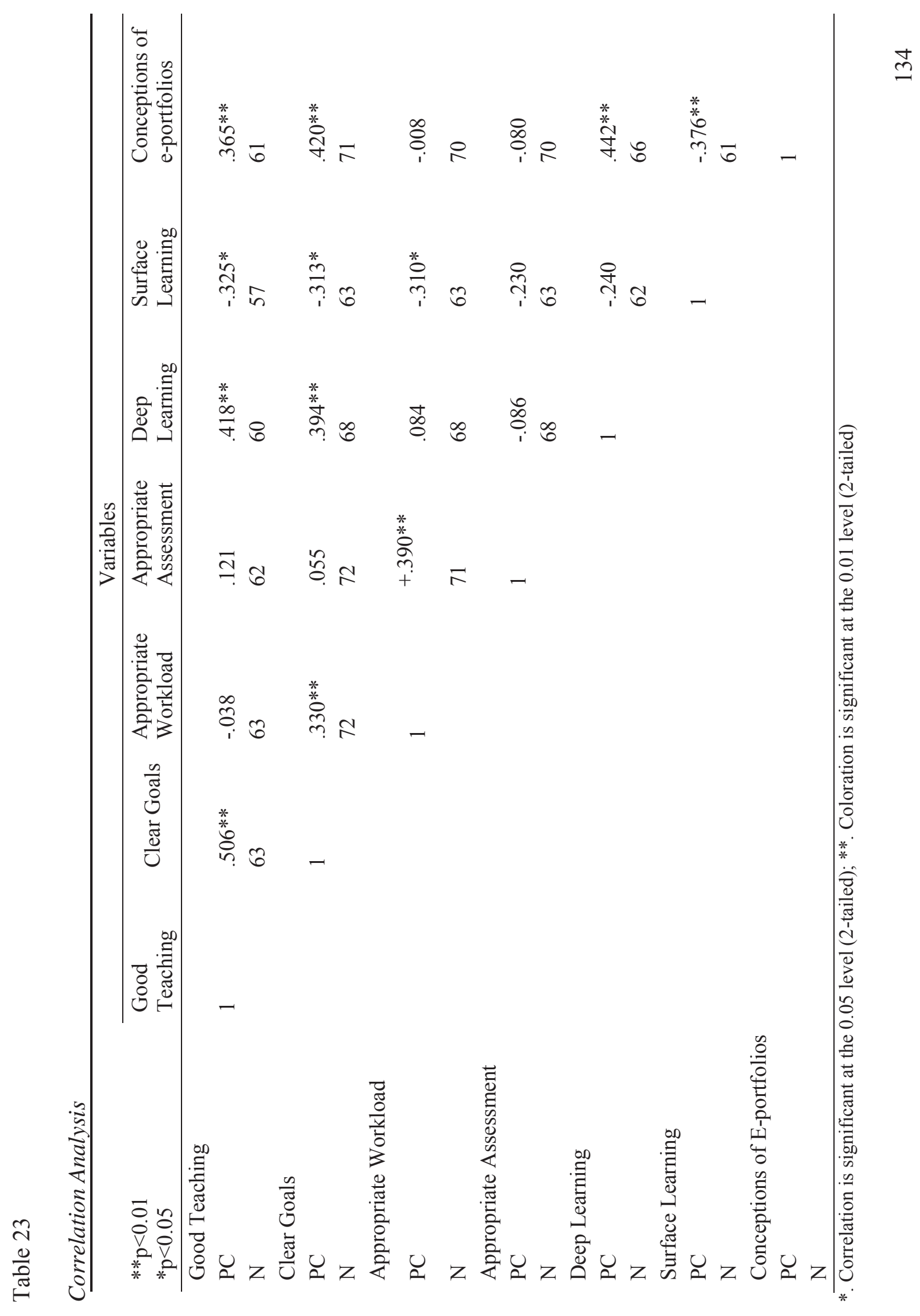




\section{The Second Order Factor Analysis}

The associations between the scales were explored through a second order exploratory factor analysis of the scales. In particular, the second order factor analysis, in this case, is conducted to examine the underlying structure of the scales, not just the relations between pairs of scales. For example, Prosser and Trigwell (1999) used a second order factor analysis to show that there was an underlying structure in the relationship between perceptions of context and approaches to study, with a deep approach being positively associated with good teaching and clear goals and a surface approach being negatively associated with appropriate assessment and appropriate workload.

The findings are discussed according to the result of second order factor analysis in the following paragraphs. The result of second factor analysis is reported below in table 12. $\mathrm{KMO}=.531$ for the second factor analysis, and Bartlett $\mathrm{Sig}<.001$. Most importantly, factor 1 showed high positive loadings on conceptions of eportfolio (.769), good teaching (.729), clear goals (.777) and deep approach to learning (.711). It also showed a high negative loading on surface approach to learning (-.608).. Factor 2 showed negative loadings on appropriate workload (-.799) and appropriate assessment (-.853) and a positive loading on surface approach (.356), but again caution needs to be exercised in drawing conclusion from these results. 
Table 24

The Second Factor Analysis of Conceptions of the E-portfolios

\begin{tabular}{lcc}
\hline Variables & \multicolumn{2}{c}{ Factors } \\
\cline { 2 - 3 } & Factor 1 & Factor 2 \\
\hline Conceptions of E-portfolios & .769 & .096 \\
Good Teaching & .729 & -.071 \\
Clear Goals & .777 & -.213 \\
Deep Learning & .711 & .009 \\
Surface Learning & -.608 & .356 \\
Appropriate Assessment & -.076 & -.853 \\
Appropriate Workload & .197 & -.799 \\
\hline
\end{tabular}

\section{The New Findings in this Research}

The findings from this research contributed to the development of new knowledge as, for the first time, the results show the importance of the PSTs' conceptions in terms of how they approach their learning and how they perceive the quality of teaching, clarity of goals, appropriate assessment and appropriate workload. If students have low-level conceptions of an e-portfolio, they are also likely to adopt surface and not deep approaches to learning, and as previous researches have shown, they are more likely to achieve low-level learning outcomes. It seems that inappropriateness of workload and assessment may be associated with the adoption of a surface approach to learning.

\section{The Results Which Are Consistent with the Previous Research}

Some results from the second factor analysis in the current study were consistent with those found in numerous earlier studies discussed in chapter 2 . In this research, good teaching with the factor loading of .729 was positively associated with clear goals (.777), and a deep approach to learning (.711). In particular, those who scored the good teaching and clear goals scales high (.729, and .777 respectively) also believed the workload was appropriate (.197), and the assessment 
(.076) was more appropriate, and they adopted a deep approach to learning (.711). It confirms that in this research, similar to the findings of the previous researches, better understanding of the context of teaching and learning encouraged most of the participants to adopt a deep approach to learning with the factor loading of .711. Although needing to be treated with caution, Appropriate workload and appropriate assessment (-.799, and -.853 respectively) had negative associations with surface learning (.356).

\section{Conclusion}

This chapter explored PSTs' conceptions of e-portfolios and their perceptions of the e-portfolio-based teaching and learning context in a teacher education unit to investigate the role of their perspectives on adoption of deep or surface approach to learning when using e-portfolios.

The literature review revealed that a number of researchers have already emphasised the role of context in higher education, but this is the first research which picked the e-portfolio-based unit as the context of teaching and learning to investigate the associations between these conceptions and the aspects of students' learning, and the approaches that they adopt according to these conceptions and perceptions.

To do this, a sample of 73 participants used e-portfolios for nine weeks and shared their perspectives through responding to a questionnaire. In the quantitative phase of the research factor analysis was used to describe how different variables of the study grouped in factors. To understand the interrelationship between various aspects of the PSTs' learning experiences in the e-portfolio based unit, an item factor analysis and a Pearson correlation were conducted. Correlation coefficients were computed to test the degree of relation between factor loading on the scales of the 
conceptions of the e-portfolios, the participants' perceptions of the teaching and learning, and their approaches to studying. In particular, the item level factor analyses were conducted to confirm the construct validity of the various scales in the study. The reliability of the scales was confirmed using Chronbach's Alpha. The association between the scales was explored using a correlation analysis and a second order factor analysis.

The correlation and second order factor analyses is that conceptions of eportfolios are positively related to good teaching, clear goals, deep approach to learning and negatively related to surface approach to learning. However, conceptions of the e-portfolios and deep approach to learning are not associated with appropriate workload and appropriate assessment, and only surface approach to learning is related to these two variables. It means that the participants, who showed higher-level conceptions of e-portfolios, reported high quality of teaching, and clarity of goals. It confirmed the association between higher conceptions of the eportfolios and a higher quality of experience in the unit, and, as a result, adoption of a deep approach to learning. In particular, participants were more interested in making meaningful conclusions for interesting topics through reflection rather than reproduction of tasks for the purpose of passing the final exams. The response to the questionnaire indicated that the participants who were more likely to use the eportfolios to complete task, believed that the goals were unclear, and the teaching quality was not high. The analyses indicated that the participants' perceptions of the context are associated with their experience of the teaching and learning in the unit, and also the adoption of their approaches to learning. 


\section{Chapter 6: Discussion and Conclusions}

\section{Purpose of the Thesis}

My $\mathrm{PhD}$ research investigated "The Role of E-Portfolios in Higher

Education: The Experience of Pre-Service Teachers". PSTs in their final year of the teacher education program at an Australian university are currently using eportfolios to assist them in collating evidence to meet the teaching standards. Qualitative and quantitative data were collected according to the epistemology and the theoretical framework of the research. This data was analysed to address the research questions. The results from the qualitative analysis indicated that the adoption of e-portfolios may enhance reconceptualisation of the teaching standards because using an e-portfolio seemed to facilitate reflection on coursework, internship, practicum and teaching practice in the process of becoming a teacher. However, there was variation in the academic achievement of the participants. In particular, participants who mainly expected their lecturer to help them with the physical aspects of the e-portfolio implementation achieved different learning outcomes from those who perceived the role of the lecturer as a constant feedback provider, and a person who challenged their philosophy of teaching through posing different questions and building conversations. These conceptions and perceptions deeply influenced the strategies the participants used, the motives they held, and what they did when using the e-portfolios. Therefore, the role of participants' conceptions of the technology used in the learning environment, and their perceptions of the teaching and learning context were highlighted.

The reason behind this claim is that parallel with the results of previous researchers as discussed in chapter 2 , the findings of the qualitative analysis in the current research found that higher conceptions and perceptions were associated with 
a deep approach to learning which is associated with higher learning outcomes. The qualitative results also indicated that two participants deviated from the common pattern as they altered their approaches to learning in the course of using their eportfolios during the semester. Therefore, this change contributed to adding a research question in this research, as it was important to investigate the rationale behind the participants' alteration of their approaches. In order to achieve this goal a case study was conducted for these participants.

Results from the quantitative phase of the study confirmed that PSTs' experience in the e-portfolio-based unit was associated with their conceptions of eportfolios. Another influential factor was the quality of their perceptions of good teaching, clarity of their goals, appropriateness of workload and assessment. Parallel with the results of qualitative analysis in this study, the quantitative correlation analysis confirmed that higher conceptions of e-portfolios are associated with the adoption of a deep approach to learning.

\section{Overview of this Thesis}

The research design underpinning this thesis allowed an investigation of the role of e-portfolios in the undergraduate and postgraduate teacher education units at the selected University in Australia. The Faculty of Education has stable and wellestablished e-portfolio-based units already in place. At the beginning of the semester, the participants' pre-conceptions of their e-portfolios and pre-perceptions of the teaching and learning context, their pre-approach to learning and their preperceptions of learning outcomes were examined through conducting a preinterview. In week 9 of the semester, the participants' post-conceptions and postperceptions, their post-approach to study, and their post- perceptions of learning outcomes were investigated through conducting a second round of interviews. At 
this stage the piloted questionnaires were distributed to explore how the participants conceived e-portfolios, how they perceived their teaching and learning context, and their approaches to learning after their exposure to the e-portfolios.

Using the participants' responses to pre- and post-interviews at two points in their study in the unit titled "Preparing for the Profession" provided an opportunity to explore their perspectives during this time frame and to investigate their possible changes after nine weeks of e-portfolio implementation. As a result, the thesis provides a grounded theory analysis of why a few participants demonstrated qualitatively better or poorer learning outcomes. Each chapter of the thesis provided a detailed discussion of the main issues.

Chapter 1 described the main arguments of the thesis. It discussed the use of e-portfolios in higher education, and the implementation of e-portfolios for students. Therefore, the research questions were developed to investigate significant variation in the participants' experience of this e-portfolio-based context. Research aims, justification and significance of the research, the ethical considerations and research methodology were discussed.

Chapter 2 was a review of the e-portfolio literature. It revealed that the majority of research and publications in this area emphasised familiarisation with and facilitation of certain aspects of e-portfolios including autonomous, reflective, collaborative and self-regulated learning. Moreover, the discussions around assessment and self-assessment, and the use of e-portfolios in higher education have been presented in the literature review. This chapter also described the use of eportfolios in the teacher education context in Australian higher education. However, the literature review indicated that the effect of PSTs' conceptions of e-portfolios and their perceptions of teaching and learning context on their academic 
achievement have not received the attention it deserves. It also discussed the importance of an investigation of the use of e-portfolios from the students' perspectives. Having identified the gap in the literature, this is the first study which has explored PSTs' perspectives to identify the challenges of e-portfolio implementation in the context of teacher education from the students views, and then, to identify a number of implications for course designers, educators, and PSTs as well as in-service teachers.

Chapter 3 described the basic elements of the research including the epistemology, the theoretical framework, methodology, and methods. It also discussed the development of the instruments used in this research. It discussed the development of the questionnaire, and it presented the results of the piloted questionnaire. Then it described the process of developing the semi-structured pre and post- interviews. Finally, the data collection and data analysis procedures were discussed in detail.

Chapter 4 focused on the qualitative results to reveal the variations in the participants' learning experience in the e-portfolio-based teacher education unit. According to the qualitative analysis the participants' conceptions of the e-portfolios, perceptions of their teaching and learning context, and their approaches to learning, and, finally their learning outcomes derived from their responses, were developed. A number of categories and themes were drawn. The qualitative analysis indicated some associations amongst the categories, and it also showed that two participants deviated from the common pattern. Therefore, a case study was conducted to explore the rationale behind the two PSTs adoption of alternative approaches to learning.

Chapter 5 quantitatively described the interrelationship of the participants' conceptions of the e-portfolios, their perceptions of learning experiences, and their 
approaches to learning in the e-portfolio-based unit. The factor item analysis identified the structure for the aspects of the participants' learning. The factor analysis study and ensuing correlation provided important knowledge. They indicated that conceptions of e-portfolios were positively correlated with good teaching, clear goals, and deep approach to learning and negatively correlated with surface approach to learning. It also revealed that conceptions of e-portfolios and deep approach to learning may not be related to appropriate workload and appropriate assessment.

Chapter 6 includes the overall discussion and the conclusions of the thesis. It includes the identification of challenges and recommendations for the use of eportfolios in higher education, and possible future research.

\section{High Level Findings of this Thesis}

This chapter brings together the combination of qualitative and quantitative analyses to provide the variables investigated.

\section{Qualitative Analysis: Chapter 4}

Qualitative analysis showed that the participants in the e-portfolio-based unit implemented e-portfolios in different ways, and, therefore, the result of the analysis suggested a number of reasons for what was happening. These are major findings for the use of e-portfolios in the teacher education context because they demonstrated that despite the fact that participants were studying in the same contexts, they adopted different approaches to learning, and in turn they achieved different levels of meeting the teaching standards through e-portfolios. A number of students indicated that they implemented the tool to present their teaching competency through reflective thinking, reconceptualisation of their teaching philosophy, and selfregulation. In contrast, a large number of the participants used the tool to complete 
the assignment to achieve a good grade, and they used their lecturers' advice to import the evidence of teaching to the e-portfolios, and, as a result their learning outcomes were limited to learning about the practical aspects aspects of e-portfolios and the development of ICT skills rather than professional development as PSTs. That is why some students reported a higher quality of experience than others, and that there existed some additional contextual factors which could help to explain variation across the context.

\section{Quantitative Analysis: Chapter 5}

The conclusions drawn from factor analysis and correlation in chapter 5 explored the participants' conception of the e-portfolios, their experience in the unit including their perception of quality of teaching, clear goals, appropriate assessment and workload, as well as their approaches to learning. The quantitative analysis in this phase of the study broadly confirmed the associations found in the qualitative analysis. Therefore, after qualitative analysis, consistent associations amongst variables in the participants' conceptions of the e-portfolios, their perceptions of teaching and learning context, and their approaches to learning were confirmed, both in terms of the relatedness of the variables as well as statistically significant results amongst the variables.

A number of findings identified reasons for differences in the student experiences when using e-portfolios, and in turn, their adoption of different approaches to learning. In particular, in the results analysis the participants showed variation in high and low conceptions of the e-portfolios, and perceptions of the teaching and learning context. The results analysis also indicated that the participants, who showed higher conceptions of e-portfolios, reported high perceptions of the context including clarity of goals, high quality of teaching, 
appropriateness of workload, and assessment. These findings confirmed the associations between higher conceptions of the e-portfolios, and a higher quality of experience in the unit, and, as a result, adoption of a deep approach to learning. Therefore, this research provided reasons behind the variation in the quality of the experience in the e-portfolio-based unit, and it also clarified why some students were more successful than others.

\section{Limitations of this Research}

Before looking at the results in detail, it is worthwhile acknowledging the limitations of the research. In this study students enrolled in a Faculty of Education were participants in this study. In particular, only face-to-face PSTs who were enrolled in the unit titled: "Preparing for the Profession" were invited to participate in the research to ensure that they were studying in the same teaching and learning context. There were nine weeks between the participants' responses to the pre and post-interviews. Student assessment results were not available for this thesis and consequently were not one of the variables in this study. Another limitation of this research is that this research did not provide more targeted analysis connecting the characteristics of the actual e-portfolios with the participants' responses.

\section{Summary of the Results: Two Research Questions}

The summary of results is presented through discussing the research questions and responding to the research questions and sub-questions. This research aimed to answer two main research questions and five sub-questions. 


\section{Research Question 1}

This research examined how PSTs perceived the role of e-portfolios in their studies. One of the main contributions of this thesis to the literature is a deeper understanding of the variations in the participants' perceptions of the teaching and learning context. The main perception variables were investigated both in the pre and post- interviews, and the survey. The results from the qualitative phase of the study revealed that there was a variation in the perceived role of the e-portfolios amongst the participants. The results showed that, during the semester, the participants acted according to their perceptions of the teaching and learning context. Most of them perceived that e-portfolios facilitated evidence collection, development of online resumes to apply for a job, and task fulfilment. For example, those who used eportfolios for the purpose of completing the task used it for collection purposes. However, a smaller group of the participants perceived that e-portfolios contributed to demonstrating the kind of teacher they want to be. To do so, they reflected on their weaknesses and strengths, their teaching philosophy, and their internship experiences. They tried to change their teaching philosophy according to their reflection and deeper understanding of the teaching standards. Pre- and postperceptions of the tool seemed to remain constant for all except two of the students throughout the semester. A case study was constructed to explore the underpinning reasons for a change in their perceptions of the teaching and learning context. The result of the study also revealed the consequences for changing of their perceptions. The results of the quantitative analysis showed the variation in the participants' perceptions of the quality of teaching, clarity of goals, and appropriate assessment and workload. There was an association between higher conceptions and perceptions of e-portfolios, deep approach to learning and higher learning outcomes. 


\section{Sub-question 1}

Sub-question one investigated how e-portfolio-based learning has changed the participants' perceptions. The results of the qualitative analysis showed that only 2 of the 13 participants changed their conceptions of e-portfolios, and perceptions of the teaching and learning context after using it for nine weeks. The differing perceptions and conceptions for these two students lead the researcher to conduct a case study to investigate how the use of e-portfolios may have changed the participants' perceptions.

The results of the case study revealed that the changing perceptions on the eportfolio after having meaningful exposure to the e-portfolio encouraged participant 5 to adopt a deeper approach to learning. In particular, the participant's conceptions of e-portfolios improved during the course of studying in the Unit. According the $3 \mathrm{P}$ model of learning which is part of SAL, higher conception of the e-portfolios facilitated conceptual change regarding her teaching, and identification of her weaknesses and strengths in meeting the teaching standards. This participant also mentioned that motivation had an effective role in her learning strategies including planning, monitoring and the metacognitive strategies she applied when using the eportfolio. Therefore, this case study approves the associations amongst SAL, SRL, and higher learning outcomes.

In contrast, participant 8 went from deep perceptions to poor perceptions after the use of the e-portfolio, and used the tool to only complete the required tasks. Participant 8 perceived the e-portfolio as a tool to apply for jobs. The case study revealed the key factors behind the participant's change of their perceptions and in turn their academic achievements. Therefore, the results of the study indicated that the level of participants' prior knowledge, their motives for undertaking the 
strategies, the quality of teaching, and e-portfolio development and their integration with the unit are influential factors in shaping and changing the participants' perceptions of the context of teaching and learning. These influential factors are discussed below in detail.

\section{Level of Prior Knowledge (the 3P model)}

The results drawn from the case study showed that the level of prior knowledge affected the participants' perceptions. In particular, their tendency to higher conceptions of the e-portfolios and perceptions of the teaching and learning context depended on the level of prior knowledge. For example, in the postinterview with participant 5 , there was a shift from a surface to deep approach in this unit. It was revealed that the participant had used an e-portfolio in previous units, and her appropriate level of prior knowledge contributed to the participant building on new knowledge. A number of studies (Schmidt, De Volder, De Grave, Moust, \& Patel, 1989; Brand-Gruwel, Wopereis, \& Vermetten, 2005) have already discussed prior knowledge and its associations to higher learning outcomes.

\section{Redirecting Students'Strategies and Motives (SRL)}

Parallel with having an appropriate level of prior knowledge, strategies and motives that students' use may change their perceptions of the context. Particularly, students may use the same activities with different motives. For example, the result of the case study showed that participant 5, adopted a deep approach to learning in this unit, used reflective thinking to reflect teaching competency when SRL encouraged appropriate the motives and strategies which were associated with a deep approach to learning. Interestingly, the qualitative analysis revealed that almost all of the participants, even the surface learners in this unit, mentioned that they reflected on their learning. However, when the researcher asked them what they meant by the 
words reflection, understanding, learning, improvement, and progress, they used different meanings. This indicated that students might use the same strategy with different motives for the purpose of reproduction, or development. It appears that supporting students to apply the correct motives and strategies through negotiation, instruction, and discussions during the tutorials and lectures, and constantly providing insightful feedback, as well as formative assessment during the semester, may change their perceptions for the better when using e-portfolios. The results of the research confirmed that better strategies and motives are associated with higher perceptions of the e-portfolios as the result of qualitative analysis showed that students who adopted a deeper approach to learning used better strategies and held higher motives for those strategies. Therefore, it confirms the association between higher perceptions, a deep approach to learning, and higher strategies and motives, and therefore, if teaching staff encourages students to create and maintain better motives and strategies when using e-portfolios, it may facilitate higher perceptions of e-portfolios. Structuring the context of teaching and learning in an e-portfoliobased unit or course is vital in structuring the students' perceptions for the better.

\section{The Role of High Quality Teaching}

Encouraging students to set clear goals, to become engaged with learning activities effectively, and to have and to maintain higher perceptions of their role may contribute to having higher perceptions of the e-portfolios. In particular, the ways that teachers present the purposes of e-portfolio implementation, and the skills, which students are supposed to achieve at the end of the unit, play an important role in students' higher perceptions of the tool. This means that in the future teaching staff should assist students to differentiate between poorer and higher perceptions of e-portfolios through providing activities that enhance their perceptions. The result of 
this research indicated that participants who had higher perceptions of their role as a student, perceived that the assessment method used by the teaching staff fitted the nature of the unit and its objectives. Therefore, they perceived that e-portfolios were well integrated into the unit, and the assessment was appropriate. As a result, the quality of teaching in an e-portfolio based environment may influence students to have higher perceptions of the e-portfolios.

\section{Integration of E-portfolios with the Unit}

Most of the participants in this research mentioned that e-portfolio implementation was integral to the unit as it facilitated reflection, professional development, and showcasing their teaching competence. However, a number of participants believed that e-portfolios were not well integrated into the unit as there were two different emphases in the lectures and the tutorials during the semester. The objectives in these two different sets of teaching content were not explicitly related to the assignment.

In this unit most of the participants' pre and post -perceptions of e-portfolios remained the same and a large number of them mainly used the tool to apply for a job. In such an environment the participants were not encouraged to reflect on their philosophies of teaching, their teaching strategies, and their learning outcomes. Consequently, it seems that reflections did not receive the attention they were intended to. This shortcoming may encourage students to hold poorer perceptions of e-portfolios during and after implementation. Therefore, the results of this research highlight the role of teaching staff in the integration of e-portfolios with the unit to guide the participants in the right direction. Applying appropriate tasks, setting appropriate assessment methods, and ensuring the appropriateness of workload motivates the students to reflect, assess and monitor themselves. In this case students 
may use e-portfolios for professional development rather than fulfilling the tasks to simply pass the unit. In this unit, for example, a summative method of assessment was used at the end of the e-portfolio development, and the participants did not receive any feedback on their e-portfolios from the teaching staff until their final assessment was due, and therefore, it seems that they lost the opportunity to progress during the semester. Consequently, most of the students had poorer perceptions of the tool after implementing e-portfolios.

\section{Sub-questions 2}

Sub-question 2 examined which factors lead to adopting a deep approach to learning when using e-portfolios. The results from the quantitative analysis showed that the participants who had higher perceptions of teaching and learning context believed that the teaching was good, underlying perceptions of the goals of the unit were clear, and the assessment and workload were appropriate. Positive perceptions of the goals, teaching, were related to the deep approach to learning. In this research,

- A deep approach to learning was closely associated with high pre and postconceptions and pre and post-perceptions of e-portfolios;

- A deep approach to learning was closely associated with SRL, and the use of metacognitive activities including monitoring, planning, reflection, and appropriate level of motivation for learning.

- A deep approach to learning was closely related to a high quality experience in the e-portfolio-based unit when the aspects of the participants' experiences included:
a. Good teaching,
b. Clear perceptions of the goals
c. Appropriate assessment and workload. 
The results discussed identified the links between deep approaches to learning in an e-portfolio-based context with higher conceptions of e-portfolios, perceptions of the context, and higher quality experience in the unit have not been reported in the literature previously.

\section{Sub-question 3}

Sub-question 3 examined which factors lead to adopting a surface approach to learning when using e-portfolios. One of the main contributions of this thesis to the literature is the more detailed understanding of the structure of variation in the participants' conceptions of e-portfolios investigated through the qualitative aspect of the research. This was replicated in the quantitative phase of the research. It is significant that both the qualitative and quantitative results in chapters 4 and 5 confirmed the existence of different conceptions of e-portfolios and perceptions of context amongst the participants. However, the results of both phases of the analysis in this thesis found that a larger number of the participants had relatively poor conceptions and perceptions both at the beginning and at the end of the unit, which is associated with adoption of a surface approach to learning.

\section{Research Question 2}

This research investigated how PSTs implemented e-portfolios to facilitate high quality learning in the higher education. The results of chapter 4, introduced, for the first time, the positive relationship amongst the high conceptions of the eportfolios, high perceptions of the context, deep approach to learning, and higher learning outcomes in an e-portfolio-based unit. Previous researchers and also the findings in this research revealed that there is an association between a deep approach to learning and higher learning outcomes. Therefore, it is important for teachers to help students to set clear goals for themselves. The nature of assessment 
should fit the objectives of the unit, and the workload should be appropriate.

Consequently, these factors may contribute to facilitating high quality learning in the context of higher education.

\section{Sub-question 1}

Sub-question one examined the role of e-portfolios in effective learning. The results of the study revealed that holding higher conceptions and perceptions and having prior knowledge, and high quality teaching around the implementation of the tool besides clear goals are associated with a deep approach to learning. A deep approach to learning was associated with quality learning outcomes, academic success, and effective learning.

\section{Sub-question 2}

Sub-question 2 investigated how students gained knowledge through using eportfolios. Chapter 3 of the thesis explored e-portfolio-based learning within a theoretical framework (Babaee et al., 2014) combining constructivism (Dewey, 1929), SAL, the 3P model of learning and SRL in order to gain a deeper understanding of how PSTs learned when implementing e-portfolios. SAL indicates how students perceive and understand the role of e-portfolios in their learning and how this affected adoption of a deep or surface approach to learning. The 3P model of students' learning structures different variables in e-portfolio-based learning, and SRL explored the role of motivation and also the importance of teaching and learning context on students' learning. Therefore, constructivism, SAL, the 3P model and SRL, create the theoretical framework for e-portfolio-based learning in the context of higher education.

The results of the quantitative analysis revealed that the participants who had high conceptions of the e-portfolios in terms of enhancement of active involvement, 
independent learning, networking, learning ownership, and motivation, as well as appropriate learning styles, were more likely to adopt a deep approach to learning which is associated with higher learning outcomes. The reason behind this claim is that in this research, the participants with higher perceptions of e-portfolios also asserted that teaching quality was high, goals were clear, and assessment and workload were appropriate. Therefore, this research clarified how the participants obtained knowledge when using e-portfolios. They tried to achieve teaching standards by the use of e-portfolios during the course of a semester. The qualitative analysis showed that deep learners in this unit used e-portfolios as a reflective tool, and they tried to reflect on their four years of being a PST as well as their practicum period to provide evidence for their teaching competency. A number of the participants believed that e-portfolios allowed them to reconceptualise their understanding of teaching as they could reflect on their weaknesses and strengths they could highlight the areas they needed to practice more, and, as a result, they gained knowledge to reflect on the teacher they wanted to be.

\section{The Implications of the Results to Design E-portfolio-based Units}

This section discusses the implications of the results for program designers, e-portfolio coordinators, and lecturers to ensure quality in the teacher education programs when using e-portfolios. The identification of barriers to e-portfolio implementation is discussed, and solutions are proposed. The findings of the research aimed at improving the participants' experience of e-portfolio-based learning may be transferable across higher educational contexts. Therefore, it seems that those concerned with the efficiency of the use of e-portfolios in higher education may find the following obstacles. 


\section{A Surface Approach to Learning}

Prosser (2000) asserted that learning achievements depends on the students' perceptions towards the aims of the new technologies in their learning. The theoretical framework in this research stressed that the experience and development of the e-portfolios was orientated towards the participants' perspectives rather than from the unit coordinator's standards or the university lecturers'. Peterson (2004) asserted that a critical period for successful program implementation to enhance students' learning is before the students start. The research results indicated that the qualities of the post-conceptions of e-portfolios were related to the quality of the participants' prior knowledge and their pre-conceptions of the e-portfolios. The reason is that the majority of the participants held low pre-conceptions of eportfolios and pre-perceptions of teaching and learning context on entry and on completion of the unit. Only two students changed their post-approaches to learning on completion of the unit. As a result, the maturation of the participants' conceptions of e-portfolios and their perceptions of the teaching and learning context are ongoing and fundamental challenges. The challenges of helping students to recognise and approach e-portfolios as a reflective practice cannot be underestimated or assumed to be non-problematic. Fortunately, this thesis suggests that the conception and difficulties that the participants seemed to face in the e-portfolio-based unit were comparable across most of the students, so that remedies are also likely to be helpful for most of them.

In order to resolve the issues, it is required for designers to encourage a deep approach to learning through embedding instruction within the task that is likely to encourage students to reflect, self-assess, and undertake ongoing monitoring. The desirable conceptions of e-portfolios such as promoting the culture of reflection for 
reconceptualisation of teaching standards, and identification of the weaknesses and strengths through ongoing monitoring during studying in the unit can be used as a fundamental construct to inform the design and teaching of students in the eportfolio-based learning to structure a more appropriate context. When using eportfolios, teaching staff should enable students to understand the difference between lower and higher conceptions and perceptions through providing activities to contribute to their reflections and ongoing monitoring. Provision of insightful feedback on the students' activities, and redirecting the motives associated with a surface approach to learning are important to secure their transition from a surface to a deeper approach to learning. In this way, teaching staff may also help students to gain an appropriate level of prior knowledge so that they build their new knowledge after having meaningful exposure to e-portfolios. The students need to understand how to develop their understanding through benefiting from reflection through eportfolios. The resistance to this aspect of e-portfolios is likely only to be addressed if course designers address it to reshape students' approaches towards deep learning, and also to explicitly address their pre-conceptions and pre-perceptions on entry to the unit or course. The goals and standards of the e-portfolio-based program should be clearly articulated in the design of tasks given to the students. Assessment methods should be aligned with the unit objectives. Appropriate workload is another essential factor to develop higher perceptions of teaching and learning context for the students.

\section{Developing Students' Motivation}

Teaching staff are able to give motivation and encouragement to students as the quality and quantity of an educator's support may lead to higher engagement and satisfaction amongst the students (Salmon, 2000). SRL theory of learning focuses on 
the associations between motivation and higher learning outcomes. In short, the role of the teaching staff in using e-portfolios is very important as it may determine the quality of the e-portfolios and the performance of students in self-assessment and independent and reflective learning. It is, therefore, essential to provide training for the educators relating to how to help learners to engage in e-portfolio based activities including reflection (Kabilan \& Kahn, 2012).

\section{Helping Students Master the Use of Technology}

The result of this study showed that a large number of the participants used e-portfolios for the first time, and therefore, it is necessary to provide support for them in terms of ICT skills. However, the participants who had used the tool before were more confident in terms of developing their e-portfolios. As a result, having an appropriate level of ICT skill would be helpful.

\section{Integration of the E-portfolios into the Unit}

As presented in chapter 2, there are different types of e-portfolios available for educational purposes including: documental e-portfolio; assessment e-portfolio; process e-portfolio; record e-portfolio; work e-portfolio; course e-portfolio; reflective e-portfolio; structured e-portfolio; e-learning portfolio; and developmental e-portfolios (Carlson, 1999; Cole, Ryan, \& Kick, 1995; Danielson \& Abrutyn, 1997; Greenberg, 2004; Tillema \& Smith, 2000). Tosh, Light, Fleming, and Haywood (2005) suggested that an institution, or a course, is required to examine the learning outcome of using e-portfolios to ensure that the e-portfolio is aligned with the rest of the course. They emphasised that students need to know why the tool is useful, and why they are doing this. Therefore, implementing appropriate task development to encourage reflections through developing the most appropriate type of e-portfolios is 
proposed. In this research, for example, assessment e-portfolios were used. The participant did not receive any formative feedback for their e-portfolios.

\section{Appropriate Task Development}

The results of this thesis suggest that the design of tasks for students should be taken into consideration. The tasks should have specific content to address the particular goal, and the goal should be clear for the students. Further to this, the tasks should be integrated according to the evidence-based research such as the results of this thesis to increase the quality of students' experience through encouraging them to adopt a deep approach to learning to improve their understanding of the issues being studied.

\section{Requirement for Appropriate Level of Reflection}

Another challenge in using e-portfolios is the requirement for reflection; this needs to be approached with great care, as it requires students to reflect on their weaknesses for the purposes of later evaluation. The risk of insincere reflections in this situation is very high (Meeus, Questier, \& Derks, 2006) because without a focus on reflection, e-portfolios may become a simple collection of information rather than an approach for achieving knowledge (Zubizarreta, 2004). E-portfolios can increase reflection, develop content and pedagogy skills and facilitate communication (Shepherd \& Skrabut, 2006). Students need reflection to showcase evidence of assessment, lesson plans, and presentations to process information and develop professional skills gleaned from their pre-service courses (Napper \& Smith, 2006).

In the unit under study, the participants were required to reflect on their teaching practice and years of studying in the course to write their teaching philosophy. They were asked to reflect on their learning with reference to selected graduate teacher standards from AITSL's framework. . The participants were 
advised to collect relevant artefacts representing their own work, students' evaluation and assessment all of which was valuable in the development of their eportfolios. Here is an example related to the participants' reflection form postinterviews.

Post-interview: Reflection helped me to understand how much I have learned and also demonstrate in terms of assessment or teaching strategies and observing other teachers teaching, and it helps me to think can I do as a teacher or not. It helps on self-obedience, not sure it helps my learning but only self-obeisance and self-reflection. It makes me more understand 8th standard and what criteria I have to address as a teacher. It helps me to keep in mind, try to keep me understand as a teacher you have to align with this. I understand professional knowledge and practice bad engagement and what I have to do when I'm a teacher. How I can address the standard and knowledge and how I deliver knowledge to student. It help me to learn the standards, it helped me in the first year as well, but here we have to more explicit on how we have shown the evidence in the standards required for the teaching standards”.(Participant 1)Post-interview: I reflected as I was looking deeply at the standards and I was thinking about what I can do well. What areas I need to improve. I think it was good to have different requirements and think about what I might miss. (Participant 2)

Post-interview: I think you reflect when you are doing the work because we have to provide evidence of things we are matching with criteria. I'm reflecting back on my works in 4 years in Uni and it is a good form of reflection. (Participant 7) 


\section{Implementing the Most Appropriate Type of E-portfolios}

As discussed in chapter 3 Vygotsky's sociocultural theory of human learning was used as a type of constructivism in this research. The major theme of Vygotsky's theoretical framework is that social interaction plays a fundamental role in the development of cognition as Vygotsky believed everything is learned on two levels (Vygotsky, 1978). First, through interaction with others, and then integrated into the individual's mental structure. In the unit under study, although the participants did not share their e-portfolios formally, there were opportunities for incidental collaboration as the participants might ask for help, or they could possibly share their ideas and perceptions towards e-portfolios informally. Moreover, during the lectures, students answered lecturers' questions collaboratively, and they shared their ideas in the face-to-face class. Therefore, collaborative learning was possible for these participants and therefore Vygotsky's sociocultural theory was applied in the students' learning. The qualitative phase of the research and the PSTs' responses to the interview questions proved that they had experienced informal collaboration. However, in the unit under investigation assessment e-portfolios were applied. In the post-interviews students mentioned that they did not start developing their eportfolios from the beginning of the unit as it was a summative assessment portfolio, and therefore, they lost the chance to receive ongoing feedback from the lecturer, and the design of the e-portfolios for this unit did not allow students to provide comments for peers. They had less time to develop their e-portfolios during the semester, and they focused on completing the task near the end of the semester. However, the students were supposed to show their progress over time as they were studying in the unit to develop their teaching competency and professional 
development. Therefore, it seems that this summative e-portfolios assessment did not support students to achieve this goal.

Course designers should consider that higher conceptions and perceptions of eportfolios may depend on the implementation of the most appropriate type of the eportfolio as different types of them cater for different goals, objectives and assessment methods. For example, implementing the wrong type of e-portfolio may end in inappropriate assessment. Therefore, it is really important for the course designers to implement the type of the e-portfolio, which fits the nature of the tasks and objectives of the unit or course.

\section{Time Constraint Issue}

Wetzel and Straddler $(2005,2006)$ also stressed the amount of time and effort expended as a challenge in e-portfolio-based learning. Gülbahar and Tinmaz (2006) asserted that, in terms of contact hours and tasks, any work associated with eportfolios should substitute similar face-to-face activities to solve time constraint issues. Therefore, it is of importance to determine workload and time constraints (Stefani, Mason, \& Pegler, 2007) to improve students' conception of e-portfolios.

\section{Appropriate Workload}

Moon (2004) claimed that e-portfolios were time consuming to create, maintain and evaluate. The result of the quantitative analysis revealed that the participants' perceptions of appropriate workload were associated with a deep approach to learning. The way students adopted different approaches to learning in the technology-enhanced environment affected their outcomes (Prosser, 2012). For example, the current study showed that the participants' adopted a surface approach to learning when they perceived that the workload was inappropriate while using e- 
portfolios. Therefore, ensuring an appropriate workload for the students is an important factor which that influences students' achievements.

\section{Appropriate Assessment}

Over the last few years, there have been calls to move away from the dominance of summative assessment towards a focus on multiple assessments throughout the learning period, combined with rich feedback (Harrison, Könings, Lambert \& Wass, 2017. However, Luce \& Kirnan (2016) asserted that the actual determination of the best assessment method depends on several factors including program learning objectives, program size, course sequence, and institutional resources to support assessment. However, in the unit under study summative assessment was applied. The participants did not receive any feedback until the end of the unit.

Apart from different type of assessment through e-portfolios there are several concerns related to e-portfolio assessment, reliability, validity, assessment rubric, and student assessment ability (Chang \& Tseng, 2009; Barrett, 2010). E-portfolios provide multi-dimensional assessment (Burch, 1999) such as peer assessment, selfand teacher-assessment (Lin, Liu, Feng, \& Yuan, 2001), yet the challenges of eportfolio assessment need to be assessed. Factors such as reliability and validity of eportfolios, and not having precise criteria for evaluating students may lead to difficulties. Learners as unprofessional raters or even teachers newly introduced to eportfolio implementation may cause problems in the learning environment. For example, engaging in new ways of assessment, such as peer and self-assessment, are potential challenges of using e-portfolios. Reliability and validity of e-portfolio assessment is under question due to learners' inadequate assessment skills. Therefore, one of the most controversial issues of implementing assessment e- 
portfolios is reliability and validity. Two aspects of reliability, internal and external, play a significant role in peer assessment. Internal or inter-rater reliability refers to the consistency shown by an individual rater, while external or intra-rater reliability refers to the consistency among distinct student raters (Bouzidi \& Jaillet, 2009). In order to calculate the reliability of e-portfolio based assessment, it is essential to check both the internal and external reliability of e-portfolios. The professional judgment of teachers provides consistent teacher-based scores, and having a large number of well-trained and experienced teachers as raters assures a valid exterior criterion. An exterior criterion including teacher-assessment scores or examination scores can effectively calculate peer-assessment validity (Chang et al., 2011). In order to tackle the issue of reliability and validity, it is necessary to thoroughly train learners to develop an in-depth understanding of portfolio assessment (Oskay, Schallies, \& Morgil, 2008).

\section{Creating a Rubric}

In order to achieve the full benefits of e-portfolios, the following suggestions have been made (Chang et al., 2011). When learners are introduced to a new method of assessment, they need to be educated thoroughly. Learners may not be aware of the goals and reasons for implementing e-portfolios. In order to achieve the full benefits of e-portfolios, the identification of criteria and goals is essential for educators and learners alike. Students need to be aware of the evaluation criteria. Therefore, creating a rubric gives them the standards, and goals that need to be followed. Recognition of these criteria contributes to learners feeling secure and well organised. Reckase (2002) designed a rubric including: 1) the extent to which learners grasps the subject matter; 2) portfolio contents; 3) reflective thinking; 4) the content richness and difficulty; and 5) organisation and presentation. Burch (1999) 
proposed another assessment rubric including e-portfolio layout, self-reflection and documents.

\section{Organising a Well-designed E-portfolio Induction for the Students}

Students enter the learning environment with individual conceptions and perceptions of the context. Although they go through the same e-portfolio based context, each individual may have different conceptions of the e-portfolios and perceptions towards the context of teaching and learning. The result of this research indicated that those participants who did not have any prior knowledge about eportfolios had poorer conceptions of the tool. The results of this thesis suggest that clarifying possible goals and introducing the full potential of e-portfolios though the unit outline, tutorials and lectures may contribute to shaping higher pre-conceptions of e-portfolios and their pre-perceptions of the teaching and learning context which are associated with a deeper approach to learning and high quality learning outcomes. As a result, a well-designed e-portfolio induction may contribute to students having a better impression of e-portfolios. In this way the students may use their prior knowledge to receive new and important ideas to build the new knowledge on.

Through organising the induction, the course designers should offer lecturers and tutors a number of pathways to take to alter poor conceptions and perceptions of e-portfolios. In order to correct misconceptions of e-portfolios and misperceptions of the teaching and learning context the course designers may benefit from some of the literature reviewed and the results of qualitative and quantitative analysis including both examples of poor and deep conceptions in this thesis. 


\section{Alterations in the Development of E-portfolios According to the Case Study}

The participants' responses and direct feedback through the use of two interviews contributed to exploring a number of strategies to remove the challenges of using eportfolios in the context of higher education. It is expected that applying these recommendations provided from participants' comments will set the ground for the professional use of the e-portfolios to address participants' individual needs through flexing their skills and abilities as well as their weaknesses. E-portfolios are meant to be used as a platform for providing the possibility of ongoing assessment, engagement, and collaboration to allow students to become involved with the learning activities meaningfully. Therefore, the following strategies are proposed to achieve these goals.

\section{Lifelong Learning Through E-portfolios}

Most common definitions suggest that e-portfolios should be used to augment and assess growth over time (Parker, Ndoye, \& Ritzhaupt, 2012). In regards to this requirement, participant 5 raised a concern around the lack of opportunity to use the eportfolio from the beginning of her degree:

I would much prefer to start using it from the beginning of my degree, because that way all of the stuff I have I would put straight in the e-portfolio, and if there were some stuff that weren't suited by the third year, or if my philosophy changed, then I could change it. It is something you reflect upon, and goes with time. If they want to use an e-portfolio, and I think is beneficial and modern, then it needs to be something that we can have access to use it forever.

Participant 5 mentioned that "I don't like to put it all in another place especially when we don't get to keep it, and basically it frustrates me more than anything else". 
It shows that this participant was willing to keep using the e-portfolio after

graduation. Participant 6 , for example, mentioned that e-portfolio implementation did not fit into the unit as she was not sure if she could use her e-portfolio after graduation.

For me, to have that expectation that we need to have it all perfect, and do all of these justifications to meet the certain standards of the profession and then not be able to take that with us seems pointless, but I don't think it fits really well unless it's something we could actually keep with us. We pay for the unit, and the thing that we use in the unit we should be able to use when we come out. It seems like the whole point of doing an e-portfolio is to be able to use it professionally rather than just for one unit. (Participant 6)

\section{Perceptions of Schools Hiring Personnel}

Another shared concern of both cases was their uncertainty about the benefit of using an e-portfolio to put a successful job application together. Participant 5 asserted that she had worked with schools, and they prefer something explicit on a page rather than navigating what is in an e-portfolio. Little is known about how school personnel perceive the use of e-portfolios in the hiring of teacher candidates. Interviews with principals, for example, may lead to alterations in the development and implementation of e-portfolios that increase their meaningfulness for students (Parker et al., 2012).

\section{Promoting Motivation to Learn Through E-portfolios (SRL)}

It seems that many factors affect students' motivation to use e-portfolios. As discussed earlier, according to these participants' comments, factors such as being able to use the e-portfolios after graduation, and having prior knowledge around the use of the eportfolio through applying it from the beginning of the degree may increase their motivation to learn through using e-portfolios. Participant 5, for example, touched on having prior knowledge of e-portfolios as she said: "I am not taken with the notion of an 
e-portfolio. I think that's just because we haven't used them enough throughout the course and then all of a sudden we need to know how to navigate it”. In regards to motivation to use e-portfolios, there are two other important influential factors, namely strategies and motives which are discussed below.

\section{Redirecting Students' Strategies and Motives}

Prosser and Trigwell (2004) highlighted two important components of students' approaches to learning as being strategies and motives. They defined strategies as what students do, and motives as what students try to achieve. These researchers discussed how students use different strategies to learn, and their motives play an important role in adopting approaches to learning as they may use the same strategy with different intentions. They emphasised that students may use memorisation to reproduce and rote memorisation for passing exams is associated with a surface approach to learning. Conversely, memorisation can be associated with deep learning if it is used for understanding. Therefore, strategies such as memorisation do not necessarily lead to surface learning. Consequently, students use diverse learning strategies, and adopt approaches to learning depending upon their intentions (see Figure 6).

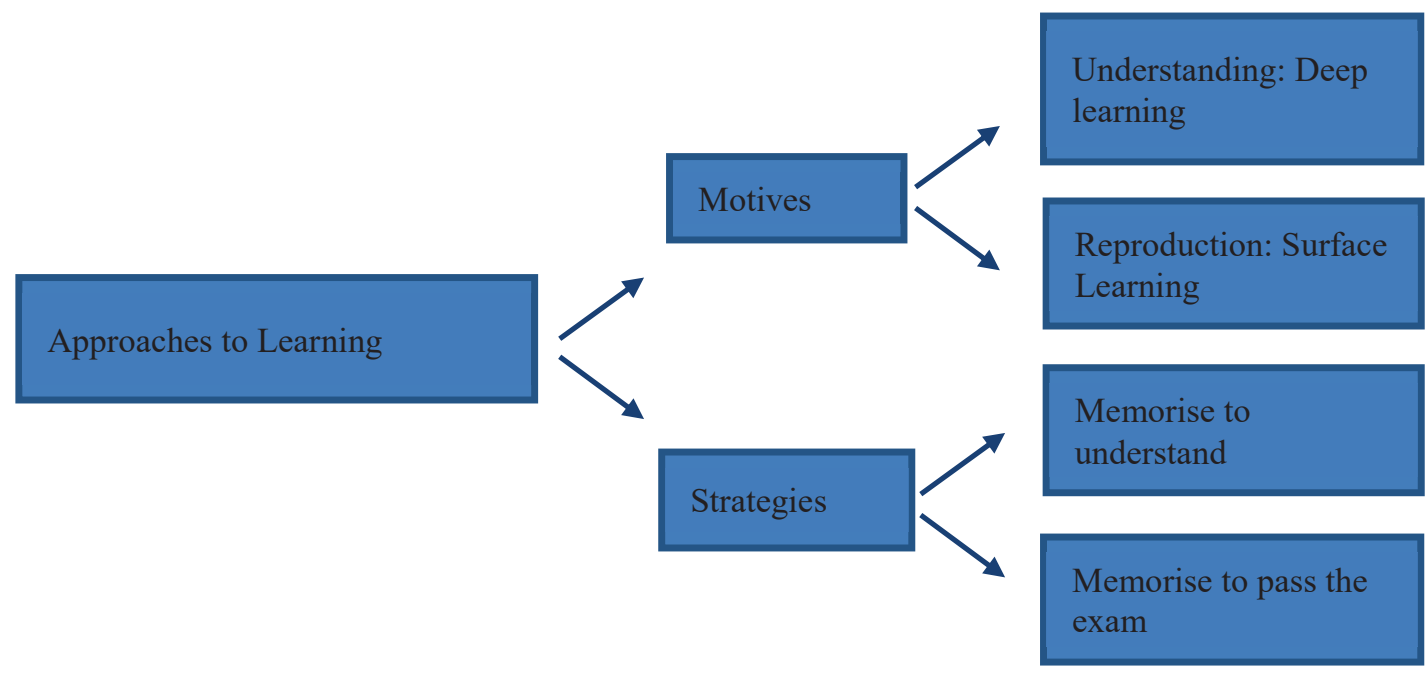

Figure 6. The role of strategies and motives on adoption of approaches to learning 
Choice of approach is generally made in response to the participants' perceptions of course contexts. Therefore, raising students' awareness about the context of teaching and learning through clarifying the purpose of tasks they are required to do, and guiding them to choose appropriate intentions for the learning activities they get involved in, may contribute to encouraging them to adopt a deep approach to learning. In regards to eportfolios, it is possible for lecturers to set clear goals for the students to guide them in the right direction. Another strategy is the provision of formative feedback to monitor students to identify their motives and intentions behind their learning activities when using the e-portfolio. Therefore, the lecturers would be able to recognise students' intentions and motives when using the tool.

\section{Conclusion}

This research showed that there was variation in the academic achievements of the PSTs when using e-portfolios and the result of the analyses confirmed that the learning outcomes in the surface or deep approach to learning responded on the participants' conceptions of the e-portfolios, their perceived role, and the perceptions of their lectures role. In particular, their experience in the course depended on their perception of good teaching, clarity of their goals, and appropriate workload and assessment in the unit. Therefore, these factors seemed to be significantly related what they did, and the strategies they used when using the e-portfolio.

Conclusions drawn from the qualitatively analysed data proposed that the adoption of the e-portfolios enhanced reconceptualising of teaching standards and teaching philosophy through reflection on their teaching practice in their internship and practicum as well as their professional development during the course. Finally, the result of qualitative phase of the study also indicated that two participants deviated from the common pattern as they altered their approaches to learning in the 
course in the way they used their e-portfolios. Therefore, the rationale behind the change was investigated through conducting a case study in order to answer the research questions. The result of the case study confirmed the result of the quantitative analyses as it showed that when participant 5 implemented the eportfolio, her conceptions of the tool, and perceptions of the teaching and learning context improved and, as a result, her higher understanding of the e-portfolio, and familiarisation with the objectives and goals of using the tool encouraged her to reflect on the process of being a teacher during the four years of their teacher education course. Therefore, participant 5 applied self- assessment, and reflective learning to identify her weaknesses and strengths as a pre-service teacher through reflection on her practicum and her professional development during the four years of studying in the course. In contrast, participant 8 lost her motivation when she used the tool, and the analyses of the post-interviews showed that participant 8 has lower post-conceptions of the tool and post-perceptions of the teaching and learning context. The participant used the tool to collect and archive data, and believed the eportfolio did not help her to reflect. This particular participant did not have any exposure to e-portfolios before this unit, and therefore, her prior knowledge about eportfolios was poor. The participant showed surface learning in this unit.

Although, in the context of this research, a large number of the participants did not use e-portfolios as a learning tool, one participant transferred from a surface to a deep approach to learning after implementing the e-portfolio. There were five participants who adopted a deep approach to learning in the unit under study. The qualitative part showed that these participants had a good understanding of eportfolios. They believed it was a tool that facilitated reflection, self-assessment and independent learning, and the use of e-portfolios facilitated improving their teaching 
philosophy. Although the context of this unit encouraged eight participants to use eportfolios for reproduction, there were five students who used the e-portfolios as a tool for learning and improvement. Therefore, the outcomes of the thesis reinforced the importance of PSTs' conceptions of the technology and perceptions on the experience of learning and teaching through e-portfolios as influential factors on the academic success in the e-portfolio based teacher education program. If the research design and theoretical framework had ignored these participants' perspectives, it would not have been possible to identify the aspects of e-portfolio-based context, and then further research to explore the most fundamentally significant aspects and their relationships. However, similar research in the future is essential if we are to constantly improve quality assurance of e-portfolio implementation in higher education contexts. The results of this thesis suggest that:

- The role of PSTs' perspectives on their e-portfolio- based learning at the selected university may be applied to national and international contexts. Further research is required on this matter;

- The evidence provided by the qualitative and quantitative studies suggests the design of the e-portfolio-based unit should include the clarification of goals, assessment approaches, workload, and teaching methods according to the context;

- The identification of common aspects of the PSTs' experience of e-portfolio programs may contribute to those who are concerned about the quality of eportfolio based learning in the context of higher education;

- The existence of fundamental aspects of PSTs' experiences identified in this thesis should be emphasised in the design and teaching of e-portfolio 
programs in institutions, no matter what country the e-portfolio program is in. Further research is required on this matter;

- Educational designers in higher education should consider development of the students' prior knowledge in the e-portfolio-based context right from the beginning of the course to provide the opportunity for lifelong learning, independent learning, self-assessment and reflection as well as ongoing selfmonitoring;

- Course designers who are developing e-portfolio programs should introduce activities at the beginning of the program to help PST's to deeply understand their conceptions of e-portfolios, and their perceptions of the teaching and learning context in relation to quantitative aspects of their experience and qualitative categories suggested by this thesis;

- Particular emphasis should be on the benefits for learning that can be achieved through reflection. Student progress in this area of learning should be monitored by learners and teaching staff throughout the unit rather than providing a summative assessment at the end of the unit,

- It is suggested that teaching staff apply the type of e-portfolios which best fit the requirements, objectives and the nature of the unit or course;

- Integration of the e-portfolio into the unit or course to improve aspects of students' learning, which are associated with deep approach to learning, is vital;

- Teaching staff in e-portfolio-based units or courses should identify students at the beginning of the unit or course that seem to hold relatively poor concepts of e-portfolios in order to help those students clarify their misconceptions and poor approaches. Such associations will be enhanced if 
the goals and standards of the e-portfolios are made particularly clear to students; and

- By using the knowledge identified by this thesis, PSTs can identify key variables, which are likely to affect the quality of experiences of e-portfoliobased units in which they are being educating. 


\section{References}

Abrami, P. C., \& Barrett, H. (2005). Directions for research and development on electronic portfolios. Canadian Journal of Learning and Technology, 31(3), $1-15$.

Albert, S., \& Kussmaul, C. (2008). Why wikis are wonderful for writing. In T. Carter \& M. Clayton (Eds.), Writing and the iGeneration: Composition in the computer mediated classroom (pp. 49-67). Southlake, TX: Fountainhead Press.

Alexiou, A., \& Paraskeva, F. (2010). Enhancing self-regulated learning skills through the implementation of an e-portfolio tool. Procedia Social and Behavioral Sciences, 2(2), 3048-3054.

Allan, G. (2003). A critique of using grounded theory as a research method. Electronic Journal of Business Research Methods, 2(1), 1-10.

Anderson, J., Reder, L., \& Simon, H. (1996). Situated learning and education. Educational Researcher, 25(4), 5-11.

Andre, K. (2010). E-portfolios for the aspiring professional. Collegian, 17(3), 119124.

Australian Institute for Teaching and School Leadership (AITSL). (2014). Australian professional standards for teachers. Retrieved from http://www.aitsl.edu.au/australian-professional-standards-for$\underline{\text { teachers/standards/list }}$

Ausubel, D. P., Novak, J. D., \& Hanesian, H. (1968). Educational psychology: A cognitive view. New York, NY: Holt, Rinehart \& Winston.

Babaee, M. (2012). E-portfolios in social media for facilitating language. The Internet Journal of Language, Culture and Society, 16(35), 29-35. 
Babaee, M., Swabey, K. J., \& Prosser, M. (February-March, 2014). A theoretical framework for use of e-portfolios: A combination of constructivism, SAL and the 3P model. Paper presented at the International Academic Conference on Education, Teaching and e-Learning, (pp. 1-8). Prague, Czech Republic.

Baird, D. E., \& Fisher, M. (2005). Neomillennial user experience design strategies: Utilizing social networking media to support" always on" learning styles. Journal of Educational Technology Systems, 34(1), 5-32.

Barone, H., Berliner, D., Blanchard, J., Casanova, U., \& McGowan, T. (1996). A future for teacher education. In J. Sikula (Ed.), Handbook of research on teacher education (2nd ed., pp. 1008-1149). New York, NY: Macmillan.

Barrett, H. (2001). Electronic teaching portfolios: Multimedia skills + portfolio development $=$ powerful professional development. Proceedings of the Society for Information Technology and Teacher Education International Conference (pp. 1111-1116). ERIC Document Reproduction Service No. ED 444514.

Barrett, P. (2007). Structural equation modelling: Adjudging model fit. Personality and Individual Differences, 42(5), 815-824.

Baturay, M. H., \& Daloğlu, A. (2010). E-portfolio assessment in an online English language course. Computer Assisted Language Learning, 23(5), 413-428.

Bhattacharya, A., \& Chauhan, K. (2012). Augmenting learner autonomy through blogging. ELT Journal, 64(4), 376-384.

Biggs, J., \& Tang, C. (2011). Teaching for quality learning at university: What the student does ( $4^{\text {th }}$ ed.). Berkshire England: McGraw-Hill Education. 
Biggs, J. (1982). Student motivation and study strategies in university and colleges of advanced education population. Higher Education Research and Development, 1(1), 33-55.

Biggs, J. (1987). Student approaches to learning and studying. Research Monograph. Hawthorn, VIC: Australian Council for Educational Research. Biggs, J. (1999). What the student does: Teaching for enhanced learning. Higher Education Research and Development, 18(1), 57-75.

Biggs, J. (April, 2003). Keynote address: Aligning teaching and assessing to course objectives. . International Conference on Teaching and Learning in Higher Education: New Trends and Innovations, University of Aveiro, Portugal. Retrieved from http://event.ua.pt/iched/main/invcom/p182.pdf

Biggs, J., Kember, D., \& Leung, D. Y. (2001). The revised two-factor study process questionnaire: R-SPQ-2F. British Journal of Educational Psychology, 71(1), 133-14.

Bitsch, V. (2005). Qualitative research: A grounded theory. Example and Evaluation Criteria. Journal of Agribusiness, 23(1), 75-91.

Bonk, C.J. \& Zhang, K. (2006). Introducing the R2D2 Model: Online learning for the diverse learners of this world. Distance Education, 27(2), 249-264.

Borko, H., Michalec, P., Timmons, M., \& Siddle, J. (1997). Student teaching portfolios: A tool for promoting reflective practice. Journal of Teacher Education, 48(5), 345-357.

Bouzidi, L., \& Jaillet, A. (2009). Can online peer assessment be trusted? Journal of Educational Technology \& Society, 12(4), 257-268. 
Bowden, J.,Hart, G., King, B., Trigwell, K., \& Watts, O. (2000). Generic capabilities of ATN university graduates. Retreived from $\underline{\text { http://www.clt.uts.edu.au/ATN.grad.cap.project.index.html }}$

Boyd, D. (2008). Taken out of context; American teen sociality in networked publics (Unpublished doctoral dissertation). University of California, Berkeley.

Brand-Gruwel, S., Wopereis, I., \& Vermetten, Y. (2005). Information problem solving by experts and novices: Analysis of a complex cognitive skill. Computers in Human Behavior, 21(3), 487-508.

Bridgstock, R. (2009). The graduate attributes we've overlooked: enhancing graduate employability through career management skills. Higher Education Research and Development (HERDSA), 28(1), 31-44.

Burch, C. B. (1999). Inside the portfolio experience: The student's perspectives. English Education, 32(1), 34-49.

Butler, P. (2006). A review of the literature on portfolios and electronic portfolios. Retrieved from https://eduforge.org/docman/view.php/176/1111/ePortfolio\%20Project\%20R esearch\%20Report.pdf

Byrne, M., \& Flood, B. (2003). Assessing the teaching quality of accounting programmes: An evaluation of the Course Experience Questionnaire. Assessment \& Evaluation. Higher Education, 28(2), 135-145.

Carlson, R. D. (1999). Portfolio assessment of instructional technology. Journal of Educational Technology Systems, 27(1), 81-92.

Case, J., \& Gunstone, R. (2002). Metacognitive development as a shift in approach to learning: An in-depth study. Studies in Higher Education, 27, 459-470. 
Cerdà, F. L. (2012). Facebook's potential for collaborative e-learning. RUSC, 8(2), 197-210.

Challis, D. (2005). Towards the mature e-portfolio: Some implications for higher education. Canadian Journal of Learning and Technology, 31(3), 17-32.

Chan, V. (2001). Readiness for learner autonomy: What do our learners tell us? Teaching in Higher Education, 6(4), 505-519.

Chang, C. C., \& Tseng, K. H. (2009). Use and performances of web-based portfolio assessment. British Journal of Educational Technology, 40(2), 358-370.

Chang, C. C., Tseng, K. H., Yueh, H. P., \& Lin, W.C. (2011). Consideration factors and adoption of type, tabulation and framework for creating e-portfolios. Journal of Computer and Education, 56(2), 452-465.

Chau, J., \& Cheng, G. (2010). Towards understanding the potential of e-portfolios for independent learning: A qualitative study. Australasian Journal of Educational Technology, 26(7), 932-950.

Cheng, G., \& Chau, J. (2013). Exploring the relationship between students' selfregulated learning ability and their e-portfolio achievement. The Internet and Higher Education, 17 (1), 9-15.

Chuang, H. H. (2010). Weblog-based electronic portfolios for student teachers in Taiwan. Educational Technology Research and Development, 58(2), 211227.

Cobb, P., \& Bowers, J. (1999). Cognitive and situated learning perspectives in theory and practice. Educational Researcher, 28(2), 4-15.

Cole, D. J., Ryan, C., \& Kick, F. (1995). Portfolio across the curriculum and beyond. Thousand Oaks, CA: Corwin Press. 
Cooper, T., \& Love, T. (2001). Online portfolio assessment in information systems. In S. Stoney \& J. Burn (Eds.), Working for excellence in the economy (pp. 417-426). Perth, WA: We-B Research Centre, Edith Cowan University.

Corcoran, C. A., Dershimer, E. L., \& Tichenor, M. S. (2004). A teacher's guide to alternative assessment: Taking the first steps. The Clearing House: A Journal of Educational Strategies. Issues and Ideas, 77(5), 213-218.

Crawford, K., Gordon, S., Nicholas, J., \& Prosser, M. (1994). Conceptions of mathematics and how it is learned: The perspectives of students entering university. Learning and Instruction, 4(4), 331-345.

Creswell, J. W. (2003). Research design: Qualitative, quantitative, and mixed methods approaches. Thousand Oaks, CA: Sage.

Creswell, J. W. (2007). Qualitative inquiry and research design: Choosing among five approaches (2nd ed.). Thousand Oaks, CA: Sage.

Creswell, J. W. (2009). Research design: Qualitative, quantitative, and mixed methods approach (3rd ed.). Los Angeles, CA: Sage.

Cronbach, L. J. (1951). Coefficient alpha and the internal structure of tests. psychometrika, 16(3), 297-334.

Dabbagh, N., \& Kitsantas, A. (2012). Personal learning environments, social media, and self-regulated learning: A natural formula for connecting formal and informal learning. The Internet and Higher Education, 15(1), 3-8.

Dabbagh, N., \& Reo, R. (2011). Back to the future: Tracing the roots and learning affordances of social software. In M. J. W. Lee, \& C. McLoughlin (Eds.), Web 2.0-based e-learning: Applying social informatics for tertiary teaching (pp. 1-20). Hershey, PA: IGI Global. 
Dalton, J. C. (2007). Concluding observations and implications of e-portfolios for student affairs leadership and programming. New Directions for Student Services, 119, 99-106.

Dana, T. M., \& Tippins, D. J. (1998). Portfolios, reflection and educating prospective teachers of science. In B. J. Fraser \& K. G. Tobins (Eds.), International handbook of science education (pp. 719-732). Dordrecht, Netherlands: Kluwer Academic.

Danielewicz, J. (2001). Teaching selves. Identity, pedagogy, and teacher education. Albany, NY: State University of New York Press.

Danielson, C., \& Abrutyn, L. (1997). An Introduction to using portfolios in the classroom. Alexandria, VA: Association for Supervision and Curriculum Development.

Dewey, J. (1929). The sources of a science of education. New York, NY: Horace Liveright.

DiBiase, D. (2002). Using e-Portfolios at Penn State to enhance student learning. Retrieved from https://www.e-education.psu.edu/portfolios/eport report.doc

Entwistle, N. J. (1991). Approaches to learning and perceptions of the learning environment. Higher Education, 22(3), 201-204.

Entwistle, N. J., \& Ramsden, P. (1982). Understanding student learning. London: Croom Helm.

Entwistle, N.J., \& Tait, H. (1990). Approaches to learning, evaluations of teaching and preferences for contrasting academic environments. Higher Education, 19(2), 169-194. 
Evans, S., Daniel, T., Mikovch, A., Metze, L., \& Norman, A. (2006). The use of technology in portfolio assessment of teacher education candidates. Journal of Technology and Teacher Education, 14(1), 5-27.

Fan, S. (2011). Significance of the web as a learning resource in an Australian university context (Unpublished doctoral dissertation). University of Tasmania, Launceston, TAS.

Faulkner. M., \& Allan, G. (2009). Building communities of practice for e-portfolio implementation: An initial approach by two Australian institutions. International Journal of Learning in Social Contexts, 2, 30-51.

Fei, F. (2007). Resourcing change: A grounded theory explaining the process by which managers address challenges in their initiation of change as learning at work (Unpublished doctoral dissertation). University of Bath, Bath, UK.

Fielke, J., \& Quinn, D. (2011). Improving student engagement with self-assessment through ePortfolios. Proceeding of the AAEE Conference, Fremantle, WA.

Friesen, N., \& Anderson, T. (2004). Interaction for lifelong learning. British Journal of Educational Technology, 35(6), 679-687.

Gasson, S. (2004). Rigor in grounded theory research: An interpretive perspective on generating theory from qualitative field studies. In M. E. Whitman \& A. B. Woszczynski (Eds.), The handbook of information systems research (pp. 79102). Hershey, PA: Idea Group.

Gathercoal, P., Love, D., Bryde, B., \& McKean, G. (2002). On implementing webbased electronic portfolios. Educause Quarterly, 25(2), 29-37.

Ghosh, S., \& Agravat, H. H. (2009). Need for innovative assessments in medical schools following traditional curriculum. Proceedings of the 2nd 
International Conference of Teaching and Learning (ICTL) (pp. 1-6). INTI University College Malaysia.

Gibbs, G., \& Simpson, C. (2004). Conditions under which assessment supports students' learning. Learning and Teaching in Higher Education, 1(1) 3-31.

Gipps, C. (2002). Sociocultural perspectives on assessment. In G. Wells \& G. Claxton (Eds.), Learning for life in the 21st century (pp. 73-83). Oxford, UK: Blackwell.

Glaser, B. G. (1978). Theoretical sensitivity: Advances in the methodology of grounded theory. Mill Valley, CA: Sage.

Glaser, B. G. (1992). Basics of grounded theory analysis: Emergence vs. forcing. Mill Valley, CA: Sociology Press.

Glaser, B. G., \& Strauss, A. (1967). The discovery of grounded theory. Chicago, IL: Aldine.

Goldman-Segall, R. (1998). Points of viewing children's thinking: A digital ethnographer's journey. Routledge Psychology Press, Mahwah, NJ: Lawrence Erlbaum Associates.

Goodlad, J. (1990). Places where teachers are taught. San Francisco, CA: Jossey Bass.

Gordin, D., Grueneberg, K., Laff, M., Martinez, S., \& Lam, R. (2004). Using collaborative e-portfolios to reinvent teacher education. In C. Crawford (Ed.), Proceedings of Society for Information Technology and Teacher Education International Conference, pp. 100-105. Chesapeake, VA: AACE.

Gray, L. (2008). Effective practice with e-portfolios. London, UK: Higher Education Funding Council for England. 
Greenberg, G. (2004). The digital convergence: Extending the portfolio model. EDUCAUSE Review, 39(4), 28-37.

Greene, J. C., Caracelli, V. J., \& Graham, W. F. (1989). Toward a conceptual framework for mixed-method evaluation designs. Educational Evaluation and Policy Analysis, 11(3), 255-274.

Greene, K. (2011). Research for the classroom: The power of reflective writing. English Journal, 100(4), 90-93.

Griffith, S., \& Liyanage, L. (2008). An introduction to the potential of social networking sites in education. In Emerging Technologies Conference, Australia: Wollongong.

Gülbahar, Y., \& Tinmaz, H. (2006). Implementing project-based learning and eportfolio assessment in an undergraduate course. Journal of Research on Technology in Education, 38(3), 309-327.

Hair, J. F., Black, W. C., Babin, B. J., Anderson, R. E., \& Tatham, R. L. (2006). Multivariate data analysis (Vol. 6). Upper Saddle River, NJ: Pearson Prentice Hall.

Hall. Simsek, O. (2009). The effect of weblog integrated writing instruction on primary school students writing performance. International Journal of Instruction, 2(2), 31-46.

Hallam, G., \& Creagh, T. (2010). ePortfolio use by university students in Australia: a review of the Australian ePortfolio Project. Higher Education Research \& Development, 29(2), 179-193.

Hallman, H. L. (2007). Negotiating teacher identity: Exploring the use of electronic teaching portfolios with pre-service English teachers. Journal of Adolescent and Adult Literacy, 50(6), 474-485. 
Harrison, C. J., Könings, K. D., Schuwirth, L. W., Wass, V., \& van der Vleuten, C. P. (2017). Changing the culture of assessment: the dominance of the summative assessment paradigm. BMC medical education, 17(1), 73.

Harun, R. N. S. R., \& Jhee, Y. S. (2012). Enhancing learning through process eportfolio among ESL graduate students in an education university. The International Journal of Learning, 18(10), 235-252.

Hattie, J., \& Timperley, H. (2007). The power of feedback. Review of Educational Research, 77(1), 81-112.

Heikkilä, A., \& Lonka, K. (2006). Studying in higher education: Students' approaches to learning, self-regulation, and cognitive strategies. Studies in Higher Education, 31, 99-117.

Heikkilä, A., Niemivirta, M., Nieminen, J., \& Lonka, K. (2011). Interrelations among university students' approaches to learning, regulation of learning, and cognitive and attributional strategies: a person oriented approach. Higher Education, 61(5), 513-529.

Henn, M., Weinstein, M., \& Foard, N. (2006). A short introduction to social research. London, UK: Sage.

Hicks, T., Russo, A., Autrey, T., Gardner, R., Kabodian, A., \& Edington, C. (2007). Rethinking the purposes and processes for designing digital portfolios. Journal of Adolescent and Adult Literacy, 50(6), 450-458.

Holec, H. (1980). Autonomy and foreign language learning. Strasbourg, Germany: Council of Europe.

Hunt, E., \& Pellegrino, J. W. (2002). Issues, examples, and challenges in formative assessment. New directions for Teaching and Learning, 89, 73-85. 
Huot, B. (2002). (Re)-articulating writing assessment for teaching and learning. Logan, UT: Utah State University Press.

Huxley, A. (1995). Research article the Kurudhamma: from ethics to statecraft. Journal of Buddhist Ethics, 2,191-203.

Hyatt, D. (2005). Yes, a very good point! A critical genre analysis of a corpus of feedback commentaries on master of education assignments. Teaching in Higher Education, 1(3), 339-353.

Ivers, K. S., \& Barron, A. E. (1998). Multimedia projects in education: Designing, producing, and assessing (pp. 1-56308). Englewood, CO: Libraries Unlimited.

Janisch, C., Liu, X., \& Akrofi, A. (2007). The educational forum, implementing alternative assessment: Opportunities and obstacles. The Educational Forum, 71(3), 221-230.

Johansson, B., Marton, F., \& Svensson, L. (1985). An approach to describing learning as change between qualitatively different conceptions. In L. H. T. West \& A. L. Pines (Eds), Cognitive structure and conceptual change (pp. 233-257). London: Academic Press.

Johnson, R. B., \& Onwuegbuzie, A. J. (2004). Mixed methods research: A research paradigm whose time has come. Educational Researcher, 33(7), 14-26.

Kabilan, M. K., \& Khan, M. A. (2012). Assessing pre-service English language teachers' learning using e-portfolios: Benefits, challenges and competencies gained. Computers and Education, 58(4), 1007-1020.

Kavaliauskiene, G. (2004a). Quality assessment in teaching English for specific purposes. ESP world. Retrieved from: http://esp-world.info/Articles. Available: http://esp-world.info/Articles 
Kavaliauskiene, G. (2004b). Research into the integration of content-based instruction into the ESP classroom. Journal of Language and Learning, 2(1), $1-12$.

Kearns, P. (2001). Generic skills for the new economy: Review of research. Retrieved from http://www.ncver.edu.au/research/proj/nr0024.pdf Kim, A. (2014). The development of E-portfolio Assessment as a new E-learning tool: Current practices and future directions. CAUTHE 2014: Tourism and Hospitality in the Contemporary World: Trends, Changes and Complexity, 941.Kirkham, T., Winfield, S., Smallwood, A., Coolin, K., Wood, S., \& Searchwell, L. (2009). Education: A review of the literature. Journal of Research on Technology in Educational Media International, 43(2), 133-145.

Kirkwood, K. (2010). The SNAP platform: Social networking for academic purposes. Campus-Wide Information Systems, 27(3), 118-126.

Kitsantas, A., \& Dabbagh, N. (2010). Learning to learn with Integrative Learning Technologies (ILT): A practical guide for academic success. Greenwich, CT: Information Age.

Klenowski, V. (2000). Portfolios: Promoting teaching. Assessment in Education, $7(2), 215-236$.

Kuo, S. Y. (2004). Educational test and assessment. Taipei, Taiwan: Ching Hua. Lambert, S., \& Corrin, 1. (2007). Moving towards a university wide implementation of an ePortfolio tool. Australasian Journal of Educational Technology, 23(1), $1-16$.

Lapadat, J. C. (2002). Written interaction: A key component in online learning. Journal of Computer-Mediated Communication, 7(4). Retrieved from $\underline{\text { http://jcmc.indiana.edu/vol7/issue4/lapadat.html }}$ 
Lea, M. R., \& Street, B. V. (1998). Student writing in higher education: An academic literacies approach. Studies in Higher Education, 23(2), 157-172.

Leech, N. L., \& Onwuegbuzie, A. J. (2007). An array of qualitative data analysis tools: A call for data analysis triangulation. School Psychology Quarterly, 22(4), 557.

Leech, N. L., Barrett, K. C., \& Morgan, G. A. (2005). SPSS for intermediate statistics: Use and interpretation. New York, NY: Psychology Press.

Ligorio, M. B., \& Sansone, N. (2009). Structure of a blended university course: Applying constructivist principles to blended teaching. In C.R. Payne (Ed.). Information technology and constructivism in higher education: Progressive learning frameworks. Hershey, PA: IGI Global.

Lin, Q. (2008). Preservice teachers' learning experiences of constructing e-portfolios online. The Internet and Higher Education, 11(3), 194-200.

Lin, Q. (2012). Pre-service teachers' learning experiences of constructing eportfolios online. Internet and Higher Education, 11(3), 194-200.

Lincoln, Y. S., \& Guba, E. G. (1985). Naturalistic inquiry. Beverly Hills, CA: Sage. Little, D. (1991). Learner autonomy: Definitions, issues and problems. Dublin, Ireland: Authentik.

Lockyer, L. \& Patterson, J. (2008). Integrating social networking technologies in education: A case study of a formal learning environment. Eighth IEEE International Conference on Advanced Learning Technologies, Santander, Spain. Retrieved from http://ro.uow.edu.au/edupapers/73/

Lu, J., \& Le, T., \& Babaee, M. (2012). Challenges of using grounded theory in qualitative research, e-portfolio and social media. Le, T., \& Lê, Q. (2013). 
Conducting Research in a Changing and Challenging World. New York, NY: Nova Science

Luce, C., \& Kirnan, J. P. (2016). Using Indirect vs. Direct Measures in the Summative Assessment of Student Learning in Higher Education. Journal of the Scholarship of Teaching and Learning, 16(4), 75-91.

Lumsden, J. A. (2007). Development and implementation of an e-portfolio as a university-wide program. New Directions for Student Services, 119, 43-63.

Madge, C., Meek, J., Wellens, J., \& Hooley, T. (2009). Facebook, social integration and informal learning at university: 'It is more for socialising and talking to friends about work than for actually doing work'. Learning, Media and Technology, 34(2), 141-155.

Marton, F., \& Säljö, R. (1976). On qualitative differences in learning: I-Outcome and process. British Journal of Educational Psychology, 46 (1), 4-11.

Marton, F., \& Säljö, R. (1976b). On qualitative differences in learning-II: outcome as a function of the learner's conception of the task. British Journal of educational Psychology, 46(2), 115-127.

Marton, F., Hounsell, D., \& Entwistle, N. J. (Eds.). (1997).The experience of learning: Implications for teaching and studying in higher education. Edinburgh, Scotland: Scottish Academic Press.

Mason, R., Pegler, C., \& Weller, M. (2004). E-portfolios: An assessment tool for online courses. British Journal of Educational Technology, 35(6), 717-727.

Mayer, E. (1992). Putting general education to work: The key competencies report. Canberra: Australian Education Council and Ministers for Vocational Education, Employment and Training. 
McDonald, B. (2012). Portfolio assessment: Direct from the classroom. Assessment \& Evaluation, 37(3), 335-347.

Meeus, W., Questier, F., \& Derks, T. (2006). Open source e-portfolio: Development and implementation of an institution-wide electronic portfolio platform for students. Educational Media International, 43(2), 133-145.

Meyer, E., Abrami, P. C., Wade, C. A., Aslan, O., \& Deault, L. (2010). Improving literacy and metacognition with electronic portfolios: Teaching and learning with Epearl. Computers and Education, 55(1), 84-91.

Miles, M. B., \& Huberman, A. M. (1994). Qualitative data analysis: An expanded sourcebook (2nd ed.). Thousand Oaks, CA: Sage.

Milman, N., \& Adamy, P. (2009). Introduction. In P. Adamy \& N. Milman (Eds.), Evaluating electronic portfolios in teacher education (pp. vii-xiii). Charlotte, NC: Information Age.

Montero-Fleta, B. M., \& Pérez-Sabaterb, C. P. (2010). A research on blogging as a platform to enhance language skills. Procedia Social and Behavioral Sciences, 2(2), 773-777.

Moon, J. (2004). A handbook for reflective and experiential learning. London, UK: Routledge Falmer.

Motallebzadeh, K., \& Babaee, M. (2009). Developing syntactic component of EFL learners writing proficiency through e-portfolio assessment. Ferdowsi University of Mashhad, 1(3), 75-98.

Napper, V., \& Smith, R. M. (2006). E-Reflecting through a portfolio process. Paper presented at the World Conference on E-Learning in Corporate, Government, Healthcare, and Higher Education 2006, Honolulu, Hawaii, USA. Retrieved from http://www.editlib.org/p/23791 
Nevgi, A., Virtanen, P., \& Niemi, P. (2006). Supporting students to develop collaborative skills in technology-based environments. British Journal of Educational Technology, 37(6), 937-947.

Ntuli, E., Keengwe, J., \& Kyei-Blankson, L. (2009). Electronic portfolios in teacher education: A case study of early childhood teacher candidates. Early Childhood Education Journal, 37(2), 121-126.

Oakley, G., Pegrum, M., \& Johnston, S. (2014). Introducing e-portfolios to preservice teachers as tools for reflection and growth: Lessons learnt. AsiaPacific Journal of Teacher Education, 42(1), 36-50.

Oliver, B. (2013). Graduate attributes as a focus for institution-wide curriculum renewal: innovations and challenges. Higher Education Research \& Development, 32(3), 450-463.Onwuegbuzie, A. J., \& Leech, N. L. (2004). Enhancing the interpretation of significant findings: The role of mixed methods research. The Qualitative Report, 9(4), 770-792.

Oskay, O. O., Schallies, M., \& Morgil, I. (2008). Reliability of portfolio: A closer look at findings from recent publications. Hacettepe University Journal of Education, 35, 263-272.

Ottenbreit-Leftwich, A. T., Brush, T. A., Strycker, J., Gronseth, S., Roman, T., Abaci, S., \& Plucker, J. (2012). Preparation versus practice: How do teacher education programs and practicing teachers align in their use of technology to support teaching and learning? Computers and Education, 59(2), 399-411.

Parker, M., Ndoye, A., \& Ritzhaupt, A. D. (2012). Qualitative analysis of student perceptions of e-portfolios in a teacher education program. Journal of Digital Learning in Teacher Education, 28(3), 99-107. 
Pelliccione, L., \& Dixon, K. (2008). ePortfolios: Beyond assessment to empowerment in the learning landscape. Proceedings of the Ascilite Conference, Melbourne, Australia. Retrieved from www.ascilite.org.au/conferences/melbourne08/proc s/pelliccione.pdf

Penny, C., \& Kinslow, J. (2006). Faculty perceptions of electronic portfolios in a teacher education program. Contemporary Issues in Technology and Teacher Education, 6(4), 418-435.

perceived administration of self-regulated learning on students' motivation and information-processing. Learning and Instruction, 15(2), 141-160.

Perry, W. (1970). Forms of intellectual and ethical development in the college years: A scheme. New York, NY: Holt, Rinehart, and Winston.

Pintrich, P. R. (1999). The role of motivation in promoting and sustaining selfregulated learning. International Journal of Educational Research, 31(6), 459-470.

Pintrich, P. R. (2004). A conceptual framework for assessing motivation and selfregulated learning in college students. Educational Psychology Review, 16(4), 385-407.

Pintrich, P. R., \& De Groot, E. V. (1990). Motivational and self-regulated components of classroom academic performance. Journal of Educational Psychology, 82(1), 33-40.

Price, M., Handley, K., Miller, J., \& Donovan, O. B. (2011). Feedback: All that effort, but what is the effect? Assessment and Evaluation in Higher Education, 35(3), 277-289. 
Prosser, M. (1987). Is prior knowledge of subject matter more important to the development and use of meaningful learning skills? Programmed Learning, 24(4), 280-285.

Prosser, M. (1987). Is prior knowledge of subject matter more important to the development and use of meaningful learning skills? Programmed Learning, 24(4), 280-285.

Prosser, M. (2000). Evaluating the new technologies: A student learning focused perspective. Paper presented at the UniServe Science National Workshop, University of Sydney. Retrieved from http://science.uniserve.edu.au/pubs/procs/wshop5/prosser.html

Prosser, M. (2004). A student learning perspective on teaching and learning, with implications for problem - based learning. European Journal of Dental Education, 8(2), 51-58.

Prosser, M., \& Millar, R. (1989). The "how" and "what" of learning physics. European Journal of Psychology of Education, 4(4), 513-528.

Prosser, M., \& Millar, R. (1989). The "how" and "what" of learning physics. European Journal of Psychology of Education, 4(4), 513-528.

Prosser, M., \& Trigwell, K. (1999). Understanding learning and teaching: The experience in higher education. Buckingham, UK: Society for Research into Higher Education and Open University Press.

Ramsden, P. (1991) A performance indicator of teaching quality in higher education: The Course Experience Questionnaire, Studies in Higher Education, 16(2), 129-150.

Ramsden, P. (1992). Learning to teach in higher education. London, UK: Routledge. Ramsden, P. (2002). Learning To teach in higher education. London: Routledge. 
Ramsden, P., \& Entwistle, N. J. (1981). Effects of academic departments on students' approaches to studying. British Journal of Educational Psychology, 51(3), 368-383.

Ramsden, P., \& Entwistle, N. J. (1981). Effects of academic departments on students' approaches to studying. British Journal of Educational Psychology, 51(3), 368-383.

Ramsden, P., Martin, E., \& Bowden, J. (1989). School environment and sixth form pupils' approaches to learning, British Journal of Educational Psychology, $59(2), 129-142$.

Ramsden, P., Prosser, M., Trigwell, K., \& Martin, E. (2007). University teachers' experiences of academic leadership and their approaches to teaching. Learning and Instruction, 17(2), 140-155.

Rastgoo, A., \& Namvar, Y. (2010). Assessment approaches in virtual learning. Turkish Online Journal of Distance Education - TOJDE, 11(1), 42-48.

Reckase, M. A. (2002). Portfolio define. Paper presented at the Workshop of Portfolio Assessment, Taipei, Taiwan.

Rhodes, L. K., \& Shanklin, N. L. (1993). Windows into literacy: Assessing learners K-8. Portsmouth, NH: Heinemann.

Richardson, L. (1997). Fields of play: Constructing an academic life. New Brunswick, NJ: Rutgers University Press.

Richardson, V. (1997). Constructivist teaching and teacher education: Theory and practice. In V. Richardson (Ed.), Constructivist teacher education: Building a world of new understandings, pp. 3-14. Washington, DC: Falmer. 
Ritzhaupt, A. D., Singh, O., Seyferth, T., \& Dedrick, R. (2008). Development of the electronic portfolio student perspective instrument: An e-portfolio integration initiative. Journal of Computing in Higher Education, 19(2), 47-71.

Robbins, H. (2004). Reflection and the electronic teaching portfolio: The nature and quality of preservice teachers' reflective writing. In C. Crawford, N. Davis, J. Price, \& D. Willis (Eds.), Technology and teacher education annual (pp. 222-227). Norfolk, VA: Association for the Advancement of Computing in Education.

Robinson, A., \& Udall, M. (2004). A framework for formative assessment: Initiating quality learning conversations. Learning and Teaching in Higher Education, 1(1), 112-115.

Royce, D. S. (1982). Formative assessment and the design of instructional systems. Instructional Science, 18(2), 119-144.

Rozendaal, J. S., Minnaert, A., \& Boekaerts, M. (2005). The influence of teacher

Rubin, N. (2010). Creating a user-centric learning environment with Campus Pack personal learning spaces. Retrieved from $\underline{\text { http://community.learningobjects.com/Users/Nancy.Rubin/Creating a UserC }}$ entric Learning.

Ryan, G. W., \& Bernard, H. R. (2000). Data management and analysis methods. In N. K. Denzin \& Y. S. Lincoln (Eds.), Handbook of qualitative research (2nd ed., pp. 769-802). Thousand Oaks, CA: Sage.

Sadler, D. R. (1989). Formative assessment and the design of instructional systems. Instructional Science, 18(2), 119-144.

Säljö, R. (1979). Learning about learning. Higher Education, 8(4), 443-451. 
Salmon, G. (2000). E-moderating: The key to teaching and learning online. London, UK: Kogan Page.

Sarantakos, S. (2005). Social research (2nd ed.). Melbourne, VIC: Macmillan Education Australia.

Schmidt, H. G., De Volder, M. L., De Grave, W. S., Moust, J. H., \& Patel, V. L. (1989). Explanatory models in the processing of science text: The role of prior knowledge activation through small-group discussion. Journal of Educational Psychology, 81(4), 610.

Schunk, D. (2004). Learning theories: An educational perspective 4th ed.). Upper Saddle River, N.J.: Pearson Prentice Hall.

Schunk, D. H. (2000). Learning theories: An educational, perspective (3rd. ed.). Upper Saddle River, NJ: Merrill/Prentice.

Shepherd, C. E, \& Skrabut, S. (2011). Rethinking electronic portfolios to promote sustainability among teachers. TechTrends, 55(5), 31-38.

Smart, V., Sim, C., \& Finger, G. (2013, March). A view into teachers digital pedagogical portfolios showing evidence of their Technological Pedagogical Reasoning. Proceedings of Society for Information Technology and Teacher Education (SITE) Conference 2013. Chesapeake, VA: Association for the Advancement of Computing in Education (AACE).

Smith, K., \& Tillema. (2003). Clarifying different types of portfolio use. Assessment and Evaluation in Higher Education, 28 (6), 625-648.

Sorić, I., \& Palekčić, M. (2009). The role of students’ interests in self-regulated learning: The relationship between students' interests, learning strategies and causal attributions. European Journal of Psychology of Education, 24(4), $545-565$ 
Stefani, L., Mason, R., \& Pegler, C. (2007). The educational potential of eportfolios: Supporting personal development and reflective learning. New York, NY: Routledge.

Stiggins, R. (2005). From formative assessment to ssessment for learning: A path to success in standards-based schools. Reviewed work(s). Phi Delta Kappa International Stable, 87(4), 324-328.

Strauss, A., \& Corbin, J. (1998). Basics of qualitative research: Grounded theory procedures and techniques. Newbury Park, CA: Sage.

Sunal, C. S., McCormick, T., Sunal, D. W., \& Shwery, C. S. (2005). The demonstration of teaching values in elementary pre-service teachers' eportfolios. International Journal of Social Education, 20(1), 81-90.

Tashakkori, A., \& Teddlie, C. (Eds.). (2003). Handbook of mixed methods in social and behavioral research. Thousand Oaks, CA: Sage.

Thoresen, C. E., \& Mahoney, M. J. (1974). Behavioral self-control. NY: Holt, Rinehart and Winston.Tierney, R. J., \& C. Clark. (1998).

Tillema, H. H., \& Smith, K. (2000). Learning from portfolios; differential use of feedback in portfolio construction. Studies in Educational Evaluation, 26 (3), 193-210.

Tisani, N. (2008). Challenges in producing a portfolio for assessment: In search of underpinning educational theories. Teaching in Higher Education, 13(5), $549-557$.

Tosh, D., Light, T. P., Fleming, K., \& Haywood, J. (2005). Engagement with electronic portfolios: Challenges from the student perspective. Canadian Journal of Learning and Technology/La revue canadienne de l'apprentissage 
et de la technologie, 31(3). Retrieved from

http://cjlt.csj.ualberta.ca/index.php/cjlt/article/view/97/91

Trent, J., \& Shroff, R. H. (2013). Technology, identity, and community: the role of electronic teaching portfolios in becoming a teacher. Technology, Pedagogy and Education, 22(1), 3-20.

Trigwell, K., \& Ashwin, P. (2003). Undergraduate students' experience of learning at the University of Oxford. Retrieved from http://www.learning.ox.ac.uk/iaul/IAUL+3+7.asp

Trigwell, K., \& Prosser, M. (1991) Improving the quality of student learning: The influence of learning context and student approaches to learning on learning outcomes. Higher Education, (3), 22, 251-266.

Trigwell, K., \& Prosser, M. (1997). Towards an understanding of individual acts of teaching and learning. Higher Education Research \& Development, 16(2), 241-252.

Tsai, H., Lowell, K., McDonald, L., \& Lohr, L. (2004). Part two: Graduate student perspectives on the development of electronic portfolios. TechTrends, 48(3), $56-60$.

Tzeng, J. Y., \& Chen, S. H. (2012). College students' intentions to use e-portfolios: From the perspectives of career-commitment status and weblog-publication behaviours. British Journal of Educational Technology, 439(1), 163-176.

Vermunt, J. D. (1996). Metacognitive, cognitive and affective aspects of learning styles and strategies: A phenomenographic analysis. Higher Education, 31(1), 25-50.

Vygotsky, L. S. (1978). Mind in society: Development of higher psychological processes. Cambridge, MA: Harvard University Press. 
Wang, C. (2009). Comprehensive assessment of student collaboration in electronic portfolio construction: An evaluation research. TechTrends, 53(1), 58-66.

Welsh, M. (2012). Student perceptions of using the PebblePad e-portfolio system to support self- and peer-based formative assessment. Technology, Pedagogy and Education, 21(1), 57-83

Wilson, K. L., Lizzio, A., \& Ramsden, P. (1997). The development, validation and application of the Course Experience Questionnaire. Studies in Higher Education, 22(1), 33-53.

Winston.

Woo, Y., \& Reeves, T. C. (2007). Meaningful interaction in web-based learning: A social constructivist interpretation. The Internet and Higher Education, 10(1), $15-25$

Yang, H. H. (2008). Blog folios for student-centered reflection and communication. In: M, Iskander, (Ed.), Innovative techniques in instruction technology, elearning, e-assessment, and education (pp. 179-182). Springer: Netherlands.

Yang, N. (2003). Integrating portfolios into learning strategy-based instruction for EFL college students. International Review of Applied Linguistics in Language Teaching, 41(4), 293-317.

Yang, W. M., \& Xu, X. Z. (2008). Self-assessment in second language learning. USChina Foreign Language, 6(5), 63-77.

Zellers, M., \& Mudrey, R. (2007). Electronic portfolios and metacognition: A phenomenological examination of the implementation of e-portfolios from the instructors' perspective. International Journal of Instructional Media, 34(4), 419-430. 
Zhao, Y. (Ed.). (2003). What teachers should know about technology: Perspectives and practices. Greenwich, CT: Information Age.

Zimmerman, B. J. (2000). Attaining self-regulation: A social cognitive perspective.

In M. Boekaerts, P. R. Pintrich, \& M. Zeidner (Eds.), Handbook of selfregulation, pp. 13-39. New York, NY: Academic Press.

Zimmerman, J. B., \& Pons, M. P. (2012). Development of a structured interview for assessing student use of self-regulated learning strategies. American Educational Research Journal, 23(4), 614-628.

Zubizaretta, J. (2004). The learning portfolio: Reflective practice for student learning. Bolton, MA: Anker. 


\section{List of Appendices}

Below are the pre-interview and post-interview and questionnaire items.

Appendix 1: Ethics Approval

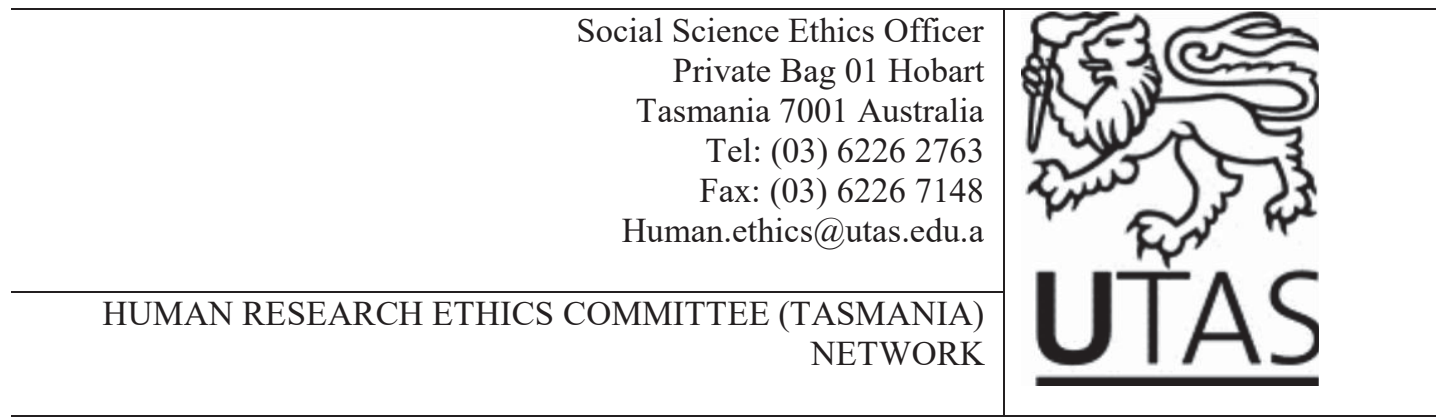

26 June 2014

Assoc Prof Karen Swabey

Faculty of Education

Locked Bag 1307

Dear Assoc Prof Swabey

\section{Re: APPROVAL FOR AMENDMENT TO CURRENT PROJECT}

Ethics Ref: H0012981 - The Role of E-portfolios in Higher Education:

TheExperience of pre-service teachers

1. A voucher will be offered to the interview participants.

2. Interview participants will give access to their e-portfolios.

3. Peter Brookes, the Manager Academic Administration - Education, will provide a list of students in three GPA categories.

4. Revised pre- and post- interview questions.

5. Revised questionnaire.

6. Revised Information Sheet and Consent Form for students.

10. Revised Consent Form for Unit Coordinator.

We are pleased to advise that the Chair of the Tasmania Social Sciences Human Research Ethics Committee approved the Amendment to the above project on 26 June 2014.

Yours sincerely

Katherine Shaw 
Appendix 2: Pre-interview Questions

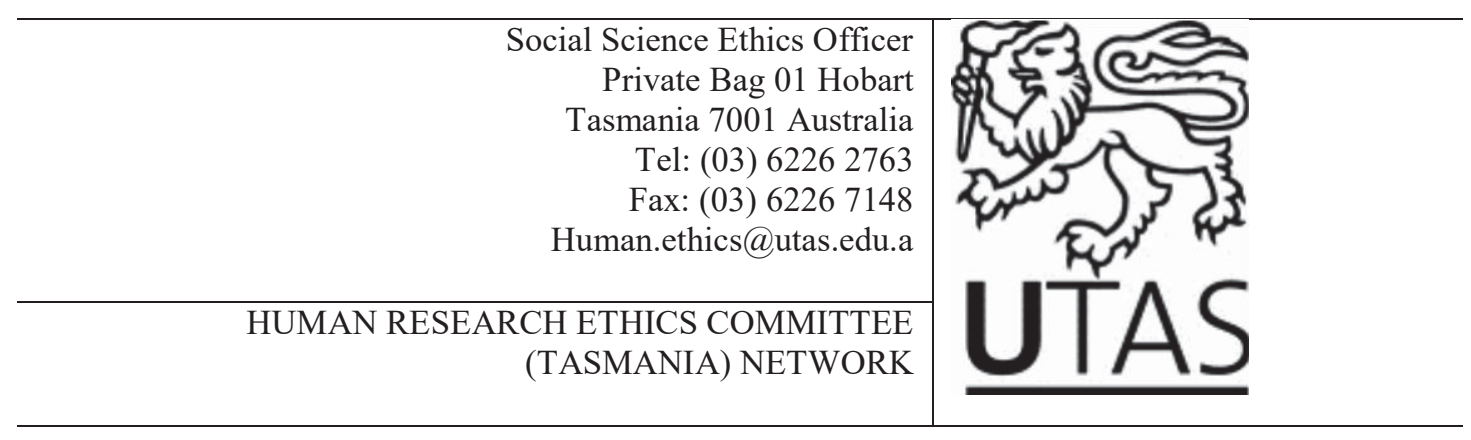

1. What do you think an e-portfolio is?

2. What do you think your role, as a student would be when using an e-portfolio?

3. What do you think your teacher's role would be when using the e-portfolios?

- How do you think e-portfolio will fit in this Unit?

4. What sort of things you will do when using an e-portfolio?

- Do you think you will reflect on your learning when using the e-portfolio?

- Do you think e-portfolio will promote your independent learning?

- Do you think e-portfolio promote your motivation to learn?

- What kind of things your teacher will ask you to put in your e-portfolio?

5. What sort of thing you think you will learn through using e-portfolio?

- What do you think you will learn about being a pre-service teacher by using e-portfolios? 


\section{Appendix 3: Post-interview Questionnaire}

\begin{tabular}{|c|c|}
\hline $\begin{array}{r}\text { Social Science Ethics Officer } \\
\text { Private Bag 01 Hobart } \\
\text { Tasmania 7001 Australia } \\
\text { Tel: (03) } 62262763 \\
\text { Fax: (03) } 62267148 \\
\text { Human.ethics@utas.edu.a }\end{array}$ & ?) \\
\hline HUMAN RESEARCH ETHICS COMMITTEE (TASMANIA) NETWORK & \\
\hline
\end{tabular}

1. What is an e-portfolio?

2. What was your role when using e-portfolio in this Unit? Why? How?

3. How did e-portfolio help you engage with learning activities? How? Why?

4. What was your teacher's role when learning through e-portfolios? Why? How?

5. How did she provide feedback about your work in the e-portfolio? Why?

6. Did e-portfolio implementation fit this Unit? Why? How?

7. Was e-portfolio integrated well with this Unit? Why? How?

8. What sort of things did you do when using e-portfolios? Why? How?

9. Did you work with other students?

10. Did you reflect on your learning when using your e-portfolio?

11. Did you do self-assessment when using your e-portfolio?

12. Did e-portfolio promote independent learning?

13. Did e-portfolio promote your motivation to learn?

14. What sort of thinks did you learn through e-portfolios? Why? How?

15. What did you learn about being a pre-service teacher by using e-portfolios? Why? How? 


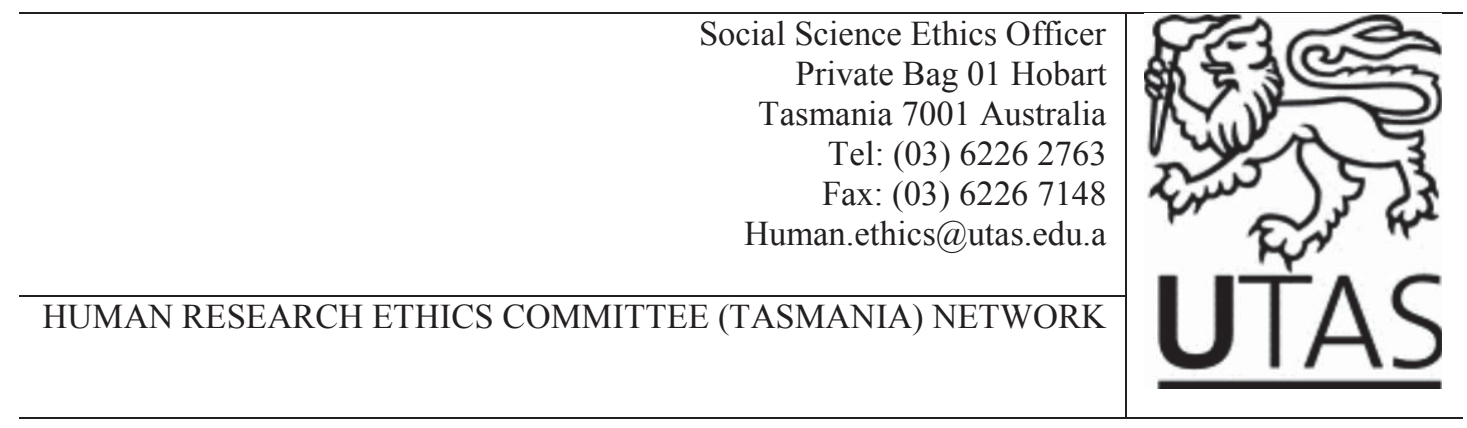

\section{QUESTIONNAIRE}

Topic: Education students' views on the significance of e-portfolios in teaching and learning

Part A: Please circle the most appropriate response.

1. Gender:
a. Male
b. Female

2. Level:
a. MTeach
b. BEd

3. Familiarity with e-portfolios
a. Very poor
b. Poor
c. Fine
d. Very good

4. Access to the Internet
a.daily
b. weekly
c. monthly 


\section{Part B: Course Experience Questionnaire (CEQ) \\ Please circle your most appropriate response.}

Items are scored on a scale from 1 to 5 , where 1 means 'definitely disagree' and 5 means 'definitely agree'.

1 It's always easy for me to know the standard of work expected in the e- 12345 portfolio

3 The workload is too heavy for me when using the e-portfolio me when using the e-portfolio memory

7 Staff seem more interested in testing what I've memorised than what

12345 I've understood through using the e-portfolio

8 The staff make a real effort to understand difficulties I may be having with my work in the e-portfolio

9 Staff give helpful feedback on how I am going in the e-portfolio

10 My lecturers are extremely good at explaining things to me in the e- 12345 portfolio

11 The aims and objectives of the e-portfolio are made very clear

12 Staff work hard to make using the e-portfolio interesting

\section{Part C: Student's Approaches to Learning}

\section{Please circle your most appropriate response.}

$1=$ Never $/$ Rarely; $2=$ Sometimes; $3=$ Half of the Time; $4=$ Frequently; $5=$ Almost Always

18 My aim is to pass the e-portfolio while doing as little work as possible. $\quad 12345$

19 I find that at times studying using the e-portfolio gives me a feeling of 12345 deep personal satisfaction.

20 I only work seriously using the e-portfolio when I complete tasks required 12345 of me in class

21 I find that I have to do enough work in the e-portfolio so that I can form 12345 my own conclusion before I am satisfied.

22 I do not find using e-portfolio very interesting so I keep my work to a 12345 minimum 
23 I find most new topics interesting and use them in developing the e- 12345 portfolio and often spend extra time trying to obtain more information about them.

24 I learn through the e-portfolio by rote, going over and over them until I 12345 know them by heart even if I do not understand them.

25 I find that studying through using the e-portfolio can at times be as 12345 exciting as a good novel or movie.

26 I generally restrict my e-portfolio to what is specifically set as I think it 12345 is unnecessary to do anything extra.

27 I work hard at my e-portfolio because I find the material interesting.

28 I see no point in learning about the e-portfolio, which is not likely to be in 12345 the examination.

29 I spend a lot of my free time finding out more about interesting topics 12345 which have been discussed in my e-portfolio

\section{Part D: Student's Perceptions}

\section{Please circle your most appropriate response.}

Directions: Please indicate your most appropriate response by using the following criteria:

$$
\begin{aligned}
& 1=\text { Strongly Disagree } \\
& 2=\text { Disagree } \\
& 3=\text { Neutral } \\
& 4=\text { Agree } \\
& 5=\text { Strongly Agree }
\end{aligned}
$$

30 E-portfolios enhance my active involvement in learning in this Unit.

31 E-portfolios promote independent learning in this Unit

32 E-portfolios enhance my networking in this Unit

33 E-portfolios enhance my self-esteem in this Unit

34 E-portfolios enhance the sense of learning ownership in this Unit

35 E-portfolios promote my motivation for learning in this Unit

36 E-portfolios accommodate my own learning styles in this Unit 
